PABLO FILGUEIRA RODEIRO

\title{
ANÁLISE DE DISTRIBUIÇÃO DE TEMPERATURAS E TENSÕES RESIDUAIS EM SOLDAS DO TIPO RING-WELD
}

Dissertação apresentada à Escola Politécnica da Universidade de São Paulo para obtenção do título de Mestre em Engenharia.

Área de Concentração:

Engenharia Naval 


\section{PABLO FILGUEIRA RODEIRO}

\section{ANÁLISE DE DISTRIBUIÇÃO DE TEMPERATURAS E TENSÕES RESIDUAIS EM SOLDAS DO TIPO RING-WELD}

Dissertação apresentada à Escola Politécnica da Universidade de São Paulo para obtenção do título de Mestre em Engenharia

Área de Concentração:

Engenharia Naval

Orientador:

Prof. Dr. Oscar Brito Augusto 
Aos meus pais, irmãs, amigos e a Babi, que dividiram comigo todas as dificuldades e satisfações proporcionadas por este trabalho. 


\section{AGRADECIMENTOS}

Aos meus pais pelo apoio e dedicação oferecidos durante todos os momentos do meu crescimento como ser humano.

À Babi pela compreensão e incentivo nos períodos difíceis

Ao departamento de Cálculo e Laboratório de Estruturas da Alstom Lapa, representado pelo Eng. MSc. Luiz Carlos Cano Fernandez, pelo incentivo ao desenvolvimento tecnológico, cedendo a licença para utilização do código de elemento finitos Ansys Mechanical 6.1 assim como a utilização dos equipamentos de medição empregados neste trabalho.

Aos amigos do COCLA.

Ao departamento de Engenharia Naval e Oceânica da Escola Politécnica da USP.

Ao amigo, técnico mecânico, Gilson da Costa Rodrigues pelo auxílio prestado ao longo de todos os ensaios e pelo apoio e entusiasmo demonstrado ao longo do meu trabalho.

Ao amigo e orientador Prof. Dr. Oscar Brito Augusto pela compreensão nos momentos difíceis e, principalmente, pelo total apoio e confiança oferecidos.

A todos que direta ou indiretamente colaboraram para a execução deste trabalho. 


\section{SUMÁRIO}

\section{RESUMO}

\section{ABSTRACT}

\section{LISTA DE FIGURAS}

LISTA DE TABELAS.

\section{LISTA DE SÍMBOLOS}

1. INTRODUÇÃO

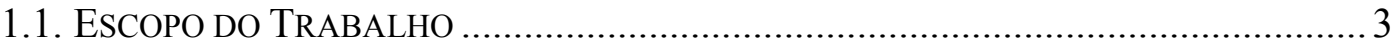

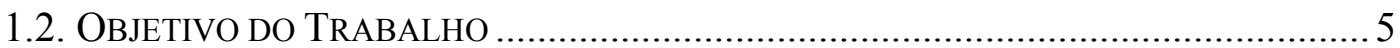

1.3. O SURGIMENTO DAS TENSÕES TÉRMICAS E RESIDUAIS ..................................... 8

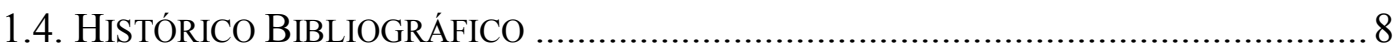

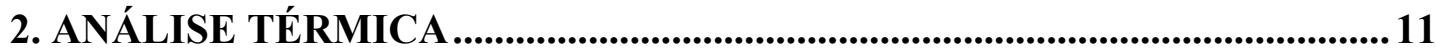

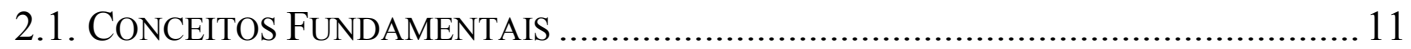

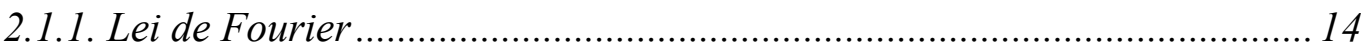

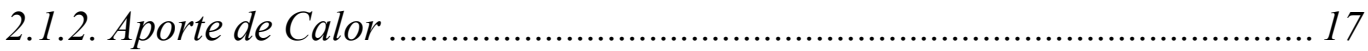

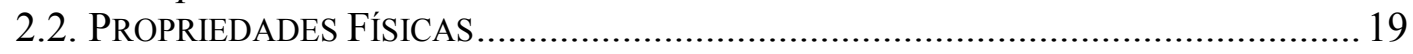

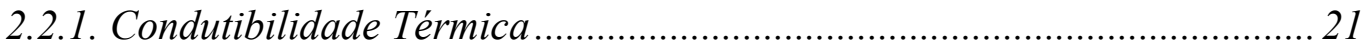

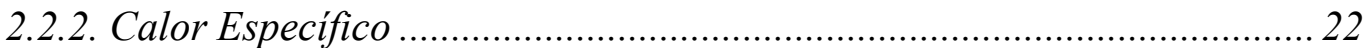

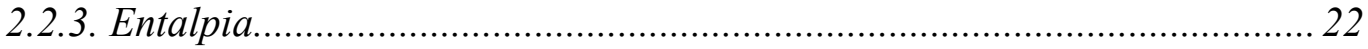

2.2.4. Consolidação das Propriedades Físicas .................................................. 26

2.3. MODELO DE ELEMENTOS FINITOS ..................................................................... 26

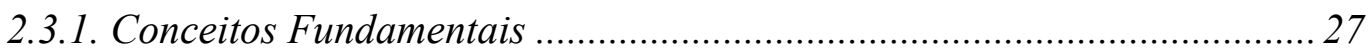

2.3.2. Modelagem do Aporte de Calor em Elementos Finitos............................ 30

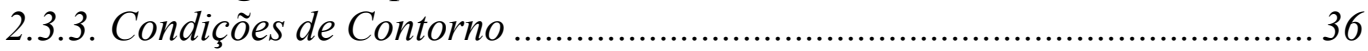

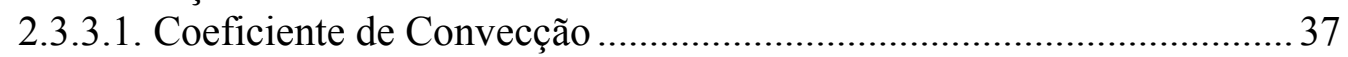

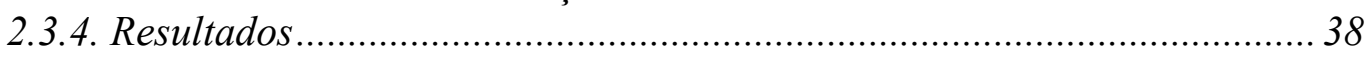

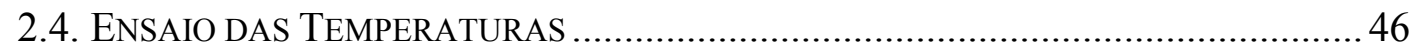

2.5. CORRELAÇÃO MODELO NUMÉRICO X ENSAIO .................................................... 48

3. ANÁLISE MECÂNICA ….................................................................................5

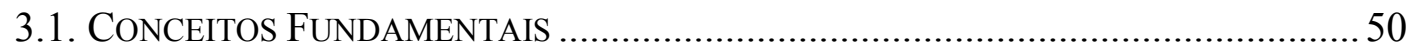

3.1.1. Tensões Residuais no Estado Plano de Tensões.......................................... 51

3.2. PROPRIEDAdES MECÂNICAS.......................................................................... 52

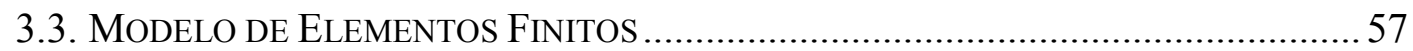

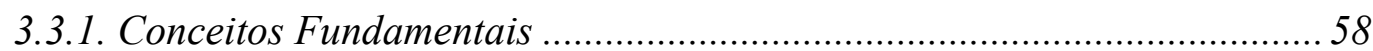

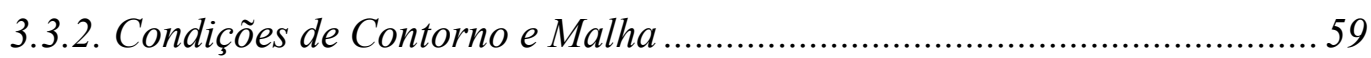

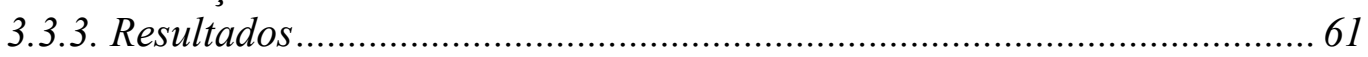

4. CONCLUSÕES E RECOMENDAÇÕES PARA FUTUROS TRABALHOS 66 
5. REFERÊNCIAS BIBLIOGRÁFICAS 


\section{RESUMO}

Este estudo apresenta uma abordagem para a determinação do campo de temperaturas e tensões residuais desenvolvidos durante a soldagem de uma solda do tipo ring-weld. Devido à complexidade da junta soldada e à velocidade de deposição, um modelo de elementos finitos sólido-tridimensional foi elaborado para a solução do campo de temperaturas e tensões residuais. As características não-lineares do fenômeno tais como a dependência das propriedades físicas e mecânicas com a temperatura e a deposição de material ao longo da soldagem foram consideradas neste estudo. Um ensaio com termopares foi realizado com a finalidade de comparação e validação do modelo térmico utilizado. Os resultados obtidos mostraram uma boa correlação entre o ensaio e o modelo numérico, permitindo uma maior confiabilidade para a execução do modelo mecânico subseqüente. Os resultados do modelo mecânico para a determinação das tensões residuais não foram comprovados por ensaio, porém os resultados se apresentaram qualitativamente satisfatórios. 


\begin{abstract}
This study presents an approach to determine the temperature field and residual stresses developed during the welding of a ring-weld. Due to the complexity of the welded joint and its deposition speed, a 3D solid finite element model was constructed for solving the temperature and residual stress fields. The non-linear characteristics of the phenomenon such as, the temperature dependence of the physical properties and the material deposition through the welding process were taken into account. A thermocouple test was performed in order to compare and validate the thermal model used. The results obtained have shown a good correlation between the test and numerical model results, allowing a greater reliability to the execution of the subsequent mechanical model. The results of the mechanical model used for determining the residual stresses were not verified by testing, but the results were qualitatively adequate.
\end{abstract}




\section{LISTA DE FIGURAS}

Figura 1.1 - Esquema de uma solda do tipo ring-weld .......................................... 3

Figura 1.2 - Esquema das Etapas do Estudo ............................................................. 7

Figura 2.1 - Corrente de Transição do Modo de Deposição, Almendra et alii (1997)

Figura 2.2 - Parâmetros de Soldagem em Função do Tipo de Transferência, Arames e Varetas de Aço Inoxidável para Soldagem Sandvik (2000)...............14

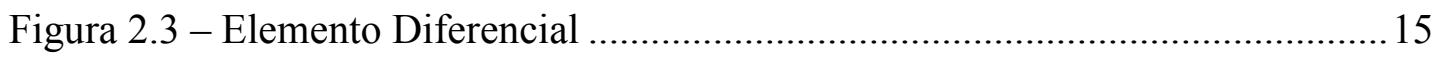

Figura 2.4 - Distribuição de Fluxo de Calor, Papazoglou (1981)............................... 18

Figura 2.5 - Condutibilidade Térmica, Calor Específico e Coeficiente de Dilatação Linear em Função da Temperatura para o AISI 301L, Department of Defense - E.U.A. MIL-HDBK-5E vol 1 (1987) .................................20

Figura 2.6 - Condutibilidade Térmica Linearizada para AISI 301L e AISI 308L.....21

Figura 2.7 - Calor Específico Linearizado para AISI 301L e AISI 308L..................22

Figura 2.8 - Influência do Calor Latente na Entalpia ...............................................24

Figura 2.9 - Calor Específico do AISI 308L em Função da Temperatura..................25

Figura 2.10 - Entalpia do AISI 308L em Função da Temperatura ............................25

Figura 2.11 - Esquema da Transferência de Calor através da Radiação.....................28

Figura 2.12 - Corpo de Prova Cortado para Macrografia ...........................................31

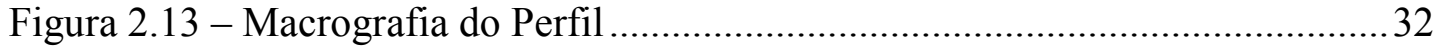

Figura 2.14 - Modelo de Elementos Finitos Vista Isométrica ...................................33

Figura 2.15 - Detalhe da Malha do Cordão de Solda...................................................33

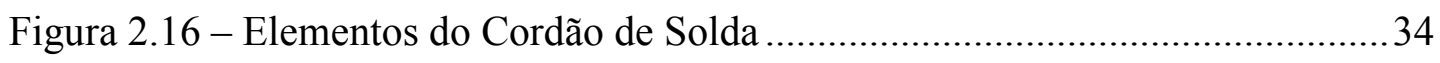

Figura 2.17 -Gráfico Representado a Imposição de Temperatura ..............................34

Figura 2.18 - Imposição de Temperatura na Segunda Deposição ...............................35

Figura 2.19 - Coeficiente de Convecção.................................................................... 36

Figura 2.20 - Coeficiente de Convecção em Função da Temperatura.........................38

Figura 2.21 - Distribuição das Temperatura $\left({ }^{\circ} \mathrm{C}\right)$ no Instante $0.42 \mathrm{~s} \mathrm{..........................3} 39$ 
Figura 2.22 - Distribuição de Temperatura $\left({ }^{\circ} \mathrm{C}\right)$ no Instante $0.84 \mathrm{~s}$ 39

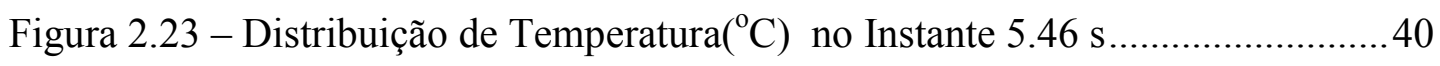

Figura 2.24 - Distribuição de Temperatura $\left({ }^{\circ} \mathrm{C}\right)$ no Instante 10.08 s.........................40

Figura 2.25 - Distribuição de Temperatura $\left({ }^{\circ} \mathrm{C}\right)$ no Instante 15.12 s..........................4 41

Figura 2.26 - Distribuição de Temperatura $\left({ }^{\circ} \mathrm{C}\right)$ no Instante 20.79 s.......................... 41

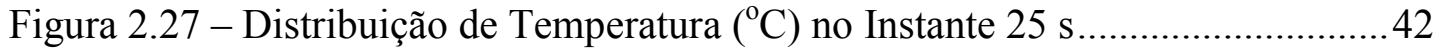

Figura 2.28 - Esquema para Identificação dos Pontos da Chapa Superior .................42

Figura 2.29 - Temperaturas Máximas no Segundo Quadrante .................................43

Figura 2.30 - Temperaturas Máximas no Terceiro Quadrante...................................43

Figura 2.31 - Temperaturas Máximas no Quarto Quadrante .....................................43

Figura 2.32 - Identificação para o Histórico de Temperaturas ...................................44

Figura 2.33 - Histórico de Temperaturas $\left({ }^{\circ} \mathrm{C}\right)$ no Segundo Quadrante.......................45

Figura 2.34 - Histórico de Temperaturas $\left({ }^{\circ} \mathrm{C}\right)$ no Quarto Quadrante...........................45

Figura 2.35 - Posição dos Termopares para o Ensaio das Temperaturas ...................46

Figura 2.36 - Evolução dos Sinais do Termopar $1\left({ }^{\circ} \mathrm{C}\right)$ e da Chave Durante Ensaio .47

Figura 2.37 - Evolução dos Sinais do Termopar $2\left({ }^{\circ} \mathrm{C}\right)$ e da Chave Durante Ensaio 47

Figura 2.38 - Comparação Entre o Resultado do Modelo de Elementos Finitos e o

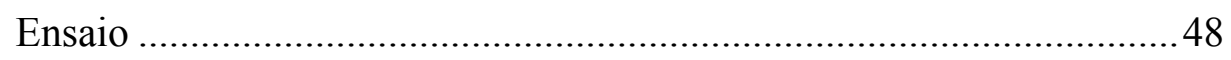

Figura 2.39 - Comparação Entre o Resultado do Modelo de Elementos Finitos e o Ensaio 48

Figura 3.1 - Tensão de Escoamento e Limite de Resistência em Função da

Temperatura para o AISI 301L, Department of Defense - E.U.A. MIL-

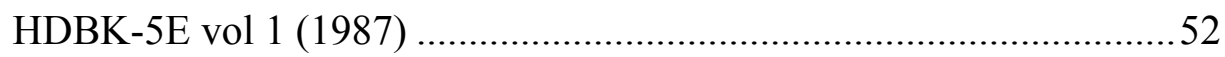

Figura 3.2 - Curva Tensão x Deformação Característica do AISI 301L/AISI 308L.53

Figura 3.3 - Caracterização Bilinear do Material .....................................................53

Figura 3.4 - Módulo de Young em Função da Temperatura para o AISI 301L,

Department of Defense - E.U.A. MIL-HDBK-5E vol 1 (1987) ...........54

Figura 3.5 - Curva Tensão x Deformação em Temperatura Ambiente do AISI 301L $1 / 2$ Hard 56

Figura 3.6 - Curva Tensão x Deformação em Temperatura Ambiente do AISI 308 L 
Figura 3.7 - Propriedades Mecânicas do AISI 308L, Arames e Varetas de Aço Inoxidável para Soldagem Sandvik (2000).

Figura 3.8 - Nós do Segundo Quadrante do Modelo de Elementos Finitos

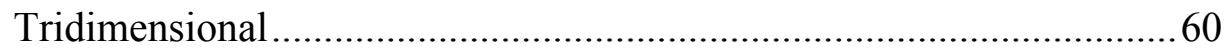

Figura 3.9 - Modelo Mecânico Axi-simétrico e Condições de Contorno...................60

Figura 3.10 - Tensões Residuais Tangenciais (MPa) ............................................61

Figura 3.11 - Tensões Residuais Radiais (MPa)..................................................... 61

Figura 3.12 - Tensões Residuais Equivalentes von Mises (MPa)............................61

Figura 3.13 - Tensões Residuais Principais Máximas (MPa) ..................................62

Figura 3.14 - Tensões Residuais Principais Mínimas (MPa)....................................62

Figura 3.15 - Tensões Residuais Tangencial e Radial em Função da Posição r na

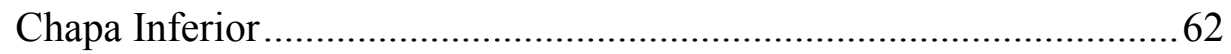

Figura 3.16 - Tensões Principais em Função da Posição r na Chapa Inferior ...........63

Figura 3.17 - Tensões Residuais Tangencial e Radial em Função da Posição r na Chapa Superior . .63

Figura 3.18 - Tensões Principais em Função da Posição r na Chapa Superior...........63

Figura 3.19 - Esquema de Solda Circular, Masubuchi (1980)..................................64

Figura 3.20 - Resultados de Tensão Residual para Solda Circular, Masubuchi (1980) 


\section{LISTA DE TABELAS}

Tabela 2.1 - Eficiências Térmicas dos Diferentes Processos de Soldagem, Almendra et alii (1997)......

Tabela 2.2 - Composição Química do AISI 308L, AISI 301L e AISI 316L - Metals

Handbook .20

Tabela 2.3 - Dados para Determinação da Entalpia, Ohkita (1995) .........................24

Tabela 2.4 - Propriedades Físicas do AISI 301L para Análise Térmica....................26

Tabela 2.5 - Propriedades Físicas do AISI 308L para Análise Térmica....................26

Tabela 2.6 - Comparação Entre os Valores de Pico do Ensaio e do Modelo .............49

Tabela 3.1 -Propriedades Mecânicas do AISI 301L (1/2 hard) .................................57

Tabela 3.2 - Propriedades Mecânicas do AISI 308L ..................................................57 


\section{LISTA DE SÍMBOLOS}

\begin{tabular}{|c|c|}
\hline Q & aporte de calor transferido para o corpo a ser soldado \\
\hline I & corrente elétrica \\
\hline $\mathrm{V}$ & tensão \\
\hline$\eta$ & eficiência térmica do processo de soldagem \\
\hline $\mathrm{T}$ & temperatura \\
\hline $\mathrm{k}$ & condutibilidade térmica \\
\hline $\mathrm{v}$ & velocidade de soldagem \\
\hline Q & taxa de transferência de calor \\
\hline$\rho$ & densidade \\
\hline $\mathrm{c}$ & calor específico \\
\hline $\mathrm{t}$ & instante de tempo \\
\hline$Q_{\mathrm{V}}$ & taxa de variação de energia interna por unidade de volume \\
\hline $\mathrm{Q}_{\mathrm{GI}}$ & calor gerado internamente por unidade de tempo e volume \\
\hline q & fluxo de calor \\
\hline $\mathrm{q}_{0}$ & máximo fluxo de calor na distribuição Gaussiana \\
\hline $\mathrm{C}$ & coeficiente de concentração do fluxo de calor \\
\hline $\mathrm{r}$ & distância radial a partir do centro da distribuição \\
\hline $\mathrm{r}_{\mathrm{h}}$ & raio do círculo da base da distribuição de fluxo de calor \\
\hline$d_{h}$ & diâmetro do círculo da base da distribuição de fluxo de calor \\
\hline $\mathrm{H}$ & entalpia \\
\hline$\{\mathrm{T}\}$ & vetor das temperaturas nodais \\
\hline$[\mathrm{K}],[\mathrm{D}]$ & matriz da condutibilidade térmica \\
\hline$[\mathrm{C}]$ & matriz do calor específico \\
\hline$\{\mathrm{Q}\}$ & vetor do fluxo de calor \\
\hline$[\mathrm{N}]$ & matriz das funções de forma do elemento finito \\
\hline $\mathrm{L}$ & calor latente de solidificação \\
\hline $\mathrm{K}_{\mathrm{nn}}$ & condutibilidade térmica na direção $n$ \\
\hline
\end{tabular}


$\mathrm{T}_{\mathrm{S}}$

$\mathrm{T}_{\mathrm{B}}$

$\mathrm{T}_{\mathrm{S}}$

$\mathrm{T}_{\mathrm{L}}$

$\sigma$

$\varepsilon$

$\mathrm{A}_{\mathrm{i}}$

$F_{i j}$

g

$\beta$

$\mathrm{T}_{\mathrm{S}}$

$\mathrm{T}_{\infty}$

$\alpha$

v

L

$\gamma$

$\gamma$

$\gamma$

$\varepsilon$

$\varepsilon$

$\sigma_{\text {esc }}$

$\sigma_{\mathrm{x}}$

$\sigma_{\mathrm{y}}$

$\tau_{\mathrm{xy}}$

E

Et

G

n

k

$\{\mathrm{F}\}$ coeficiente de convecção

temperatura do sólido

temperatura de bulbo líquido

temperatura de solidus

temperatura de liquidus

constante de Stefan-Boltzmann

emissividade, deformação

área da superfície $\mathrm{i}$

função de forma entre as superfícies i e j

aceleração da gravidade

coeficiente de expansão

temperatura da superfície da chapa

temperatura do fluido quiescente

difusividade térmica

viscosidade cinemática, módulo de Poisson

comprimento característico

distorção

distorção elástica

distorção plástica

deformação elástica

deformação plástica

tensão de escoamento

componente do tensor de Cauchy

componente do tensor de Cauchy

componente do tensor de Cauchy

módulo de Young

módulo tangente

módulo de Cisalhamento

expoente de encruamento

coeficiente de resistência

vetor de forças 
$\left\{\mathrm{R}_{\mathrm{m}}\right\}$

$\{\sigma\}$

[B]

$\{d\}$

$\{\mathrm{u}\}$

$\left[\mathrm{K}_{\mathrm{m}}\right]$

resíduo

tensões de Cauchy

matriz deslocamento-deformação

vetor velocidade de deformação

vetor velocidade nodais

matriz de rigidez 


\section{INTRODUÇÃO}

O processo de soldagem para a indústria moderna tem um papel fundamental como instrumento de união de partes metálicas, cuja eficiência é indiscutível. Grande parte das estruturas metálicas tem suas uniões executadas através dos diversos tipos de soldas existentes. Alguns exemplos típicos podem ser citados: pontes metálicas, vasos de pressão, navios mercantes, navios militares, plataformas de petróleo, reatores nucleares, veículos automotores entre outros.

O processo de soldagem exibe muitas vantagens como meio de união, porém algumas características do processo podem ser encaradas como desvantagens do processo. A seguir estão apresentados dados comparativos do processo de soldagem em relação ao processo de união por rebites bem como os principais problemas encontrados no processo de soldagem propostos por Masubuchi (1980).

- Elevada eficiência de união. Este parâmetro pode ser medido e avaliado através da seguinte relação: (resistência à ruptura da junta)/(resistência à fratura do metal base). Os valores de eficiência de juntas soldadas em relação às juntas rebitadas são maiores, chegando até 1 em casos de soldas a topo.

- Estanqueidade. Em geral é mais difícil garantir a estanqueidade de juntas rebitadas em serviço do que juntas soldadas. Para o caso do ring-weld esta observação evidentemente não se aplica.

- Diminuição do peso estrutural. O peso estrutural pode ser reduzido entre $10 \%$ e $20 \%$ se o processo de soldagem é utilizado no lugar dos rebites.

- Sem limitação de espessura. Torna-se muito difícil rebitar chapas com espessuras maiores do que 2 polegadas. $\mathrm{O}$ processo de soldagem praticamente não possui limitação de espessura para a união.

- Projeto Estrutural mais Simples. Devido a grande versatilidade de união o projeto estrutural com uniões soldadas tende a ser mais simples do que com uniões rebitadas. 
- Redução do Tempo de Fabricação e do Custo. A possibilidade de se construir módulos separadamente para uma união posterior reduziu consideravelmente o tempo de execução da estrutura bem como seus custos.

Evidentemente aspectos detrimentais também são inerentes ao processo de soldagem. Os principais aspectos detrimentais segundo Masubuchi (1980) são:

- Dificuldade de isolação de trincas. Uma vez que uma trinca surge em uma união soldada ela pode propagar indefinidamente devido à continuidade de material proporcionada pela soldagem.

- Susceptibilidade a defeitos. O processo de soldagem gera defeitos nocivos tais como: poros, trincas, inclusões entre outros.

- Tensões Residuais e Distorções. Devido ao aquecimento localizado nãouniforme, tensões térmicas complexas e distorções ocorrem durante a soldagem. As tensões residuais elevadas podem causar trincas e redução da resistência à flambagem e à fadiga da estrutura.

Grandes esforços foram gastos desde o final da Segunda Guerra Mundial para se estudar e compreender melhor os mecanismos relativos aos aspectos detrimentais do processo de soldagem. Nos primeiros anos após a Segunda Guerra Mundial os estudos se mostravam voltados para abordagens experimentais. As análises experimentais, isoladas da abordagem analítica, apresentam uma estanqueidade muito grande, não permitindo conclusões caso os parâmetros em estudo fossem alterados.

Com o advento dos computadores e das abordagens numéricas na Engenharia, o poderio de análise aumentou exponencialmente, possibilitando um estudo detalhado dos aspectos detrimentais do processo de soldagem e mais especificamente do problema das distorções e das tensões residuais. Dessa maneira soluções para problemas de soldagem se tornaram mais acessíveis e relativamente adaptáveis a variações dos parâmetros do processo de soldagem (velocidade de deposição, material, geometria, etc.). 


\subsection{Escopo do Trabalho}

Este trabalho propõe uma abordagem para a determinação das tensões residuais em soldas tipo ring-weld.

$\mathrm{O}$ ring-weld é um dos tipos de solda mais utilizado em estruturas de carros ferroviários de passageiros. Sua praticidade de execução, seu grande poder de união ao longo de superfícies afastadas das bordas das chapas tornam este tipo de solda muito freqüente, não só em reparos estruturais, mas também como parte integrante do projeto.

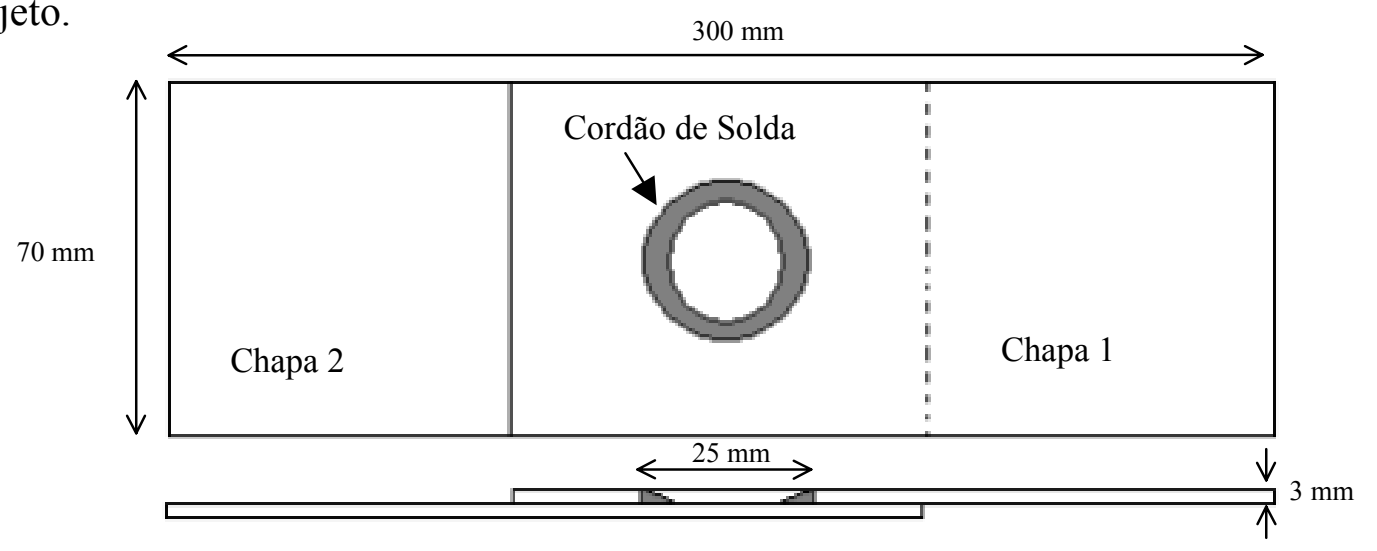

Figura 1.1 - Esquema de uma solda do tipo ring-weld

A redução do número de soldas na estrutura é um objetivo constante de qualquer projeto estrutural. A grande competitividade e os prazos cada vez mais curtos tornam esse objetivo ainda mais evidente. Este estudo para a determinação do campo das temperaturas e das tensões residuais ajudará a produzir embasamento para o desenvolvimento e conhecimento do comportamento mecânico do ring-weld, possibilitando estudos de otimização do número de soldas empregados na estrutura.

Durante o processo de soldagem uma série de eventos pode ocorrer: porosidades, falta de fusão, inclusões, trincas, fragilização etc.. Em geral esses eventos são prejudiciais para o comportamento da solda em serviço. Assim o domínio de como esses eventos ocorrem e quais são suas conseqüências é vital para o aprimoramento das soldas em geral. As tensões residuais também podem ser incluídas neste escopo.

O cálculo de uma estrutura em geral é desenvolvido a partir de hipóteses simplificadoras que permitem uma execução da análise estrutural de uma maneira relativamente rápida e com resultados de certo modo satisfatórios.

As principais hipóteses simplificadoras são: 
- Material homogêneo

- Ausência de descontinuidades

- Ausência de tensões iniciais

- Geometria perfeita

Em se tratando de uma estrutura soldada as hipóteses acima podem não ser válidas, principalmente quando se discute o comportamento real da estrutura em serviço. Análises detalhadas de fadiga e flambagem de uma estrutura soldada com as hipóteses simplificadoras acima aplicadas à análise podem não produzir resultados satisfatórios.Segundo Masubuchi (1980) os principais aspectos que diferem das hipóteses simplificadoras apresentadas acima em se tratando de estruturas soldadas são:

- Material não-homogêneo: Solda composta por diferentes zonas, incluindo a zona termicamente afetada, o material base e o metal de adição.

- Presença de defeitos e descontinuidades.

- Tensões residuais.

- Geometria imperfeita: distorção.

Com uma ferramenta numérica que permita calcular as tensões residuais e distorções causadas pela soldagem é possível modificar parâmetros de soldagem, sequência de soldagem, entre outras variáveis, e analisar com bastante detalhe suas implicações na estrutura de uma maneira rápida e com baixo custo e ainda podem ser executadas com maior detalhe análises de fadiga e flambagem das estruturas soldadas.

Desse modo torna-se possível otimizar o processo de soldagem e o projeto da estrutura soldada com reduções de custo e aumento da qualidade do produto final. 


\subsection{Objetivo do Trabalho}

Neste trabalho será desenvolvida uma análise térmica para em seguida, usando as temperaturas obtidas como carregamento para o modelo mecânico, determinar-se o campo de tensões residuais atuantes na região da solda. Para se atingir o objetivo final são necessárias informações que isoladamente também ajudarão a compreender melhor o comportamento deste tipo de junta soldada de uma maneira geral.

Deve-se salientar a utilização da hipótese de que o fenômeno térmico está desacoplado do fenômeno mecânico, ou seja, as deformações não causariam uma modificação das temperaturas, mas apenas as temperaturas causariam uma influência no campo das deformações. Esta hipótese permite a solução do modelo térmico desacoplado do modelo mecânico e isso diminui o tempo computacional necessário para a solução do problema, pois se resolve primeiro o modelo térmico para em seguida, utilizando as temperaturas obtidas anteriormente como carregamento, resolver o modelo mecânico.

Para a determinação das tensões residuais em uma solda são necessárias duas grandes etapas:

1. A determinação do campo de temperaturas no interior do corpo em função do tempo.

2. A determinação das tensões tendo como carregamento o campo das temperaturas determinado anteriormente.

A complexidade de modelagem do processo de soldagem para este caso é evidente, pois alguns pontos importantes do processo devem ser levados em consideração para a determinação dos campos de temperatura e de tensão.

Os principais aspectos que tornam a modelagem matemática da soldagem complicada podem ser destacados abaixo:

1. Variação das propriedades mecânicas e físicas dos materiais em função da temperatura.

2. O processo de soldagem de um ring-weld é rápido e transitório.

3. Modelagem da deposição do material ao longo do processo.

4. Mudança de fase do material.

5. Comportamento mecânico viscoelasto-plástico.

6. Elevada não-linearidade em função dos itens anteriores. 
Dessa maneira optou-se por uma abordagem numérica para se atingir os objetivos deste estudo. $\mathrm{O}$ código de elementos finitos utilizado para as análises foi o ANSYS 6.1 Mechanical e este código permite a solução de modelos térmicos e mecânicos não lineares e transitórios com a ferramenta de birth and death elements para a modelagem da deposição de metal. Na figura 1.2 mostra-se um esquema com a seqüência do trabalho: 


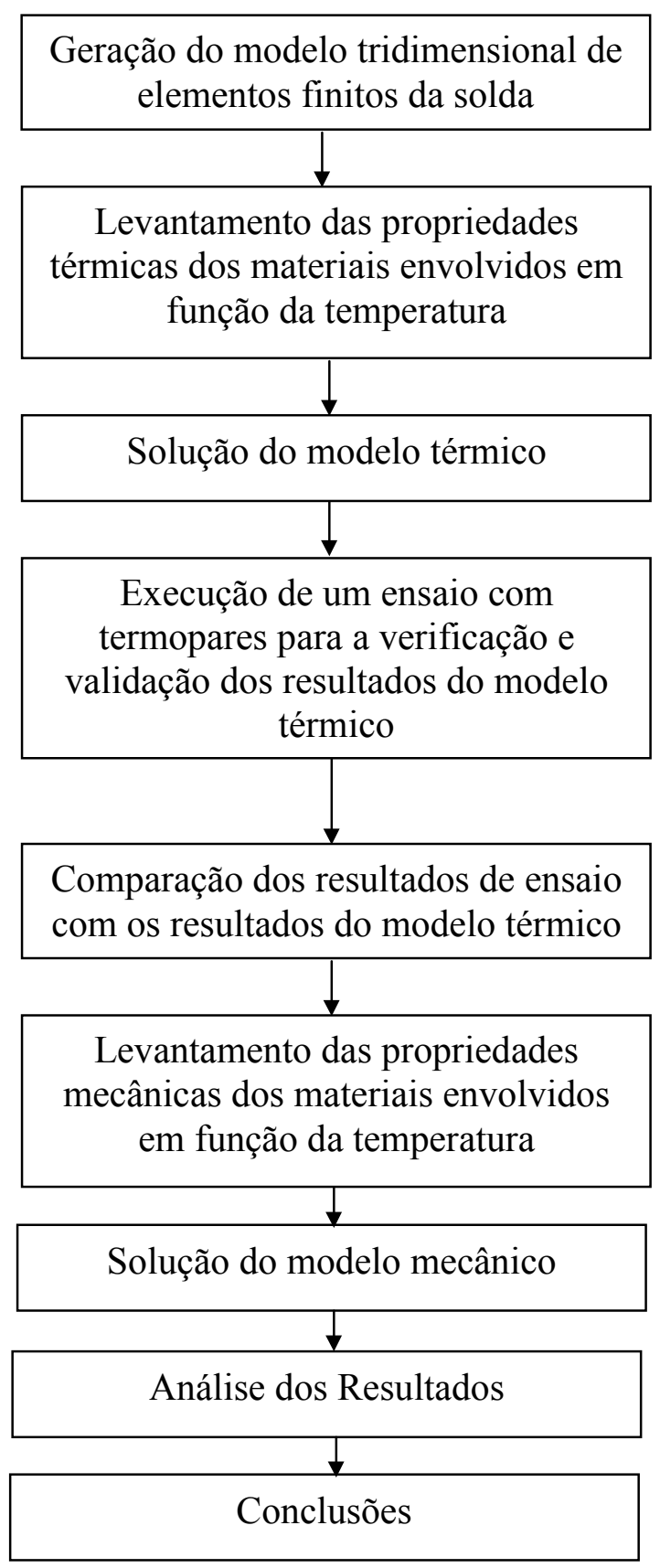

Figura 1.2 - Esquema das Etapas do Estudo

A determinação das tensões residuais de uma junta especial deve ser entendida como um importante passo para o estudo detalhado do comportamento da junta em serviço. 


\subsection{O Surgimento das Tensões Térmicas e Residuais}

As tensões residuais são esforços internos auto-equilibrados, dessa maneira elas atuam no corpo sem necessidade de uma aplicação de um esforço externo, tais como forças ou momentos.

Durante a soldagem, um aporte de calor intenso e localizado é transferido para o corpo a ser soldado. Este aporte de calor gera aquecimento não uniforme no corpo soldado dilatando algumas regiões mais intensamente do que outras. Essa maior dilatação de certas regiões do corpo é restringida por regiões mais frias do corpo que não tiveram sua temperatura aumentada e, devido a essa restrição às tensões térmicas, surgem deformações de natureza plástica. Seguindo o princípio apresentado acima essas tensões térmicas se aliviariam à medida que a parte do corpo mais intensamente aquecida atingisse sua temperatura inicial. De fato isso ocorreria, porém o mecanismo de plastificação juntamente com o grande decréscimo da tensão de escoamento devido ao aumento da temperatura exercem um papel fundamental neste processo, pois geram deformações de natureza plástica não- uniformemente distribuídas próximas ao cordão de solda dando origem as tensões residuais quando o corpo se resfria.

Vale ressaltar que as transformações de fase também são geradoras de tensões residuais, pois essas transformações são acompanhadas de mudanças no volume específico no material fazendo com que o material aquecido dentro da zona termicamente afetada se expanda sendo restrito pelo material mais frio isento de transformação de fase.

Este estudo irá desprezar as tensões residuais causadas pela mudança de fase.

\subsection{Histórico Bibliográfico}

Os primeiros estudos relacionados com tensões residuais em soldas tiveram início em 1930. Boulton et alii (1936) apud Masubuchi (1980) em seu artigo técnico analisou as tensões térmicas na aresta de uma chapa soldada. Segundo Souza (1989) também na década de 30 Rosenthal propôs uma solução analítica para uma fonte de calor (linear, pontual e plana) se deslocando a uma velocidade constante ao longo de uma chapa. Rosenthal assumiu que a soldagem era suficientemente longa para se 
atingir o estado chamado de quasi-estacionário, ou seja, para um observador posicionado no sistema de coordenadas móvel preso à fonte de calor a distribuição de temperatura permanece constante. Além da hipótese de regime quasi-estacionário Rosenthal assumiu as seguintes hipóteses:

1. Propriedades físicas do meio constantes em relação à temperatura.

2. Perdas de calor das superfícies do meio condutor para a atmosfera desprezíveis.

3. Calor gerado pelo arco por efeito Joule é desprezível.

4. Mudanças de fase e o efeito do calor latente são desprezíveis.

5. O meio condutor é infinitamente extenso para analises bidimensionais e semi-infinitamente extenso para análises tridimensionais.

As primeiras análises de tensões residuais assumiam uma série de hipóteses simplificadoras e, em geral, eram análises unidimensionais. Os estudos eram limitados devido à grande complexidade de tratar fenômenos transitórios não lineares com abordagens analíticas e a dificuldade de análise de soldas executadas na prática era enorme.

A utilização do computador para a solução dos modelos matemáticos foi um importante passo para o desenvolvimento das análises de tensões residuais no sentido de aproximar mais os modelos matemáticos das soldas executadas na realidade.

A primeira tentativa de utilização do computador para análise de tensões residuais foi feita por Tall (1961) apud Masubuchi (1980) em sua tese de doutorado. Um programa de computador foi desenvolvido especialmente para cordão depositado em chapa. A distribuição de temperatura foi considerada bidimensional, porém para a análise das tensões, considerou-se a existência apenas de $\sigma_{\mathrm{x}}$ e variando sua magnitude apenas ao longo de distância lateral y da linha de solda os demais componentes de tensões foram assumidos como nulos.

Masubuchi et alii (1968) apud Masubuchi (1980) desenvolveu com base nos estudos de Tall um programa em FORTRAN para análise unidimensional de tensões térmicas durante a soldagem. Para este programa Masubuchi também considerou que as tensões na direção transversal à linha de soldagem juntamente com a tensão de cisalhamento no plano da chapa eram nulas. Desse modo a análise se restringiu à determinação da tensão residual longitudinal. 
As análises unidimensionais, apesar das simplificações, possuíam um custo computacional relativamente baixo o que permitiu uma série de estudos paramétricos importantes para o entendimento qualitativo do fenômeno de tensões residuais provenientes da soldagem.

A partir de 1970 as análises numéricas para as tensões residuais presentes durante a soldagem ficaram mais comuns.Segundo Masubuchi (1980) na década de 70 programas de elementos finitos foram desenvolvidos em várias universidades no Mundo tais como: Brown University, Osaka University, Tokyo University e M.I.T.

Iwaki (1971) apud Masubuchi (1980) desenvolveu um programa de elementos finitos para análises bidimensionais das tensões residuais para análise da deposição simples de cordão em chapa. Muraki (1971) apud Masubuchi (1980), desenvolveu o programa inicial de Iwaki para possibilitar análises de soldas a topo introduzindo uma característica mais prática ao programa. Toshioka, também contribuiu para o desenvolvimento do programa. Ele incluiu os efeitos das transformações metalúrgicas no programa inicialmente desenvolvido por Iwaki. Basicamente ele utilizou os diagramas CCT juntamente com os resultados da análise térmica transiente para a determinação das propriedades do material juntamente com as deformações decorrentes das mudanças de fases. 


\section{ANÁLISE TÉRMICA}

A análise térmica de um processo de soldagem tem como principal objetivo a determinação do campo das temperaturas do corpo soldado ao longo do tempo.Nos itens que seguem, serão apresentados aspectos teóricos, as propriedades físicas dos metais envolvidos neste estudo, o modelo de elementos finitos para a solução das temperaturas, o ensaio realizado para a comprovação do modelo térmico e uma conclusão final sobre o campo das temperaturas.

Com a modelagem térmica comprovada por ensaio, o modelo mecânico da soldagem receberá um dado de entrada com um grau de certeza maior.

Vale ressaltar que a solução do campo de temperaturas não só é um dado fundamental para a análise das tensões residuais, mas também é um dado fundamental para o estudo das transformações metalúrgicas do processo de soldagem.

\subsection{Conceitos Fundamentais}

A intenção fundamental da soldagem é a união de duas ou mais peças metálicas através da fusão e da conseqüente solidificação do material base e do metal depositado.

A fusão do metal depositado se dá devido à energia fornecida pelo arco elétrico que é gerado entre o metal base e o eletrodo. $\mathrm{O}$ calor $\mathrm{Q}$ fornecido à peça soldada pode ser expresso através da corrente $\mathrm{I}$, da tensão $\mathrm{V}$ e da eficiência do arco $\eta$ que depende do processo de soldagem empregado. A existência da eficiência do arco está relacionada com as diversas perdas de calor presentes nos diversos processos de soldagem, ou seja, nem toda a energia elétrica é transferida para a peça em forma de calor. Frações dessa energia são transferidas para o meio através de radiação, para o próprio eletrodo, por condução entres outros mecanismos de perdas.

$$
\mathrm{Q}=\eta \cdot \mathrm{I} \cdot \mathrm{V}
$$


$\mathrm{Na}$ tabela que segue estão relacionadas às eficiências térmicas dos principais processos de soldagem.

Tabela 2.1 - Eficiências Térmicas dos Diferentes Processos de Soldagem, Almendra et alii (1997)

\begin{tabular}{|c|c|}
\hline Processo de Soldagem & Eficiência (\%) \\
\hline Laser & $5-20$ \\
\hline TIG & $30-60$ \\
\hline Plasma & $50-60$ \\
\hline MIG & $70-80$ \\
\hline Eletrodo Revestido & 90 \\
\hline Arco Submerso & 90 \\
\hline
\end{tabular}

O processo utilizado para a análise da soldagem do ring-weld foi o MIG. O processo MIG utiliza gases inertes para a proteção da poça de fusão e a região próxima a ela contra os gases da atmosfera que são prejudiciais à soldagem. $\mathrm{O}$ processo MIG utiliza o arco elétrico para a fusão do eletrodo nu e a proteção da poça de fusão fica a cargo dos gases inertes. O processo de soldagem MIG vem sendo muito utilizado na indústria automotiva, ferroviária e de equipamentos de elevação e transporte. O processo MIG possui alta produtividade em função do processo ser semi-automático e de admitir mecanização.

O modo de transferência de metal fundido é fator que deve ser compreendido para que a modelagem do aporte de calor seja o mais próximo possível da realidade e com um grau de complexidade compatível com a disponibilidade de tempo e recursos computacionais.

Basicamente o modo de transferência descreve como o material fundido do metal de adição é depositado na poça de fusão. O modo de transferência está diretamente relacionado com a intensidade de corrente, o diâmetro e a composição de eletrodo e o gás de proteção utilizado.

O modo de transferência de metal fundido do eletrodo para o metal base pode ser divido em 3 tipos: a transferência globular, a transferência por curto-circuito e a transferência por névoa. 
A principal característica da transferência globular é a formação de gotas com um diâmetro maior do que o diâmetro do eletrodo, esta gota quando atinge um tamanho crítico é então transferida para a poça de fusão.

A transferência por curto-circuito ocorre principalmente em soldagens com posições diferentes da posição plana ou para soldagem de chapas muito finas. Para este tipo de transferência a gota é formada na extremidade do eletrodo até que atinja um tamanho tal que ela entre em contato com a poça de fusão neste instante a corrente aumenta gerando um maior aquecimento do eletrodo de modo que a gota se desprenda do eletrodo reiniciando assim o ciclo de deposição.

A transferência por névoa é caracterizada pela formação de gotas de diâmetro menor do que o diâmetro do eletrodo. Há a formação de uma névoa de material fundido que se transfere para a poça de fusão. Para se atingir o regime de transferência por névoa a intensidade de corrente é parâmetro fundamental, assim como o diâmetro do eletrodo.

A corrente de transição é a corrente de soldagem cujo valor indica o fim da transferência globular e o início da transferência por spray.A figura abaixo mostra uma relação entre o diâmetro do eletrodo e a corrente de transição para o aço carbono, o aço inoxidável e o alumínio.

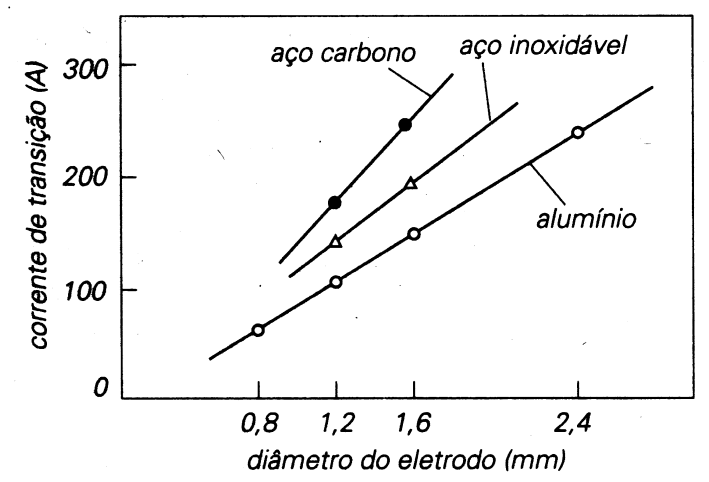

Figura 2.1 - Corrente de Transição do Modo de Deposição, Almendra et alii (1997)

Para o ring-weld estudado neste trabalho os principais parâmetros de soldagem medidos durante a execução da solda seguem:

- Intensidade de corrente contínua: $100 \mathrm{~A}$

- Tensão: $17 \mathrm{~V}$

- Velocidade de soldagem: $4 \mathrm{~mm} / \mathrm{s}$ 
- Diâmetro do Eletrodo: $0.8 \mathrm{~mm}$

- Material do Eletrodo: AISI 308L

\begin{tabular}{|c|c|c|c|c|}
\hline $\begin{array}{l}\text { Arame } \\
\text { diametro } \\
\text { mm }\end{array}$ & $\begin{array}{l}\text { Arame } \\
\text { alimentação } \\
\mathrm{m} \text { min }\end{array}$ & $\begin{array}{l}\text { Corrente } \\
\text { ampére }\end{array}$ & $\begin{array}{l}\text { Tensão } \\
\text { volt }\end{array}$ & $\begin{array}{l}\text { Gás } \\
\text { l/min. }\end{array}$ \\
\hline \multicolumn{5}{|c|}{ Solda com arco em curto-circuito } \\
\hline 0,8 & $4-8$ & $40-120$ & $14-18$ & 12 \\
\hline 1,0 & $4-8$ & $60-140$ & $14-18$ & 12 \\
\hline \multicolumn{5}{|c|}{ Solda com arco pulverizador (spray) } \\
\hline & $6-12$ & $140-220$ & 22 & 18 \\
\hline 1,2 & $5-9$ & $180-260$ & $23-28$ & 18 \\
\hline 1,6 & $3-5$ & $230-350$ & $24-30$ & 18 \\
\hline
\end{tabular}

Figura 2.2 - Parâmetros de Soldagem em Função do Tipo de Transferência, Arames e Varetas de Aço Inoxidável para Soldagem Sandvik (2000).

Considerando os valores de tensão, corrente e diâmetro do arame do processo de soldagem do ring-weld é possível verificar com a ajuda da figura 2.2 que o modo de transferência desenvolvido para o ring-weld estudado é o modo de transferência por curto-circuito.

\subsubsection{Lei de Fourier}

A equação fundamental que governa a distribuição de temperatura em um corpo condutor de calor é a equação de Fourier. A princípio a solução analítica da equação de Fourier aplicada ao processo de soldagem é extremamente complicada devido às condições de contorno características, à complexa distribuição da fonte de calor, à dependência das propriedades física com a temperatura, à fonte de calor ser móvel e, a rigor, os processos serem transitórios.

Rosenthal foi um dos primeiros pesquisadores que por meio de hipóteses simplificadoras determinou soluções para a equação de Fourier aplicadas ao processo de soldagem. 
A seguir esta apresentada uma maneira de se obter a equação de Fourier com base no balanço de energia em um elemento diferencial, segundo Masubuchi (1980).

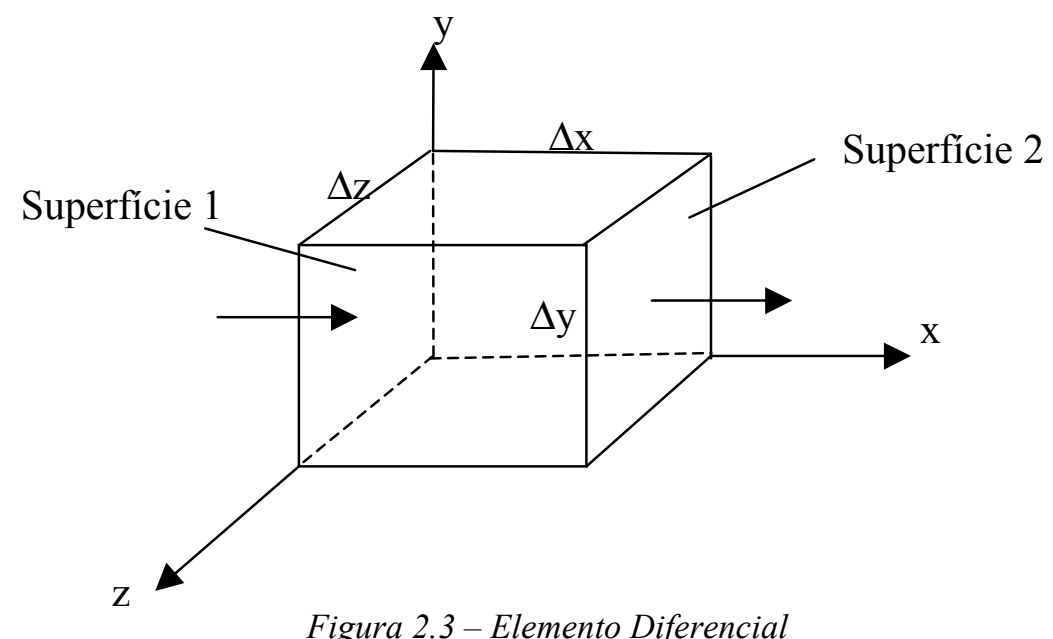

Figura 2.3 - Elemento Diferencial 
A taxa de calor através da superfície 1 e através da superfície 2 podem ser escritas respectivamente como:

$$
\begin{aligned}
& \dot{\mathrm{Q}}_{1}=-\left(\mathrm{k} \cdot \frac{\partial \mathrm{T}}{\partial \mathrm{x}}\right)_{\mathrm{x}} \Delta \mathrm{y} \cdot \Delta \mathrm{z} \\
& \dot{\mathrm{Q}}_{2}=-\left(\mathrm{k} \cdot \frac{\partial \mathrm{T}}{\partial \mathrm{x}}\right)_{\mathrm{x}+\Delta \mathrm{x}} \Delta \mathrm{y} \cdot \Delta \mathrm{z}
\end{aligned}
$$

A taxa de transferência de calor líquida na direção x por unidade de volume pode ser escrita como:

$$
\frac{\dot{\mathrm{Q}}_{1}-\dot{\mathrm{Q}}_{2}}{\Delta \mathrm{x} \cdot \Delta \mathrm{y} \cdot \Delta \mathrm{z}}=\frac{\mathrm{k} \cdot\left(\frac{\partial \mathrm{T}}{\partial \mathrm{x}}\right)_{\mathrm{x}+\Delta \mathrm{x}}-\mathrm{k} \cdot\left(\frac{\partial \mathrm{T}}{\partial \mathrm{x}}\right)_{\mathrm{x}}}{\Delta \mathrm{x}}
$$

Fazendo o limite dos membros da equação acima para $\mathrm{x} \rightarrow 0$, vem:

$$
\lim _{\mathrm{x} \rightarrow 0} \frac{\dot{\mathrm{Q}}_{1}-\dot{\mathrm{Q}}_{2}}{\Delta \mathrm{x} \Delta \mathrm{y} \Delta \mathrm{z}}=\frac{\partial}{\partial \mathrm{x}}\left(\frac{\mathrm{k} \cdot \partial \mathrm{T}}{\partial \mathrm{x}}\right)
$$

Desse modo a taxa de transferência para as três direções fica:

$$
\frac{\partial}{\partial \mathrm{x}}\left(\frac{\mathrm{k} \cdot \partial \mathrm{T}}{\partial \mathrm{x}}\right)+\frac{\partial}{\partial \mathrm{y}}\left(\frac{\mathrm{k} \cdot \partial \mathrm{T}}{\partial \mathrm{y}}\right)+\frac{\partial}{\partial \mathrm{z}}\left(\frac{\mathrm{k} \cdot \partial \mathrm{T}}{\partial \mathrm{z}}\right)
$$

A taxa de variação da energia interna de um corpo por unidade de volume é:

$$
Q_{v}=\rho c \frac{\partial T}{\partial t}
$$

Definindo $\dot{\mathrm{Q}}_{\mathrm{GI}}$ como o calor líquido gerado internamente no sólido por unidade de tempo e de volume, pode-se determinar a lei de Fourier por balanço de energia:

$$
\rho c\left(\frac{\partial \mathrm{T}}{\partial \mathrm{t}}\right)=\mathrm{Q}_{\mathrm{GI}}+\frac{\partial}{\partial \mathrm{x}}\left(\mathrm{k} \frac{\partial \mathrm{T}}{\partial \mathrm{x}}\right)+\frac{\partial}{\partial \mathrm{y}}\left(\mathrm{k} \frac{\partial \mathrm{T}}{\partial \mathrm{y}}\right)+\frac{\partial}{\partial \mathrm{z}}\left(\mathrm{k} \frac{\partial \mathrm{T}}{\partial \mathrm{z}}\right)
$$

A eq. (2.8) juntamente com as condições de contorno, a geometria do corpo e a intensidade e distribuição do aporte de calor cedido ao corpo pelo arco elétrico permitem determinar o campo de temperaturas ao longo do corpo para cada instante de tempo. 
A solução analítica da eq. (2.8) juntamente com as condições de contorno apropriadas para problemas de soldagem é em geral muito complexa e necessita de hipóteses simplificadoras para ser resolvida.

Em geral, as simplificações utilizadas pelos pesquisadores que determinaram soluções para a eq. (2.8) se resumem em 4: propriedades físicas constantes, velocidade de deposição constante, regime quasi-estático e dimensão da fonte de calor desprezível em relação ao corpo.

A dependência das propriedades físicas com a temperatura, as condições de contorno e a geometria da solda apresentam-se muito complicadas para estudos de soldas empregadas na prática, tornando impraticável a solução analítica.

O método dos elementos finitos figura como uma ferramenta robusta e versátil para a solução de problemas de aporte de calor em soldas. Os aspectos fundamentais dessa modelagem serão discutidos mais adiante.

\subsubsection{Aporte de Calor}

É unânime a questão da importância do tratamento do aporte de calor dentro de uma análise térmica de uma junta soldada. A distribuição de temperaturas ao longo do corpo depende fortemente da modelagem correta do aporte de calor cedido ao corpo soldado.

Segundo Papazoglou (1981), a potência elétrica transferida do arco elétrico para o corpo a ser soldado e para o metal de adição pode ser dada através da eq. (2.1). Desse modo é possível determinar a intensidade do aporte de calor, bastando saber qual a eficiência do processo de soldagem empregado além da corrente e da tensão empregadas durante a soldagem.

A eficiência térmica do processo de soldagem depende da penetração da solda, do gás de proteção entre outros fatores, desse modo é difícil determiná-la corretamente. Um meio de determinar a eficiência térmica de cada processo de soldagem é o ensaio de calorimetria que consiste em medir a variação de temperatura de um recipiente com água após a imersão de um corpo de prova recém soldado. Evidentemente os métodos empíricos para determinação da eficiência térmica do processo de soldagem podem estar sujeitos a algumas incertezas inerentes do método 
de medição, assim em alguns casos podem-se encontrar algumas variações dos valores da eficiência térmica publicados.

Além da intensidade do calor transferido ao corpo soldado é muito importante a determinação da distribuição do calor. As abordagens mais simplificadas de modelagem da fonte de calor assumem distribuições pontuais ou lineares, porém uma abordagem mais próxima da realidade é considerar uma distribuição Gaussiana radial cuja equação pode ser escrita como segundo Papazoglou (1981):

$$
\mathrm{q}(\mathrm{r})=\mathrm{q}_{0} \cdot \mathrm{e}^{\mathrm{Cr}^{2}}
$$

Onde,

$\mathrm{q}_{0}$ : máximo fluxo de calor no centro da distribuição $\left[\mathrm{W} / \mathrm{mm}^{2}\right]$

C: coeficiente de concentração de fluxo de calor $\left[\mathrm{mm}^{-2}\right]$

r: distância radial a partir do centro da distribuição [mm]

Na figura 2.4 apresenta-se a distribuição da eq.(2.9):

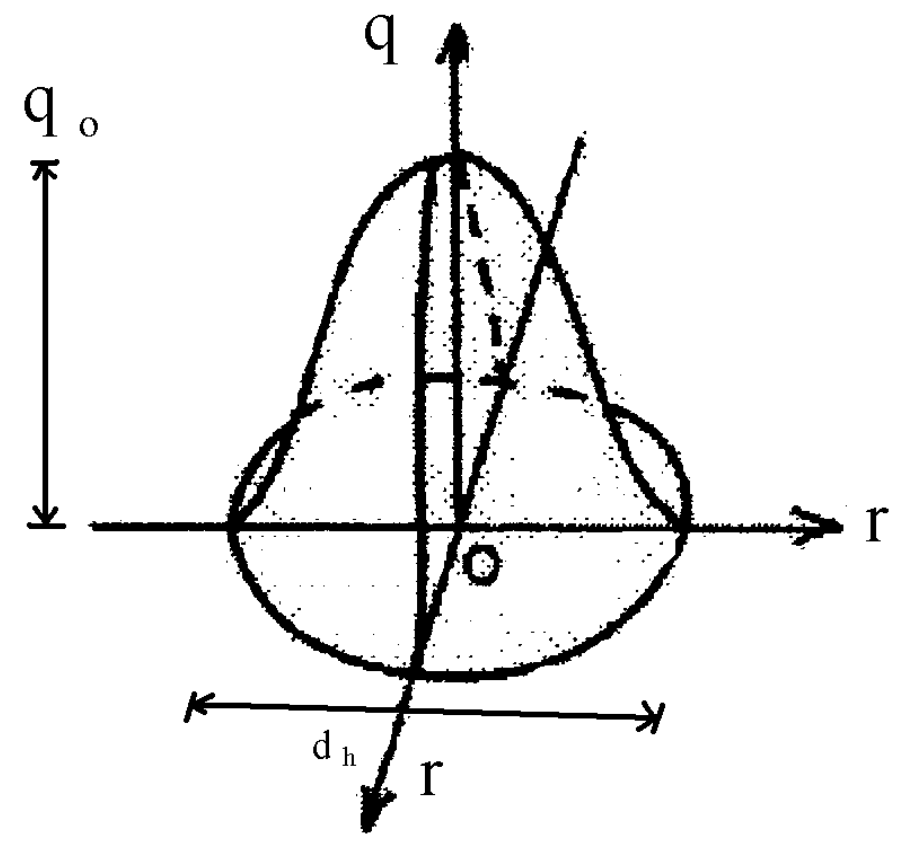

Figura 2.4 - Distribuição de Fluxo de Calor, Papazoglou (1981)

Papazoglou (1981) definiu o diâmetro do círculo da base da distribuição do fluxo de calor de tal modo que:

$$
\mathrm{q}\left(\mathrm{r}_{\mathrm{h}}\right)=\mathrm{q}_{\mathrm{o}} \cdot \mathrm{e}^{-\mathrm{Cr}_{\mathrm{h}}^{2}}=0.05 \cdot \mathrm{q}_{\mathrm{o}}
$$

Da eq.(2.10) vem: 


$$
\mathrm{d}_{\mathrm{h}}=\frac{3.46}{\sqrt{\mathrm{C}}}
$$

Considerando-se ainda que o total de energia Q é conhecido, integrando-se a distribuição do fluxo de calor vem:

$$
\mathrm{Q}=\int_{0}^{\infty} \mathrm{q}(\mathrm{r}) \cdot 2 \pi \mathrm{r} \cdot \mathrm{dr}=\frac{\pi \mathrm{q}_{\mathrm{o}}}{\mathrm{C}}
$$

Desse modo, conhecendo-se o valor de energia $Q$ transferida durante a soldagem e o coeficiente $\mathrm{C}$ define-se a distribuição do fluxo de calor proveniente do arco elétrico.Segundo Papazoglou (1981) valores obtidos experimentalmente de C para soldagem MIG estão entre 1.26 e $1.32 \mathrm{~cm}^{-2}$.

Fica claro que a determinação da distribuição do fluxo de calor depende fundamentalmente do coeficiente de concentração $\mathrm{C}$ que é obtido experimentalmente.

Vale ressaltar ainda que o equacionamento acima é válido apenas para o arco estacionário. Quando o arco elétrico se desloca a distribuição do fluxo de calor se distorce tornando o equacionamento mais complexo e difícil de determinar.

A abordagem utilizada para a modelagem do aporte de calor acima descrita é clássica e fornece mais informação para a compreensão do fenômeno, porém esta abordagem apresenta um certo grau de dificuldade e depende de parâmetros empíricos, que muitas vezes, não estão disponíveis para a maioria dos engenheiros. Em face desse problema, uma abordagem alternativa será proposta para aplicação no modelo de elementos finitos utilizado para a determinação do campo de temperaturas. A abordagem alternativa será validada através da realização do ensaio de temperatura com termopares. Os detalhes da modelagem do aporte de calor serão apresentados mais adiante.

\subsection{Propriedades Físicas}

As propriedades físicas têm um papel fundamental na determinação adequada do campo de temperaturas durante o processo de soldagem de um corpo metálico. A maior dificuldade enfrentada nesta etapa é o conhecimento das propriedades físicas do metal estudado em função da temperatura.

Especialmente a altas temperaturas, a dificuldade de determinar as propriedades físicas do metal é muito grande. Infelizmente a região de interesse para a 
determinação das temperaturas é justamente a que está sujeita às maiores temperaturas. Desse modo torna-se necessária uma boa previsão das propriedades físicas a elevadas temperaturas. A disponibilidade na literatura das referidas propriedades não é muito grande, assim algumas hipóteses simplificadoras foram adotadas com o intuito de dar prosseguimento a análise.

A junta soldada estudada neste trabalho é composta pelo metal base e pelo metal de adição. O metal base de ambas as chapas é o aço inoxidável AISI 301L e o metal de adição utilizado é o aço inoxidável AISI 308L. Devido a dificuldades em se encontrar as propriedades do AISI 308L, foram consideras as propriedades do AISI 316L para o metal de adição. As composições químicas dos três aços constam na Tabela 2.2:

Tabela 2.2 - Composição Química do AISI 308L, AISI 301L e AISI 316L - Metals Handbook

\begin{tabular}{|c|c|c|c|c|c|c|c|}
\hline \multicolumn{7}{|c|}{ Composição Química (nominal) \% } \\
\hline Aço & $\mathrm{C}$ & $\mathrm{Si}$ & $\mathrm{Mn}$ & $\mathrm{Cr}$ & $\mathrm{Ni}$ & $\mathrm{Mo}$ & Outros \\
\hline 301L & 0,03 & 1 & 2 & 16 a 18 & $6 \mathrm{a} 8$ & - & - \\
\hline 308L & 0,025 & 0,4 & 1,75 & 21 & 10 & - & - \\
\hline $316 \mathrm{~L}$ & 0,03 & 1 & 2 & 16 a 18 & 10 a 14 & 2 a 3 & - \\
\hline
\end{tabular}

A condutibilidade térmica, calor específico e coeficiente de dilatação linear podem ser obtidos da figura 2.5 em função da temperatura .

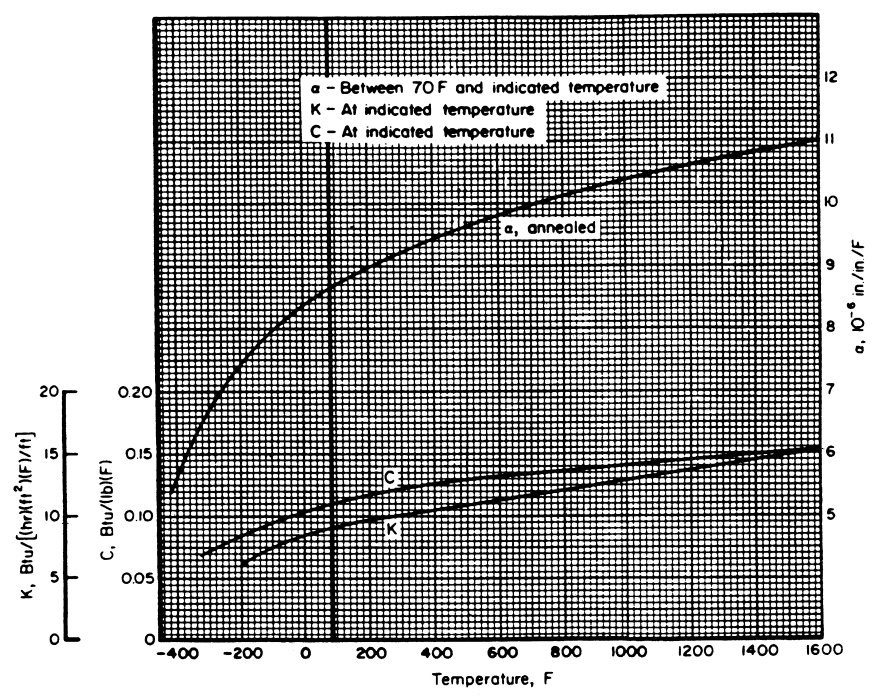

Figura 2.5 - Condutibilidade Térmica, Calor Específico e Coeficiente de Dilatação Linear em Função da Temperatura para o AISI 301L, Department of Defense-E.U.A. MIL-HDBK-5E vol 1 (1987) 


\subsubsection{Condutibilidade Térmica}

A condutibilidade térmica, tanto do AISI 301L quanto do AISI 308L, será tratada como variável com a temperatura, sendo mais evidenciada esta dependência para o metal de adição AISI 308L, devido às altas temperaturas desenvolvidas no cordão de solda.

A variação da condutibilidade térmica com a temperatura do AISI $301 \mathrm{~L}$ pode ser observada na figura 2.6. A curva que descreve a relação entre a condutibilidade térmica e a temperatura pode ser linearizada sem grande comprometimento com a precisão dos dados utilizados na análise. A condutibilidade térmica do AISI 308L será considerada igual ao do AISI 301L face à semelhança da composição química.

Devido à dificuldade de obtenção da condutibilidade térmica em temperaturas superiores a $870{ }^{\circ} \mathrm{C}$ optou-se por uma extrapolação linear a partir de $870{ }^{\circ} \mathrm{C}$. Evidentemente esta opção é questionável e somente será comprovada a sua validade através dos ensaios de termopares cujos resultados serão apresentados mais adiante. A figura que segue apresenta a linearização da condutibilidade térmica em função da temperatura já nas unidades utilizadas no modelo de elementos finitos.

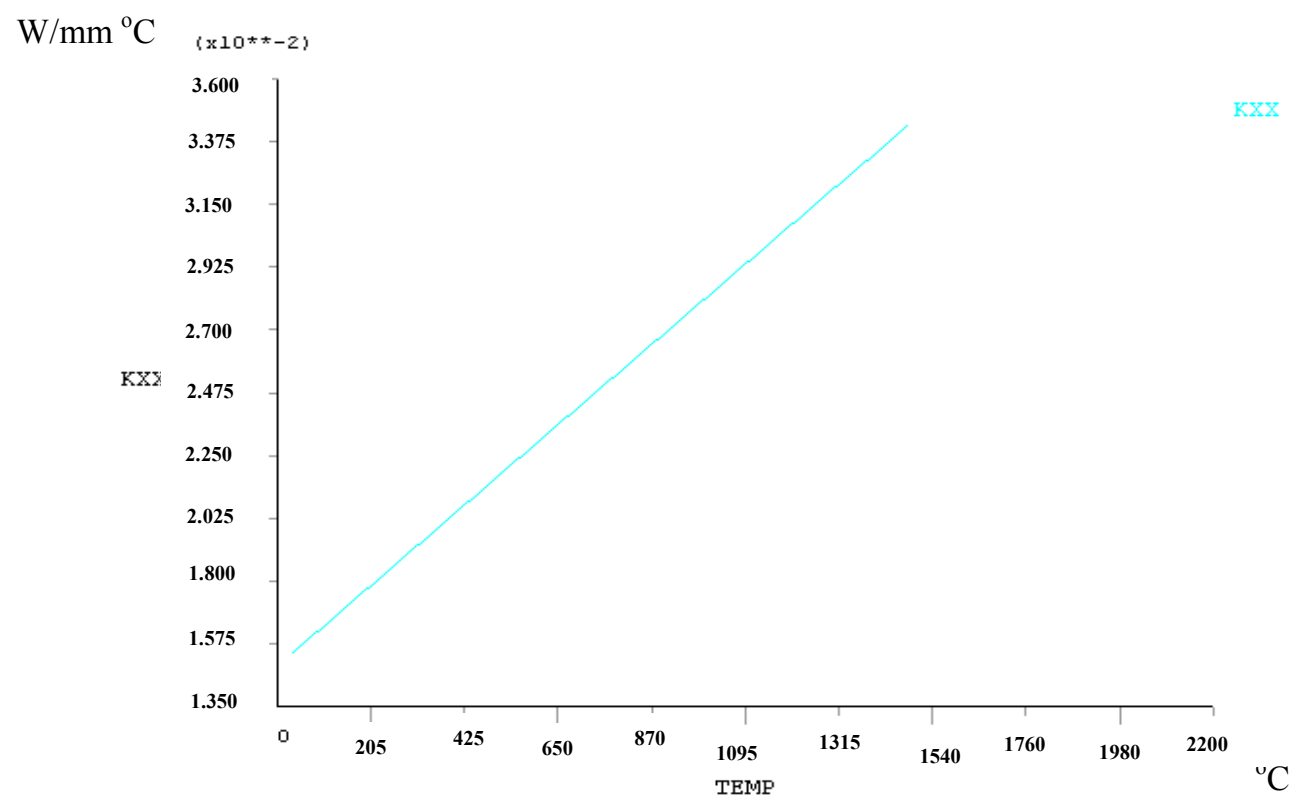

Figura 2.6 - Condutibilidade Térmica Linearizada para AISI 301L e AISI 308 L 
A condutibilidade térmica do AISI 301L e do AISI 308L será adicionada ao modelo de elementos finitos de acordo com a curva da figura 2.6.

\subsubsection{Calor Específico}

De uma maneira análoga à obtenção da condutibilidade térmica em função da temperatura a variação do calor específico com a temperatura pode ser obtida da figura 2.5. A curva representada na figura 2.5 pode ser linearizada sem prejudicar a precisão dos dados, cabendo ao ensaio de termopares a validação desta hipótese simplificadora.

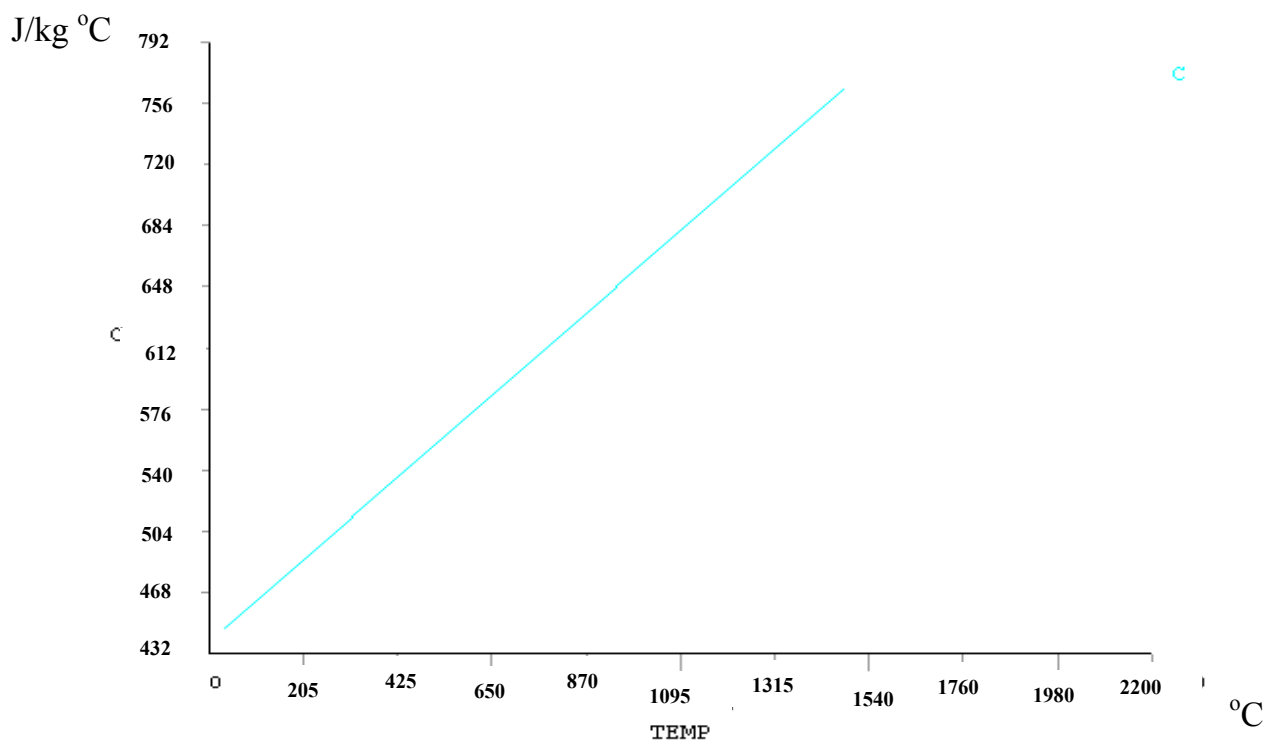

Figura 2.7 - Calor Especifico Linearizado para AISI 301L e AISI 308L

Da mesma maneira que a condutibilidade térmica o calor específico será introduzido ao modelo de acordo com a linearização presente na figura 2.7, porém esta propriedade somente será atribuída ao metal base que não sofre fusão. Para a região onde ocorre mudança de fase o calor latente de solidificação deverá ser considerado e será introduzido no modelo através da entalpia.

\subsubsection{Entalpia}

As mudanças de fase sólido-líquido e no estado sólido podem ser consideradas nas análises de distribuição de temperaturas durante a soldagem. Durante as mudanças 
de fases ocorrem liberação ou absorção de energia, influindo, portanto no balanço de energia e conseqüentemente na distribuição das temperaturas durante a soldagem. Para o método dos elementos finitos as mudanças de fases são modeladas através da entalpia, que depende, por exemplo, da temperatura o que torna o problema não linear, dificultando a obtenção dos resultados. A equação que segue ilustra como o fenômeno é considerado na modelagem de elementos finitos.

$$
\begin{aligned}
& \mathrm{H}=\int \rho \cdot \mathrm{c} \cdot \mathrm{dT} \\
& {[\mathrm{C}]\{\dot{\mathrm{T}}\}-[\mathrm{K}]\{\mathrm{T}\}=\{\mathrm{Q}\}} \\
& {[\mathrm{C}]=\int \rho \cdot \mathrm{c} \cdot[\mathrm{N}]^{\mathrm{T}}[\mathrm{N}] \mathrm{dV}}
\end{aligned}
$$

Onde,

$\mathrm{H}$ : entalpia.

$\rho$ : densidade.

c: calor específico.

$\{\mathrm{T}\}$ : vetor das temperaturas.

$[\mathrm{K}]$ : matriz da condutibilidade térmica.

[N]: matriz da função de forma.

A primeira parcela do balanço de energia (eq. (2.14)) é responsável pela inclusão dos efeitos da variação da entalpia durante a mudança de fase no material. A relação entre a primeira parcela da eq. (2.14) e a entalpia fica clara com a ajuda da eq. (2.13) e eq.(2.15).

De acordo com a eq.(2.13) a entalpia depende do calor específico e da densidade do material. Tanto a densidade como o calor específico dependem da temperatura assim torna-se necessário a determinação do calor específico e da densidade em função da temperatura. Neste estudo a densidade será considerada constante em relação à temperatura, restando apenas a determinação do calor específico ao longo da temperatura até ponto de liquidus, para isso é necessário obter o calor latente de solidificação do aço inox, a temperatura de liquidus, a temperatura de solidus e o calor latente de solidificação.

Como o aço inox não é uma substância pura ele não apresenta um ponto de fusão definido, ou seja, durante uma faixa de temperatura há uma mistura de fase 
líquida com fase sólida sendo delimitada pela temperatura de liquidus e de solidus. A figura que segue ilustra melhor o fenômeno.

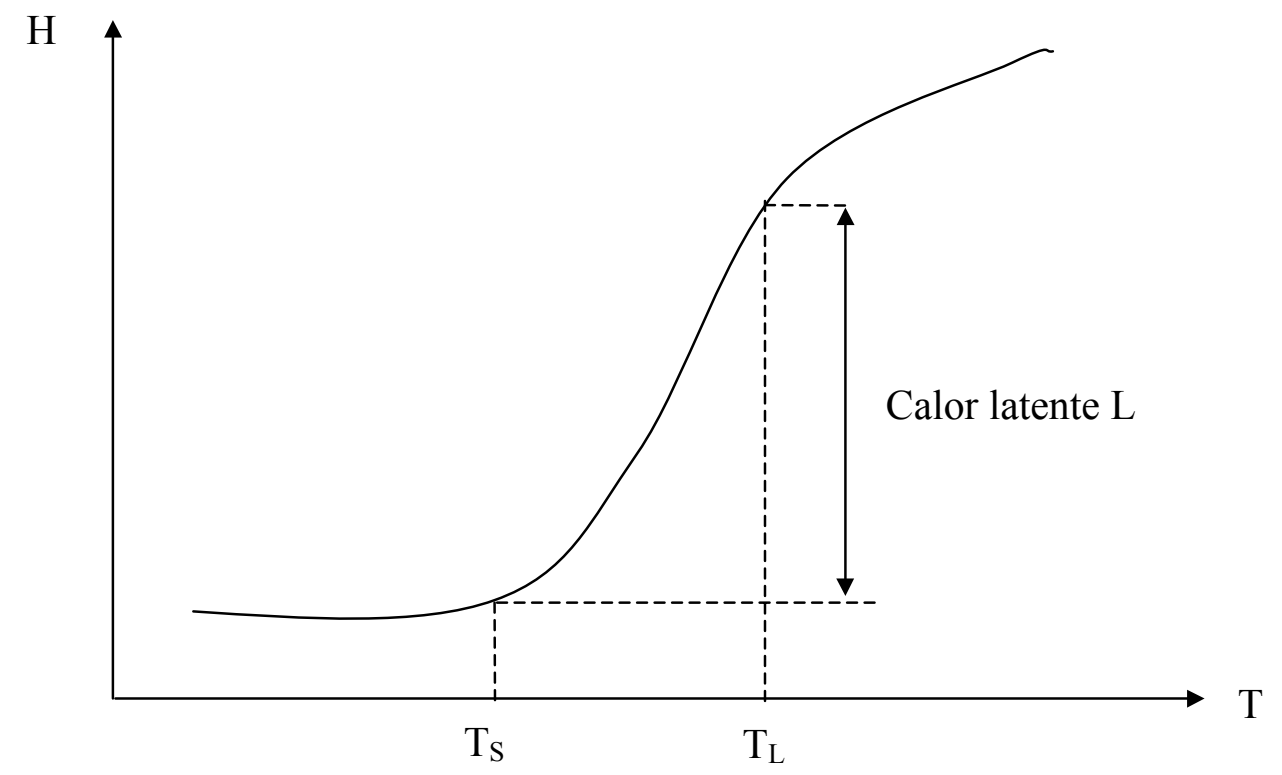

Figura 2.8 - Influência do Calor Latente na Entalpia

A Tabela 2.3 apresenta os dados necessários para o cálculo aproximado da entalpia do AISI 308L considerando-se apenas o calor latente de solidificação. Os valores de calor específico solidus, calor específico liquidus e do calor latente de solidificação utilizados para a análise são referentes ao AISI 316L, pois não houve disponibilidade de dados para o AISI 308L, porém devido à semelhança de composição química esta simplificação não comprometerá os resultados.

Tabela 2.3 - Dados para Determinação da Entalpia, Ohkita (1995)

\begin{tabular}{|c|c|c|c|c|c|}
\hline \multicolumn{7}{|c|}{ Propriedades Físicas do AISI 308L } \\
\hline $\mathrm{T}_{\mathrm{S}}\left({ }^{\circ} \mathrm{C}\right)$ & $\mathrm{T}_{\mathrm{L}}\left({ }^{\circ} \mathrm{C}\right)$ & $\mathrm{c}_{\mathrm{S}}\left(\mathrm{J} /{ }^{\circ} \mathrm{C} \mathrm{kg}\right)$ & $\mathrm{c}_{\mathrm{L}}\left(\mathrm{J} /{ }^{\circ} \mathrm{C} \mathrm{kg}\right)$ & $\rho\left(\mathrm{kg} / \mathrm{mm}^{3}\right)$ & $\mathrm{L}(\mathrm{J} / \mathrm{kg})$ \\
\hline 1275 & 1420 & 2846 & 2657 & $7,5 \cdot 10^{-6}$ & 247000 \\
\hline
\end{tabular}

Com os dados acima apresentados é possível estabelecer um diagrama com o calor específico em função da temperatura. 


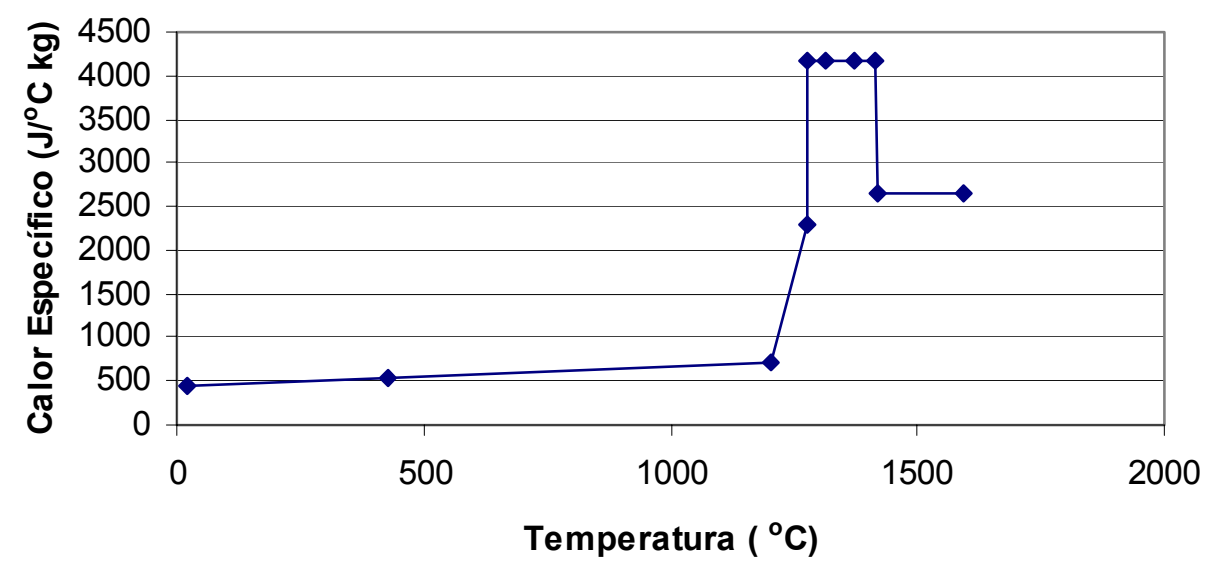

Figura 2.9 - Calor Específico do AISI 308L em Função da Temperatura

Com o auxílio da eq. (2.3) e considerando a densidade constante em função da temperatura pode-se determinar a entalpia do AISI 308L em função da temperatura, permitindo dessa maneira que o calor latente de solidificação seja considerado durante a análise de transferência de calor.

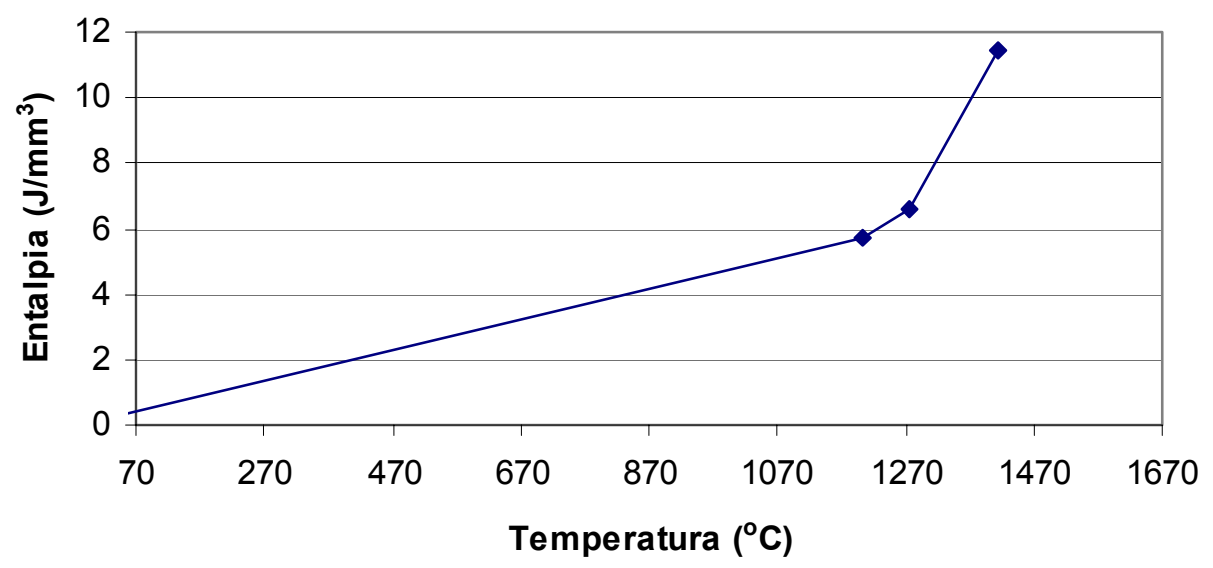

Figura 2.10 - Entalpia do AISI 308L em Função da Temperatura

A curva da figura acima será entrada como dado para análise de transferência de calor para o metal depositado apenas, para o metal base considera-se que não haja fusão de material. 


\subsubsection{Consolidação das Propriedades Físicas}

A seguir serão agrupadas todas as propriedades físicas do metal base AISI 301L e do material depositado AISI 308L necessárias para a análise de transferência de calor durante a soldagem do ring-weld.

Tabela 2.4-Propriedades Físicas do AISI 301L para Análise Térmica

\begin{tabular}{|c|c|c|}
\hline \multicolumn{3}{|c|}{ Propriedades Físicas do AISI 301L para Análise Térmica da Solda } \\
\hline Condutibilidade Térmica & Calor Específico & Densidade \\
\hline Ver figura 2.6 & Ver figura 2.7 & $7,5 \cdot 10^{-6} \mathrm{~kg} / \mathrm{mm}^{3}$ \\
\hline
\end{tabular}

Tabela 2.5 - Propriedades Físicas do AISI 308L para Análise Térmica

\begin{tabular}{|c|c|}
\hline \multicolumn{2}{|c|}{ Propriedades Físicas do AISI 308L para Análise Térmica } \\
\hline Condutibilidade Térmica & Entalpia \\
\hline Ver figura 2.6 & Ver figura 2.10 \\
\hline
\end{tabular}

Com as propriedades físicas necessárias determinadas é possível então iniciar a análise térmica com auxílio do método dos elementos finitos.

\subsection{Modelo de Elementos Finitos}

O problema da determinação do campo das temperaturas durante a soldagem é notadamente transitório e não linear. Devido a enorme complexidade do fenômeno da soldagem, torna-se impraticável e muitas vezes impossível resolvê-lo de um modo analítico. Assim, o método dos elementos finitos torna-se uma opção de ferramenta numérica robusta para a solução de problemas de engenharia, seja no campo da análise térmica de soldagem, seja na subseqüente análise de tensões residuais.

O elemento utilizado para a análise térmica foi um elemento sólido de oito nós da biblioteca do Ansys 6.1 Mechanical o Solid70. Este elemento permite a utilização da propriedade de birth and death, bem como propriedades físicas não-lineares.

A seguir serão apresentadas as equações fundamentais, juntamente com características particulares do método dos elementos finitos para a solução do campo das temperaturas durante o processo de soldagem. 


\subsubsection{Conceitos Fundamentais}

O problema da determinação das temperaturas durante a soldagem de qualquer peça metálica é basicamente um problema de transferência de calor.

Existem a priori três modos de transferência de calor envolvidos no processo de soldagem: a condução, a convecção e a radiação.

A condução pode ser compreendida como uma troca interna de energia entre partes de um corpo que possuam entre si um gradiente de temperatura.

A convecção é uma troca de energia entre um corpo e o fluido que o cerca e a radiação é uma transferência de energia de um ou mais corpos através de ondas eletromagnéticas.

Para a solução das temperaturas durante a soldagem pode-se considerar que o fenômeno se trata de uma condução através do metal base e depositado com condições de contorno de convecção e radiação.

A condução tem sua caracterização dada pela lei de Fourier já citada anteriormente.

$$
\mathrm{q}=-\mathrm{K}_{\mathrm{nn}} \frac{\partial \mathrm{T}}{\partial \mathrm{n}}
$$

Onde,

$\mathrm{K}_{\mathrm{nn}}$ : condutibilidade térmica na direção $\mathrm{n}$.

T: temperatura.

$\frac{\partial \mathrm{T}}{\partial \mathrm{n}}$ : gradiente de temperatura na direção $\mathrm{n}$.

O fluxo de calor decorrente da convecção é dado pela lei de Newton do resfriamento.

$\mathrm{q}=\mathrm{h} \cdot\left(\mathrm{T}_{\mathrm{S}}-\mathrm{T}_{\mathrm{B}}\right)$

Onde,

h: coeficiente de convecção.

$\mathrm{T}_{\mathrm{S}}$ : temperatura do sólido.

$\mathrm{T}_{\mathrm{B}}$ : temperatura de bulbo úmido do fluido.

A radiação é dada pela lei de Stefan-Boltzmann. Este modo de transferência de calor é altamente não linear com a temperatura, visto que a temperatura que é uma variável do problema global está elevada a quarta potência. Este fato torna a inclusão 
da radiação na solução de elementos finitos computacionalmente cara. Muitos pesquisadores do fenômeno de transferência de calor durante a soldagem acreditam que a influência deste modo de transferência de calor no resultado das temperaturas não é significativa justificando assim a sua desconsideração. Para este estudo a radiação não será considerada.

$$
\mathrm{Q}=\sigma \cdot \varepsilon \cdot \mathrm{A}_{\mathrm{i}} \cdot \mathrm{F}_{\mathrm{ij}} \cdot\left(\mathrm{T}_{\mathrm{i}}^{4}-\mathrm{T}_{\mathrm{j}}^{4}\right)
$$

Onde,

Q: calor.

$\sigma:$ constante de Stefan-Boltzmann.

$\varepsilon$ : emissividade.

$\mathrm{A}_{\mathrm{i}}$ : área da superfície $\mathrm{i}$.

$F_{\mathrm{ij}}$ : fator de forma entre as superfícies $\mathrm{ij}$.

$\mathrm{T}_{\mathrm{i}}$ : temperatura da superfície $\mathrm{i}$.

$\mathrm{T}_{\mathrm{j}}$ : temperatura da superfície $\mathrm{j}$.

A figura abaixo representa a transferência de calor entre duas superfícies i e j, através da radiação.

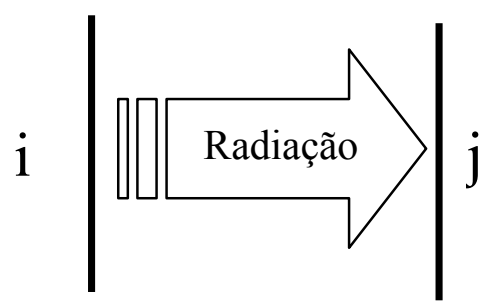

Figura 2.11 - Esquema da Transferência de Calor através da Radiação

Com os diferentes modos de transferência de calor definidos é possível, através da Primeira Lei da Termodinâmica, estabelecer a equação que segue.

Ener. armazenada + Ener. entra pelo contorno + Ener. sai pelo contorno + Ener. gerada $=0$ (2.19)

A eq. (2.19) quando aplicada em um volume diferencial nos dá a eq.(2.8). Para um meio anisotrópico a eq.(2.8) fica:

$$
\rho c\left(\frac{\partial \mathrm{T}}{\partial \mathrm{t}}\right)=\mathrm{Q}_{\mathrm{GI}}+\frac{\partial}{\partial \mathrm{x}}\left(\mathrm{K}_{\mathrm{xx}} \frac{\partial \mathrm{T}}{\partial \mathrm{x}}\right)+\frac{\partial}{\partial \mathrm{y}}\left(\mathrm{K}_{\mathrm{yy}} \frac{\partial \mathrm{T}}{\partial \mathrm{y}}\right)+\frac{\partial}{\partial \mathrm{z}}\left(\mathrm{K}_{\mathrm{zz}} \frac{\partial \mathrm{T}}{\partial \mathrm{z}}\right)
$$

De acordo com Bathe (1999), utilizando a formulação variacional é possível escrever a eq.(2.20) e suas respectivas condições e contorno na forma abaixo: 


$$
\begin{aligned}
& \int_{\text {olume }}\left(\rho \cdot \mathrm{c} \cdot \delta \mathrm{T}\left(\frac{\partial \mathrm{T}}{\partial \mathrm{t}}\right)+\{\mathrm{L}\}^{\mathrm{T}}(\delta \mathrm{T})([\mathrm{D}]\{\mathrm{L}\} \mathrm{T})\right) \mathrm{d}(\text { volume })=\int_{\delta_{2}} \delta \mathrm{T} \cdot \mathrm{qd}(\mathrm{S} 2)+ \\
& +\int_{\delta 3} \delta \mathrm{T} \cdot \mathrm{h}\left(\mathrm{T}_{\mathrm{B}}-\mathrm{T}\right) \mathrm{d}(\mathrm{S} 3)+\int_{\text {olume }} \delta \mathrm{T} \cdot \mathrm{Q}_{\mathrm{GI}} \mathrm{d}(\text { volume })
\end{aligned}
$$

Onde,

volume: volume do elemento diferencial.

$$
\{L\}^{\mathrm{T}}=\left[\begin{array}{lll}
\frac{\partial}{\partial \mathrm{x}} & \frac{\partial}{\partial y} & \frac{\partial}{\partial \mathrm{z}}
\end{array}\right] .
$$

$\delta \mathrm{T}$ : temperatura virtual.

S2: superfícies com fluxo de calor imposto.

S3: superfícies com convecção aplicada.

Discretizando o meio contínuo em elementos finitos, assumindo uma variação polinomial de temperaturas através de cada elemento e uma continuidade do campo de temperatura dentro do elemento e ao longo de seus limites pode-se escrever as incógnitas (temperaturas) como segue:

$$
\mathrm{T}=\{\mathrm{N}\}^{\mathrm{T}} \cdot\{\mathrm{T}\}_{\mathrm{e}}
$$

Onde,

$\{\mathrm{N}\}^{\mathrm{T}}$ : vetor coluna das funções de forma

$\left\{\mathrm{T}_{\mathrm{e}}\right\}$ : vetor com as temperaturas nodais

Agora é possível calcular os gradientes térmicos bem como os fluxos térmicos em cada elemento que compões o meio discretizado. Assim o vetor do gradiente térmico vem:

$$
\{\mathrm{a}\}=[\mathrm{B}]\left\{\mathrm{T}_{\mathrm{e}}\right\}
$$

Onde,

$$
[\mathrm{B}]=\{\mathrm{L}\}^{\mathrm{T}}[\mathrm{N}]
$$

O vetor do fluxo térmico pode ser então escrito como:

$$
\{\mathrm{q}\}=[\mathrm{D}]\{\mathrm{L}\} \mathrm{T}=[\mathrm{D}][\mathrm{B}]\left\{\mathrm{T}_{\mathrm{e}}\right\}=[\mathrm{D}]\{\mathrm{a}\}
$$

Onde,

[D]: matriz das condutibilidades térmicas.

Substituindo a variação das temperaturas assumidas na eq. (2.21) juntamente com as temperaturas virtuais vem: 


$$
\begin{gathered}
\int_{\text {olume }} \rho c\{\mathrm{~N}\}^{\mathrm{T}}\{\mathrm{N}\} \mathrm{d}(\text { volume })\left\{\dot{\mathrm{T}}_{\mathrm{e}}\right\}+\int_{\text {olume }}[\mathrm{B}]^{\mathrm{T}}[\mathrm{D}][\mathrm{B}] \mathrm{d}(\text { volume })\left\{\mathrm{T}_{\mathrm{e}}\right\}=\int\{\mathrm{N}\} \mathrm{qd}\left(\mathrm{S}_{2}\right)+ \\
\left.+\int_{\mathrm{S}_{3}} \mathrm{~T}_{\mathrm{B}} \mathrm{h}\{\mathrm{N}\} \mathrm{d}\left(\mathrm{S}_{3}\right)-\int_{\mathrm{S}_{3}} \mathrm{~h}\{\mathrm{~N}\}^{\mathrm{T}}\{\mathrm{N}\} \mathrm{T}_{\mathrm{e}}\right\} \mathrm{d}\left(\mathrm{S}_{3}\right)+\int_{\text {volume }} \mathrm{Q}_{\mathrm{GI}}\{\mathrm{N}\} \mathrm{d}(\text { volume })
\end{gathered}
$$

Simplificando a eq. (2.26) vem:

$$
[\mathrm{C}]\{\dot{\mathrm{T}}\}+\left(\left[\mathrm{K}^{\mathrm{d}}\right]+\left[\mathrm{K}^{\mathrm{c}}\right]\right)\{\mathrm{T}\}=\left\{\mathrm{Q}^{\mathrm{f}}\right\}+\left\{\mathrm{Q}^{\mathrm{c}}\right\}+\left\{\mathrm{Q}^{\mathrm{g}}\right\}
$$

Onde,

[C]: matriz do calor específico.

$\left[\mathrm{K}^{\mathrm{d}, \mathrm{c}}\right]$ : contribuições à condutibilidade térmica devido a difusão e a convecção.

$\left\{\mathrm{Q}^{\mathrm{f}, \mathrm{c}, \mathrm{g}}\right\}$ : contribuições à taxa de calor nodal devido ao fluxo, à convecção e à geração de calor interno.

Com os conceitos apresentados fica mais claro como o problema de transferência de calor durante a soldagem pode ser resolvido utilizando-se o método dos elementos finitos. A seguir serão apresentados os detalhes da modelagem do processo de soldagem do ring-weld, desde a modelagem geométrica até a interpretação e análise dos resultados.

\subsubsection{Modelagem do Aporte de Calor em Elementos Finitos}

Conforme já discutido anteriormente o aporte de calor pode ser modelado matematicamente através do conhecimento da intensidade da fonte de calor bem como sua distribuição. Sabe-se que a determinação da distribuição da fonte de calor é um problema de certo modo complicado de se resolver. Apuradas técnicas de experimentação têm de ser aplicadas e isto, em geral, representa custos elevados e, na maioria dos casos, o engenheiro não tem acesso a essas informações necessárias para uma modelagem apurada da distribuição de calor. A intensidade de calor transferida durante a soldagem não se apresenta tão complicada, porém um fator importante a ser considerado é a eficiência do arco elétrico. A determinação das diversas eficiências térmicas é feita a partir de rigorosos ensaios de calorimetria, e de certo modo as mesmas condições do ensaio não estão presentes no dia a dia de uma produção industrial. 
Diante dessas dificuldades a modelagem do aporte de calor utilizada nesta análise pode ser considerada simplificada, mas é de certa forma mais prática e conveniente.

A modelagem do aporte de calor proposta neste estudo parte da idéia de que o calor gerado com o arco elétrico é responsável pela fusão do material depositado, logo se pode modelar o aporte de calor impondo-se a uma certa quantidade de massa de material depositado a temperatura de liquidus do metal depositado e assim no próximo passo de deposição o material depositado anteriormente é deixado esfriar livremente.

Com este tipo de abordagem fica evidente o cuidado que se dever ter durante a modelagem geométrica do perfil do cordão, pois a quantidade de metal depositado por passo de deposição é parâmetro fundamental para a quantidade de calor adicionada ao corpo a ser soldado.

Para se determinar o perfil correto do cordão depositado uma macrografia foi realizada utilizando-se um corpo de prova da solda em estudo e os mesmos parâmetros de soldagem empregados no ring-weld.Apresenta-se nas figuras $2.12 \mathrm{e}$ 2.13 o resultado obtido da macrografia.

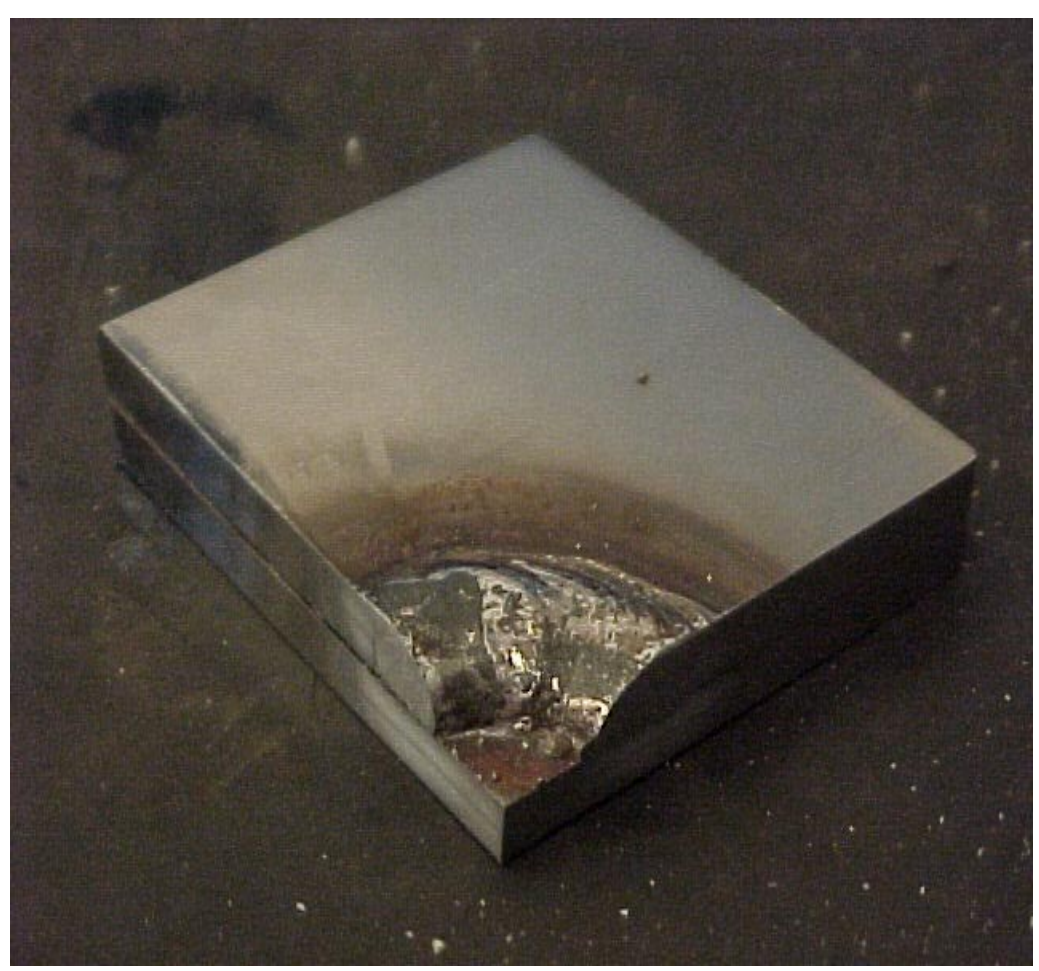

Figura 2.12 - Corpo de Prova Cortado para Macrografia 


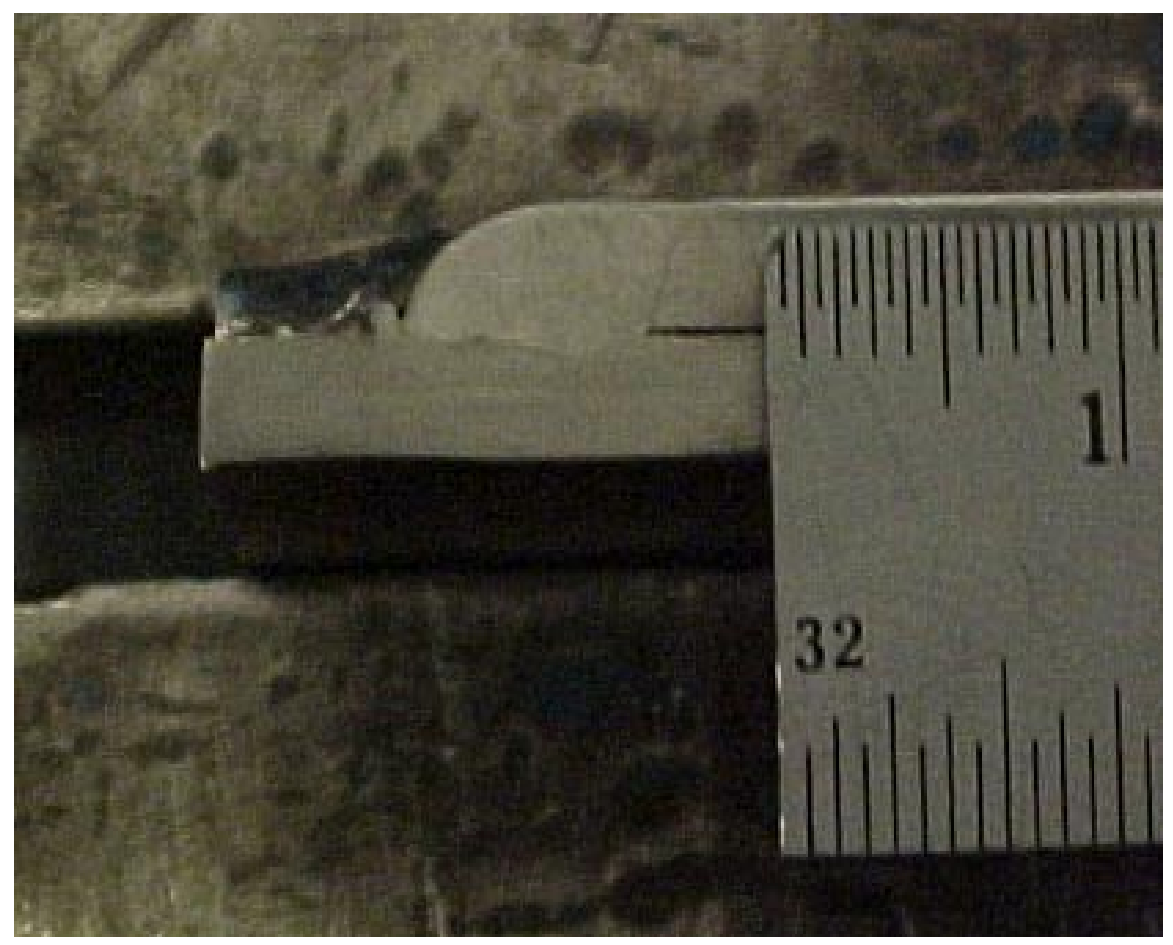

Figura 2.13 - Macrografia do Perfil

Como o perfil do cordão definido o modelo geométrico pode então ser produzido e preparado para as necessidades de modelagem da deposição de material fundido. 
O modelo de elementos finitos segue na figura 2.14:

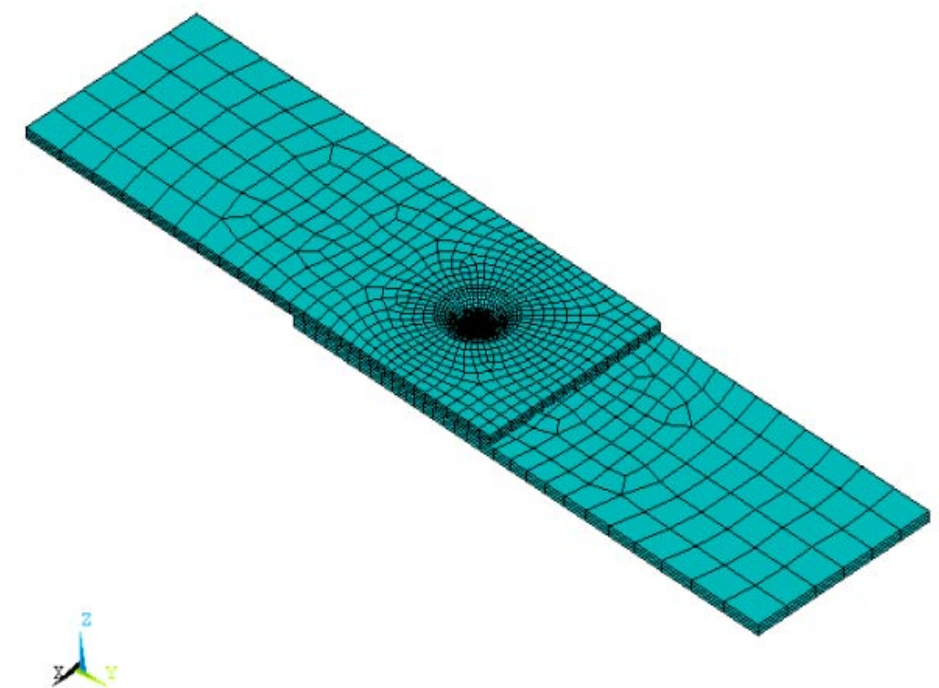

Figura 2.14 - Modelo de Elementos Finitos Vista Isométrica

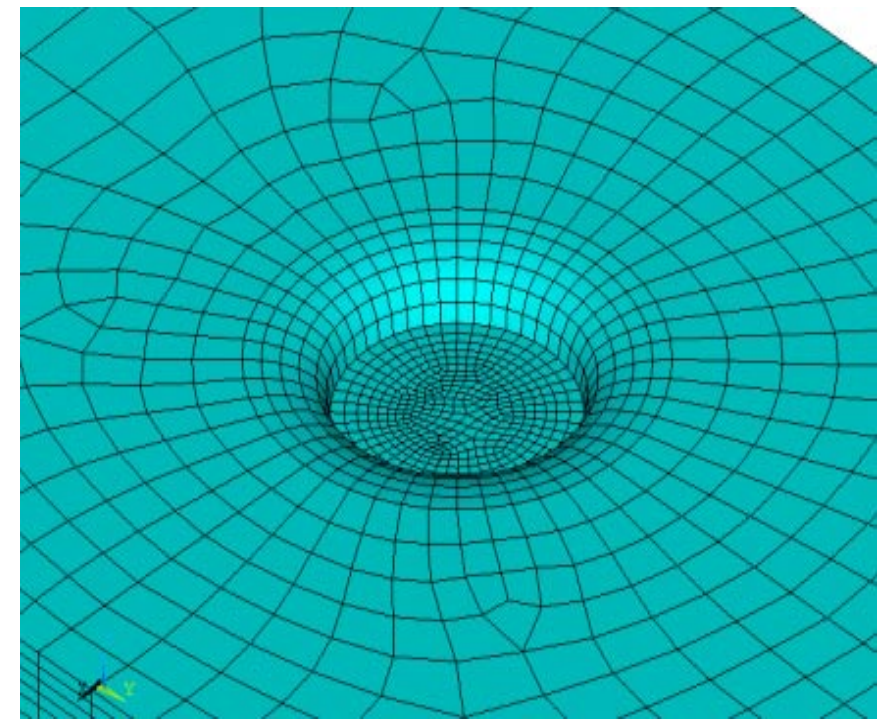

Figura 2.15 - Detalhe da Malha do Cordão de Solda

Fica evidente que quanto à modelagem do cordão de solda é necessário inicialmente gerar todos os elementos presentes no cordão de uma vez, visto que as ordens das matrizes de condutibilidade e de calor específico não podem ser aumentadas ao longo da solução. 


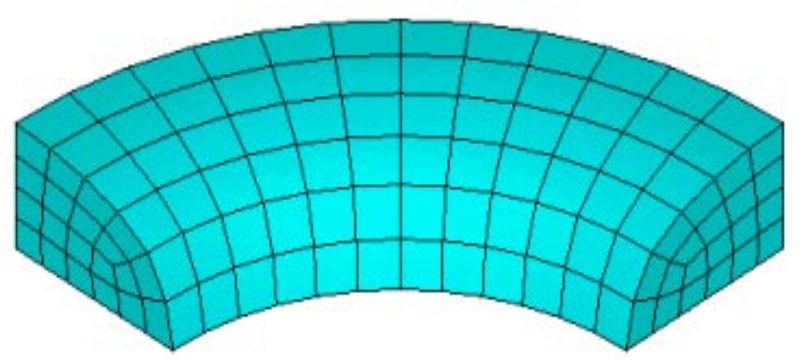

Figura 2.16 - Elementos do Cordão de Solda

A estratégia utilizada para a imposição de temperaturas está relacionada com o tempo de execução da solda e o tamanho aproximado da poça de fusão.

Para esta solda em especial o tempo médio de execução é de 21 s e o tamanho estimado da poça de fusão é de $1.5 \mathrm{~mm}$ aproximadamente duas vezes o diâmetro do arame. Com estas informações dividiu-se o cordão de solda em 48 partes iguais que terão suas temperaturas impostas no tempo determinado pela velocidade de deposição de material fundido.O tempo de deposição de cada parte do cordão é denominado td.

A aplicação das temperaturas se dará da seguinte forma: após a imposição da temperatura inicial de $25{ }^{\circ} \mathrm{C}$, a primeira porção de material depositado é ativada e todos os nós correspondentes tem a sua temperatura imposta em função do tempo de acordo com o gráfico mostrado na figura 2.17:

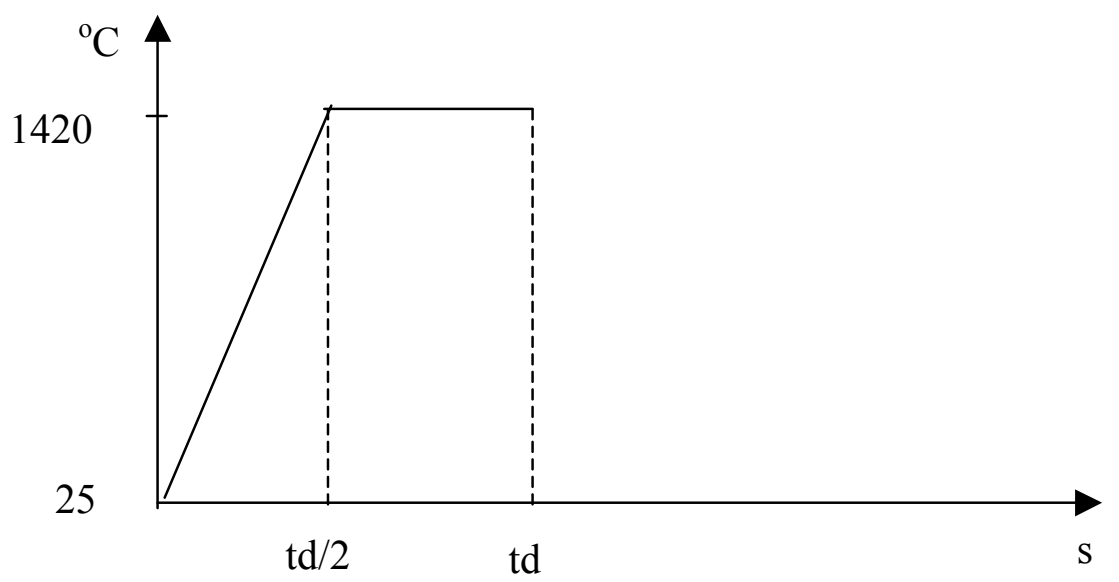

Figura 2.17-Gráfico Representado a Imposição de Temperatura 
Após atingir o instante td a primeira parte depositada do cordão é deixada em condição livre para resfriamento.

Uma vez terminada a primeira deposição (instante td), a segunda deposição inicia utilizando a mesma abordagem de carregamento, porém apenas com os nós que não fazem parte da interface com os elementos já carregados. Na figura 2.18 apresenta-se a sequência de carregamento.

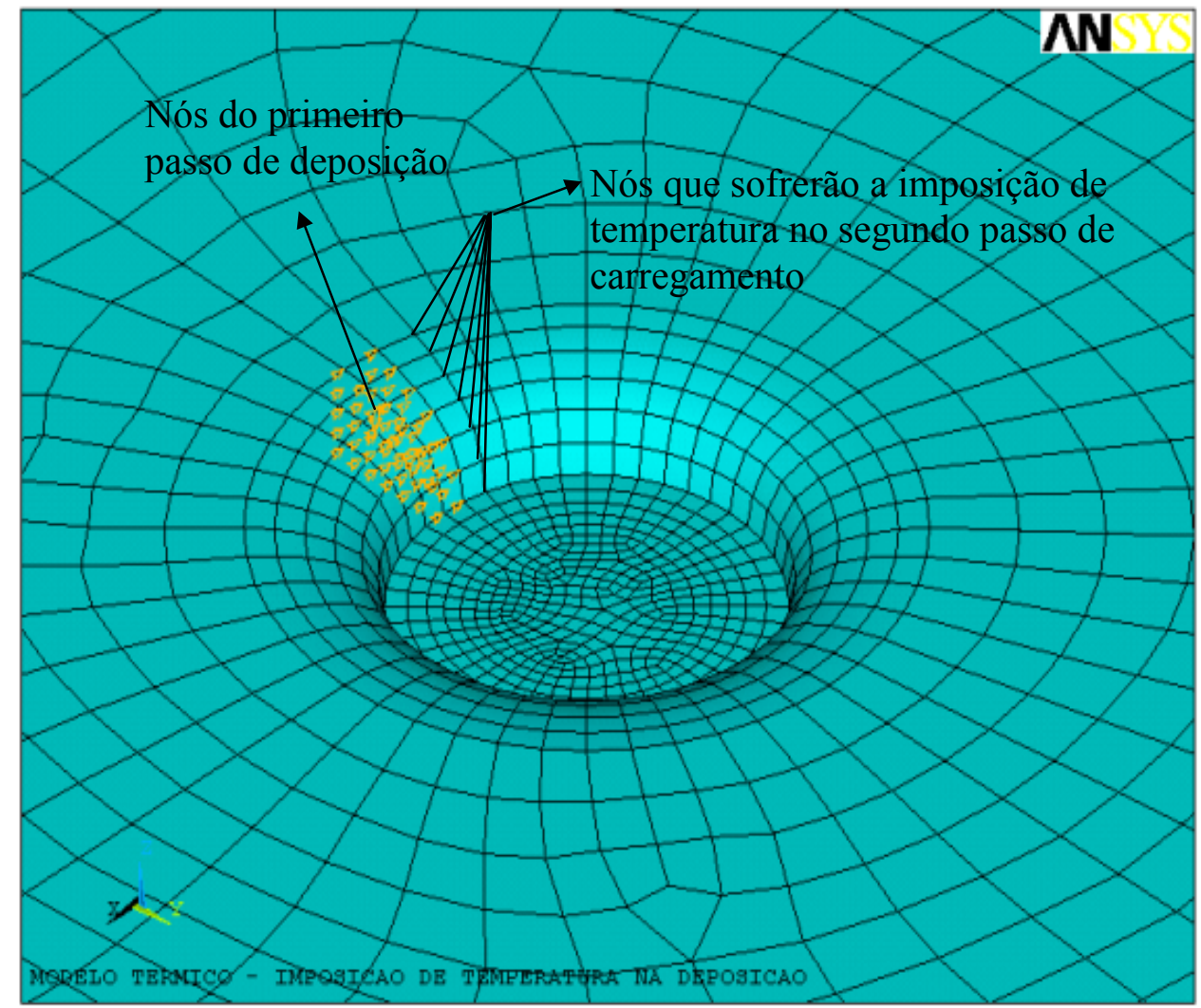

Figura 2.18 - Imposição de Temperatura na Segunda Deposição

Assim os carregamentos vão sendo aplicados até que a ultima porção de material depositado seja ativada e tenha sua temperatura imposta de acordo com o explanado acima.

Após a deposição da última porção de material fundido o modelo é deixado resfriar até que entre em equilíbrio térmico com a temperatura ambiente. Para esta análise foram considerados 3000 s até que se atinja o equilíbrio térmico. 


\subsubsection{Condições de Contorno}

Além da imposição de temperatura o modelo foi submetido a condição de contorno de convecção. Para a aplicação desta condição de contorno é necessário determinar o coeficiente de convecção. A determinação deste coeficiente pode ser feita de vários modos desde o mais simples, baseado em coeficientes e fórmulas empíricas até uma modelagem numérica refinada do fenômeno de transporte de calor e massa. Para os objetivos finais deste trabalho acredita-se que a utilização das formulações empíricas clássicas permitirá a obtenção de um resultado compatível com a finalidade do trabalho.

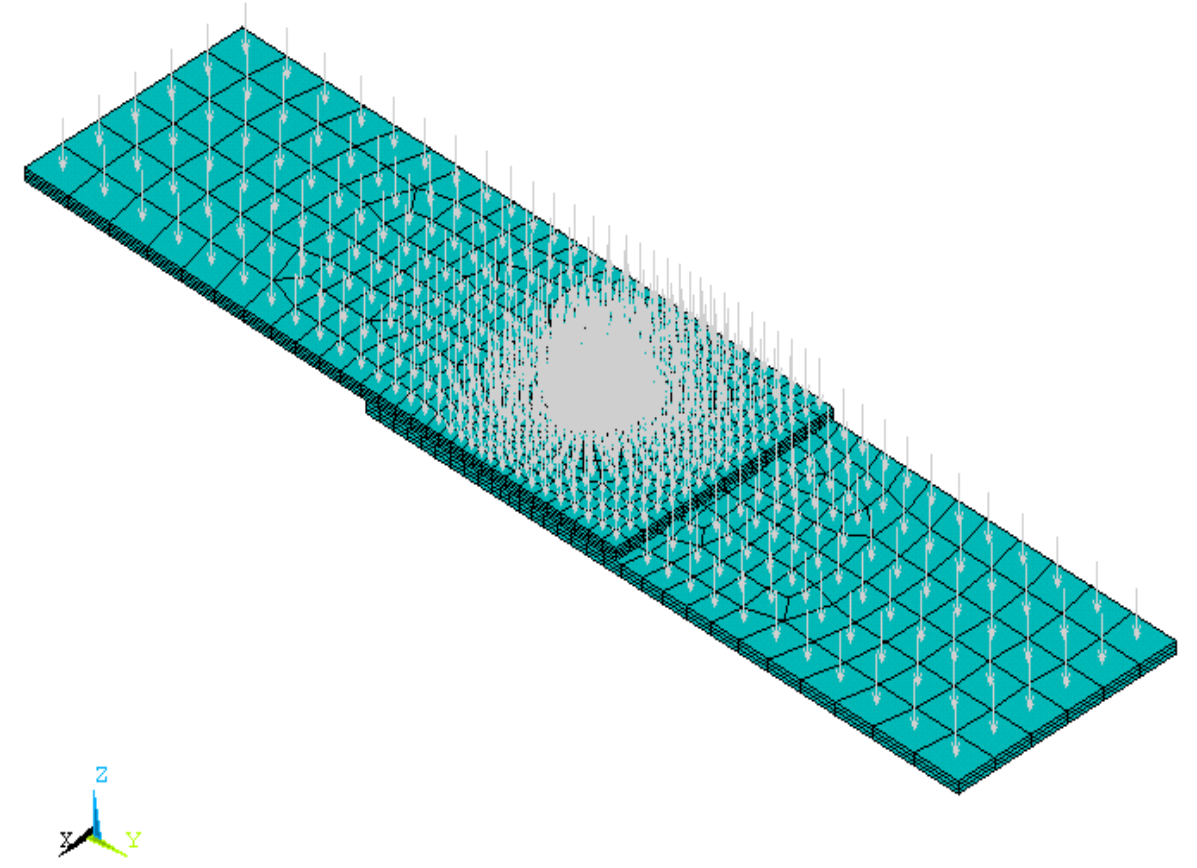

Figura 2.19-Coeficiente de Convecção

Pode-se verificar na figura acima que evidentemente a condição de contorno de convecção somente foi aplicada às superfícies quentes voltadas para cima em relação a gravidade, pois somente essas superfícies tem uma troca de calor, por convecção, considerável para este problema. 


\subsubsection{Coeficiente de Convecção}

O fenômeno de convecção que ocorre durante a soldagem pode ser considerado como um fenômeno de convecção livre, o que significa que o fluido (ar ambiente) se movimenta simplesmente devido à mudança de empuxo provocada pelo aquecimento.

A determinação do coeficiente de convecção pode ser efetuada por meio de formulações empíricas e números adimensionais.

Segundo Incropera (1992), os números adimensionais necessários para a estimativa do coeficiente de convecção são o número de Rayleigh e o número de Nusselt e serão apresentados a seguir:

$$
\begin{aligned}
& \mathrm{Ra}_{\mathrm{L}}=\frac{g \beta\left(\mathrm{T}_{\mathrm{S}}-\mathrm{T}_{\infty}\right) \mathrm{L}^{3}}{v \alpha} \\
& \overline{\mathrm{Nu}_{\mathrm{L}}}=0,54 \mathrm{Ra}_{\mathrm{L}}{ }^{1 / 4}\left(10^{4} \leq \mathrm{Ra}_{\mathrm{L}} \leq 10^{7}\right) \\
& \overline{\mathrm{Nu}_{\mathrm{L}}}=0,15 \mathrm{Ra}_{\mathrm{L}}{ }^{1 / 3}\left(10^{7} \leq \mathrm{Ra}_{\mathrm{L}} \leq 10^{11}\right)
\end{aligned}
$$

Onde,

g: aceleração da gravidade

$\beta$ : coeficiente da expansão

$\mathrm{T}_{\mathrm{S}}$ : temperatura na superfície da placa

$\mathrm{T}_{\infty}$ : temperatura do fluido quiescente

$\alpha$ : difusividade térmica

$v$ : viscosidade cinemática

L: comprimento característico

Os números apresentados acima são válidos para placas planas horizontais com a superfície quente voltada para cima.

Segundo Incropera (1992), a equação que determina o coeficiente de convecção médio pode ser escrita como segue:

$$
\overline{\mathrm{h}}=\frac{\overline{\mathrm{Nu}_{\mathrm{L}}} \mathrm{L}}{\mathrm{k}}
$$

Onde,

$\mathrm{k}$ : condutividade térmica. 
As propriedades do ar ambiente são consideradas para a temperatura de película.

Considerando uma temperatura ambiente de $25^{\circ} \mathrm{C}$, foram calculados diversos valores de $\mathrm{h}$ até a temperatura da chapa de $1827{ }^{\circ} \mathrm{C}$. O gráfico abaixo apresenta os resultados obtidos.

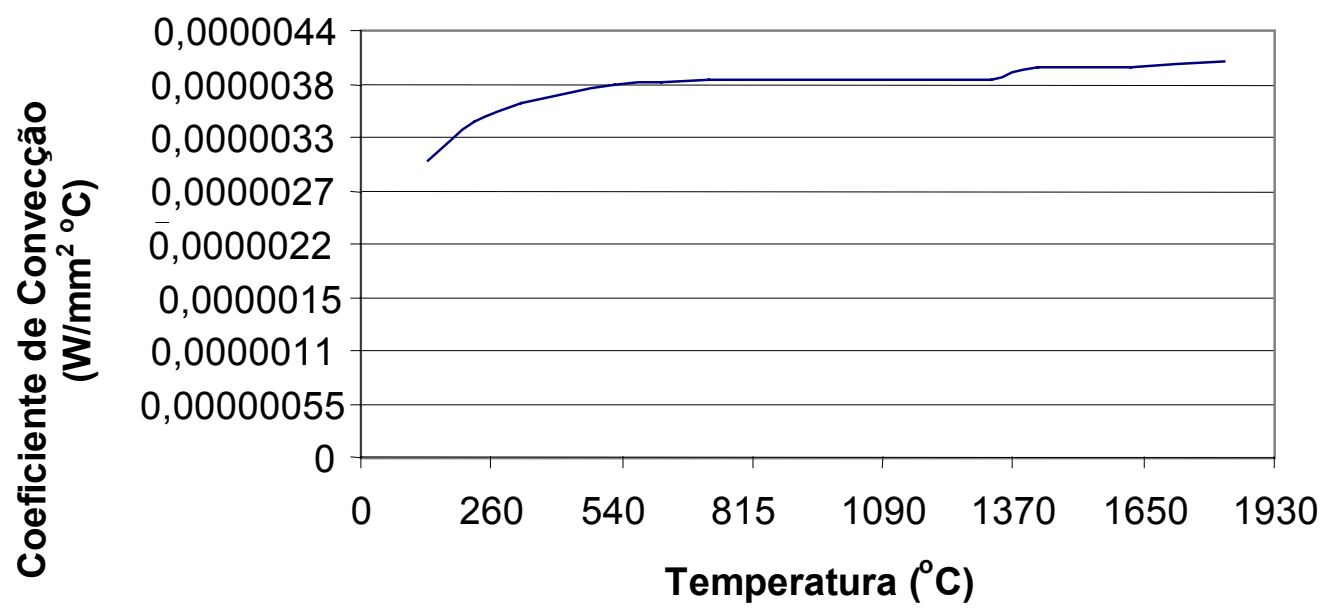

Figura 2.20 - Coeficiente de Convecção em Função da Temperatura

Observando o gráfico acima é possível verificar que o coeficiente de convecção não varia muito dentro da faixa de temperatura esperada para o processo de soldagem do ring-weld, portanto o valor médio de h será considerado para o modelo de elementos finitos.O valor médio calculado é de $3,78 \cdot 10^{-6} \mathrm{~W} / \mathrm{mm}^{2}{ }^{\circ} \mathrm{C}$ e será aplicado na superfície quente do modelo voltada para cima conforme mostrado anteriormente.

\subsubsection{Resultados}

Os resultados do modelo de elementos finitos para a análise térmica serão mostrados em termos de escala de cores e também em termos de gráficos para facilitar a análise e compreensão dos mesmos. Estes resultados servirão como carregamento para a análise das tensões residuais discutidas mais adiante.

As figuras que seguem apresentam o resultado da temperatura em ${ }^{\circ} \mathrm{C}$ e o tempo em segundos, relativo aos respectivos passos de carregamento. 


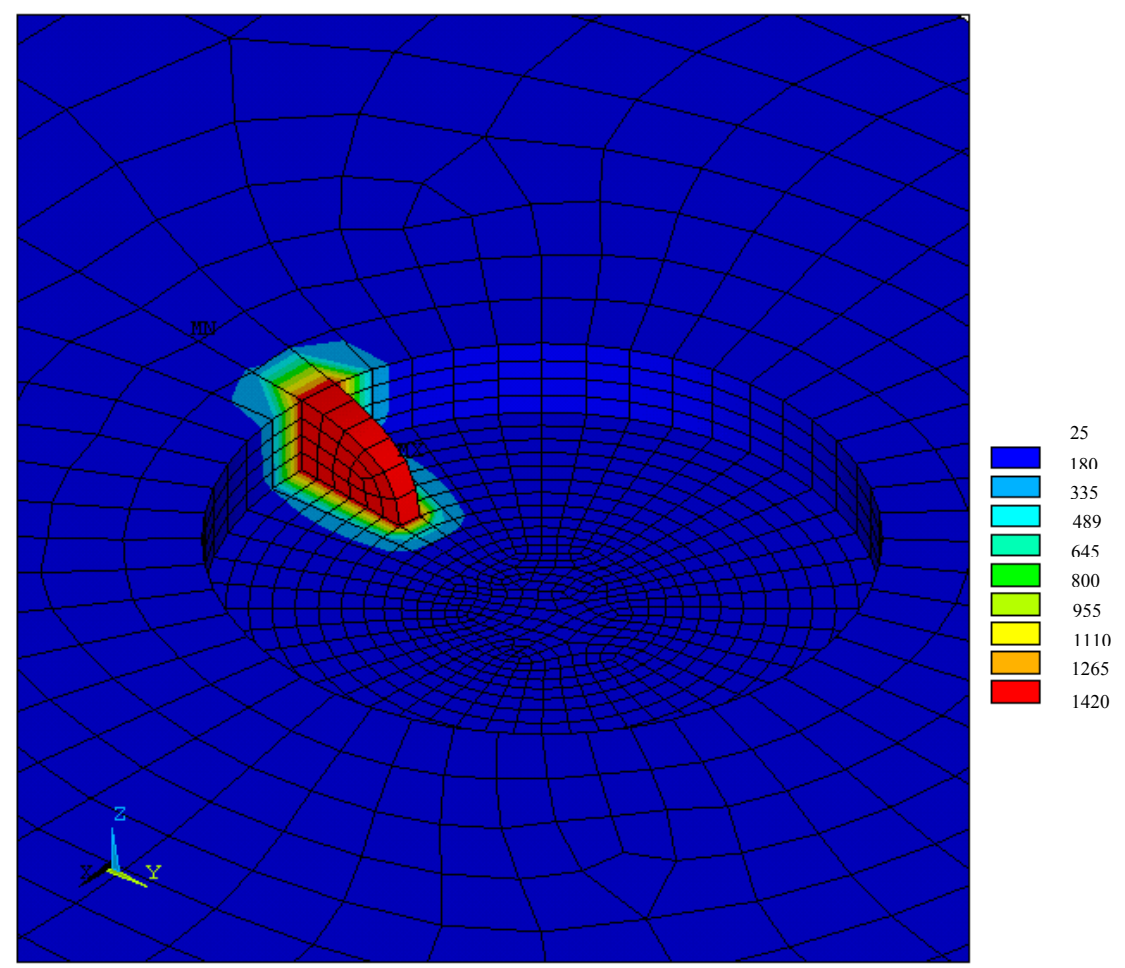

Figura 2.21 - Distribuição das Temperatura $\left({ }^{\circ} \mathrm{C}\right)$ no Instante $0.42 \mathrm{~s}$

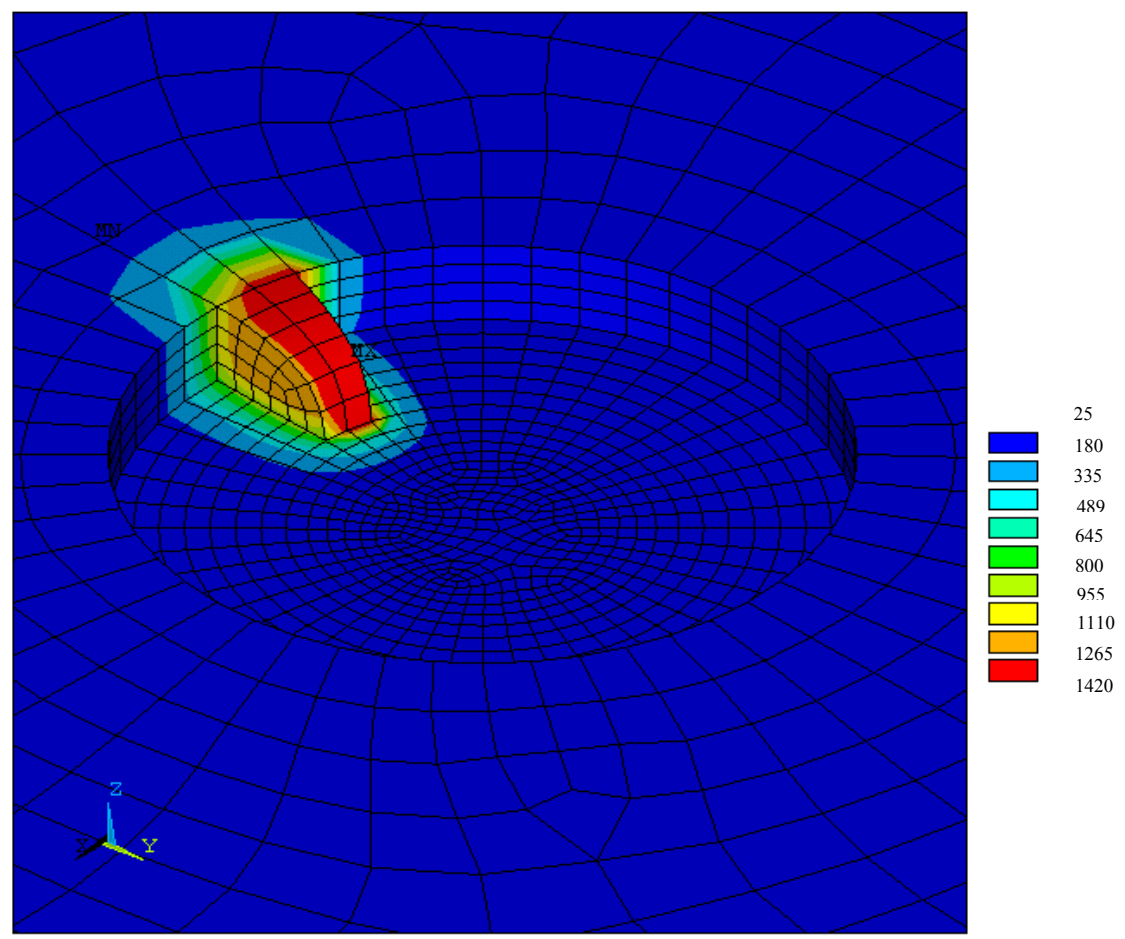

Figura 2.22 - Distribuição de Temperatura $\left({ }^{\circ} \mathrm{C}\right)$ no Instante $0.84 \mathrm{~s}$ 


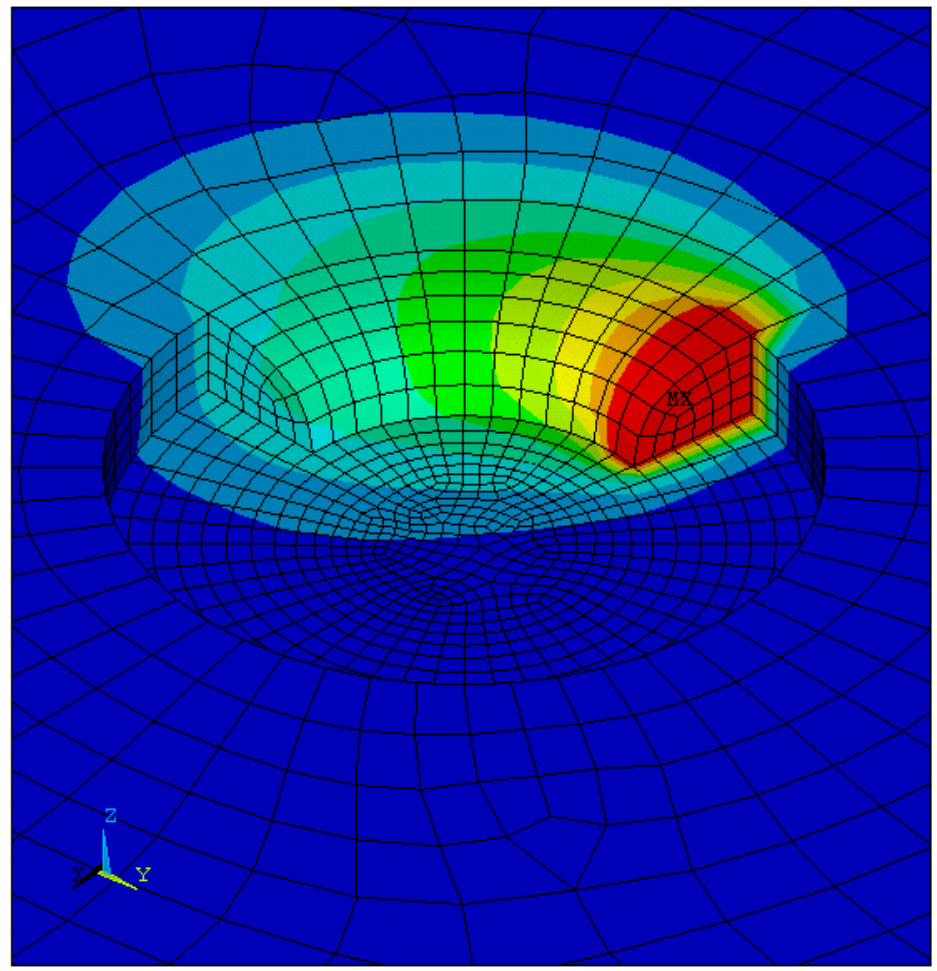

Figura 2.23 - Distribuição de Temperatura $\left({ }^{\circ} \mathrm{C}\right)$ no Instante $5.46 \mathrm{~s}$

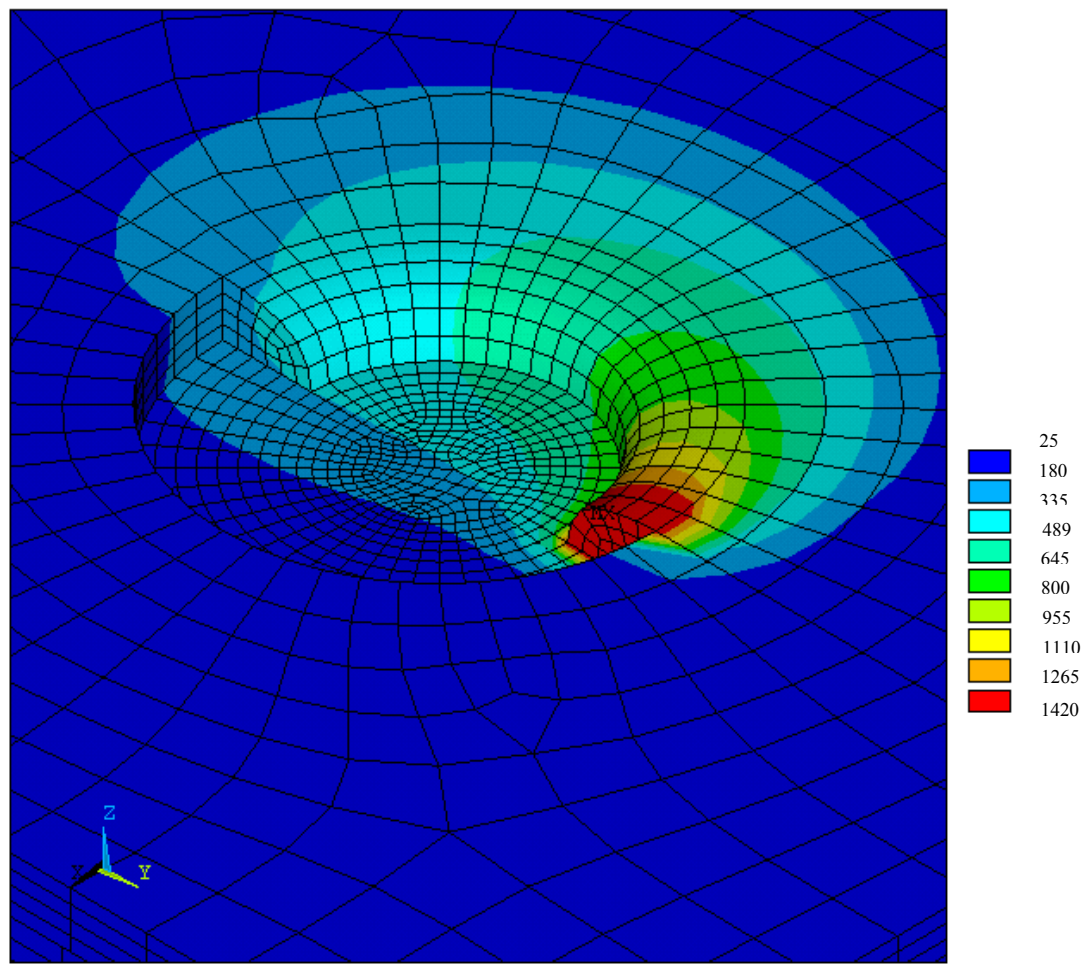

Figura 2.24 - Distribuição de Temperatura $\left({ }^{\circ} \mathrm{C}\right)$ no Instante $10.08 \mathrm{~s}$ 


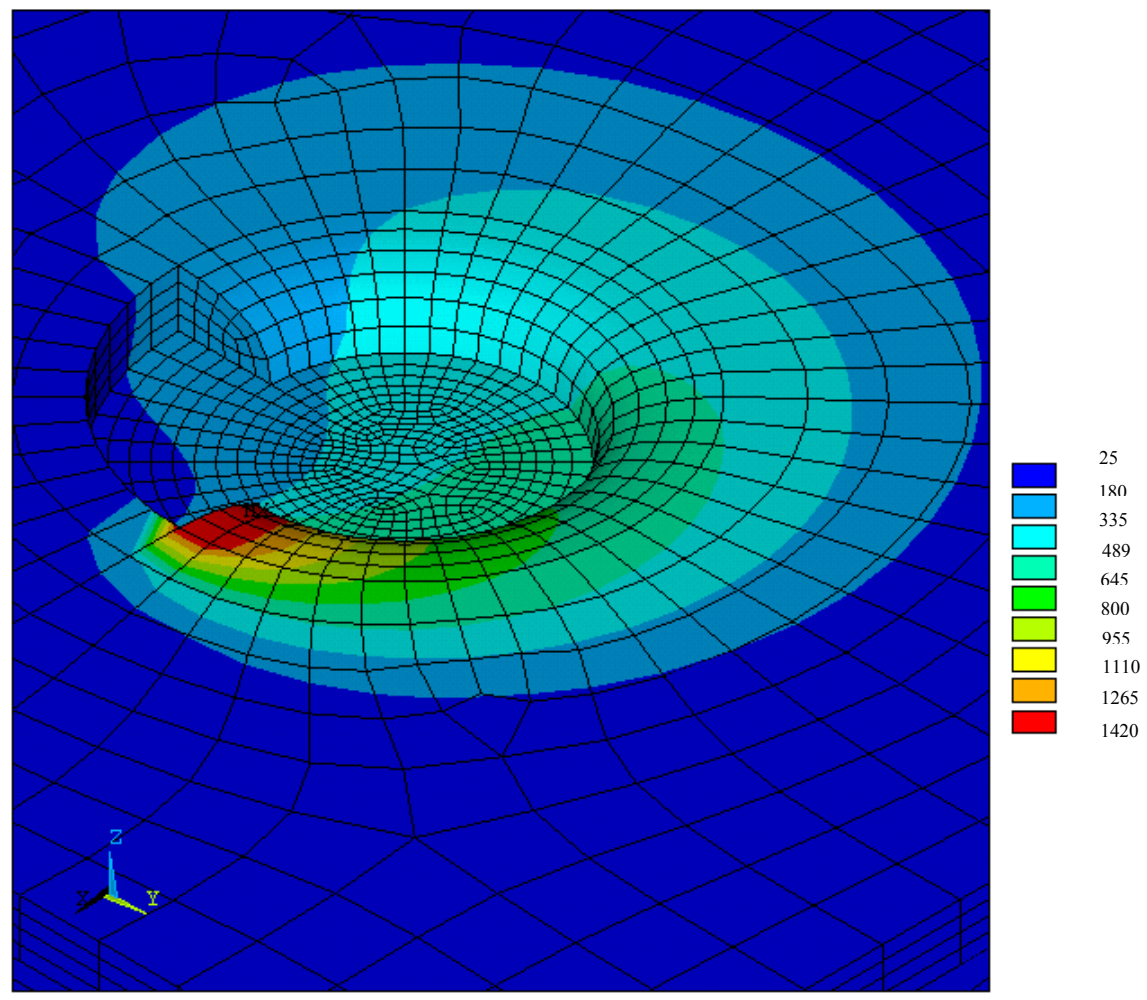

Figura 2.25 - Distribuição de Temperatura $\left({ }^{\circ} \mathrm{C}\right)$ no Instante $15.12 \mathrm{~s}$

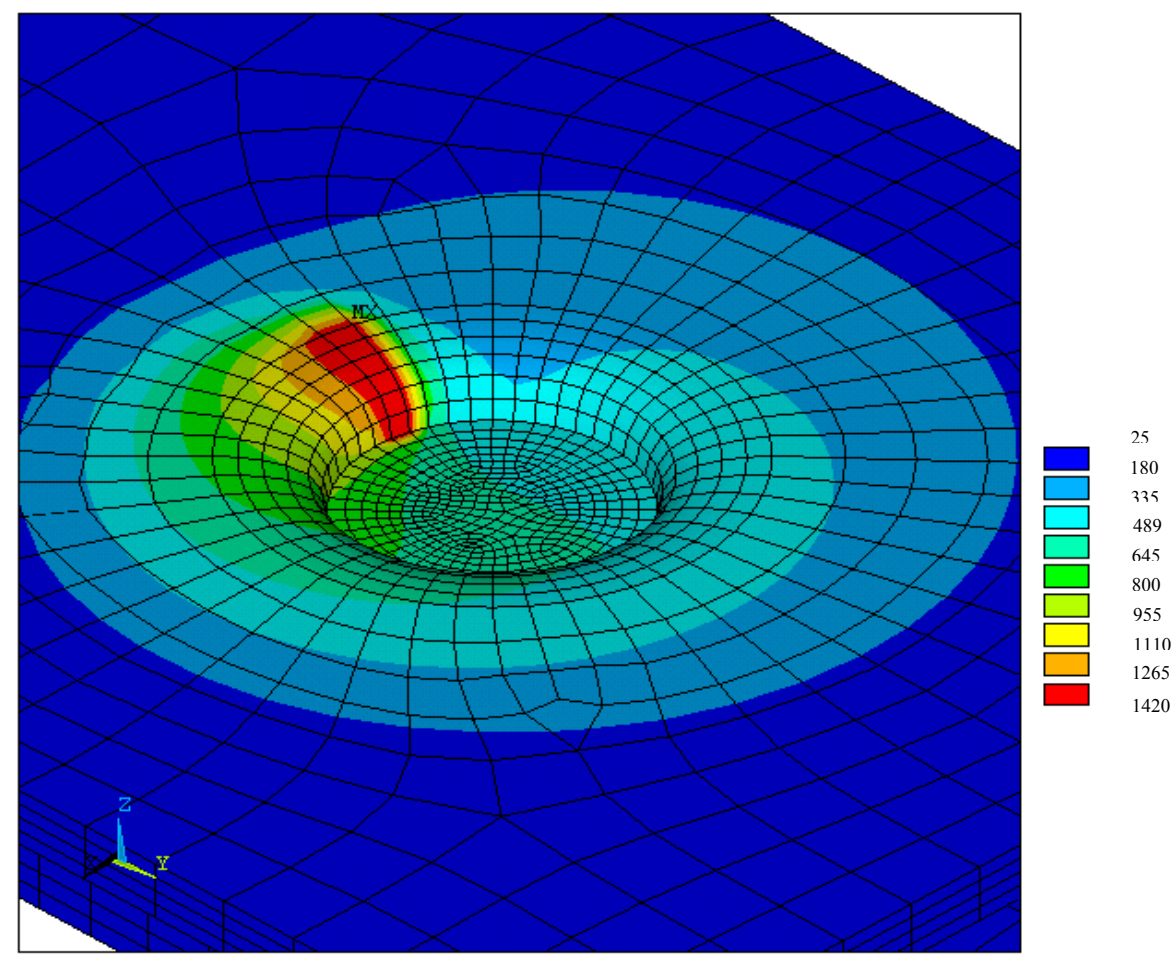

Figura 2.26-Distribuição de Temperatura $\left({ }^{\circ} \mathrm{C}\right)$ no Instante $20.79 \mathrm{~s}$ 


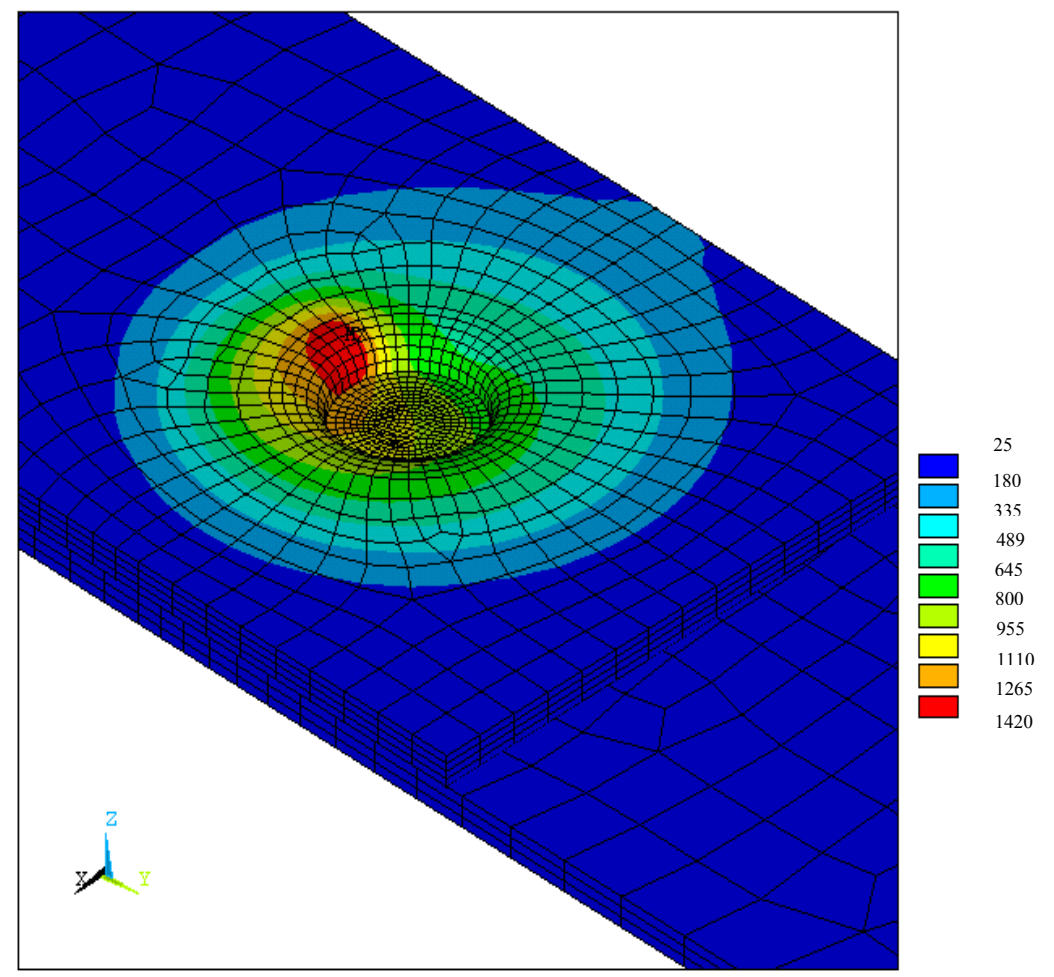

Figura 2.27 - Distribuição de Temperatura $\left({ }^{\circ} \mathrm{C}\right)$ no Instante $25 \mathrm{~s}$

Um resultado interessante, de importância para análises metalúrgicas, é a temperatura máxima que cada ponto do corpo soldado desenvolve em função da sua posição. A seguir serão apresentados gráficos com essa informação para a chapa superior (com furo circular). A referência para a posição dos pontos da chapa superior será a distância a partir da borda do furo.

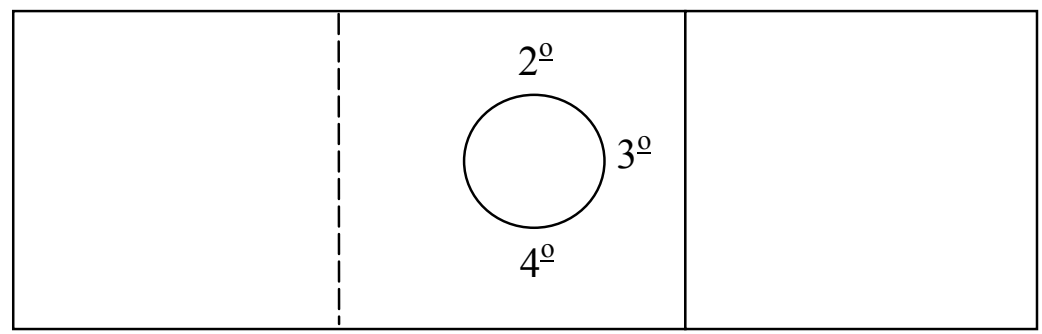

Figura 2.28 - Esquema para Identificação dos Pontos da Chapa Superior 


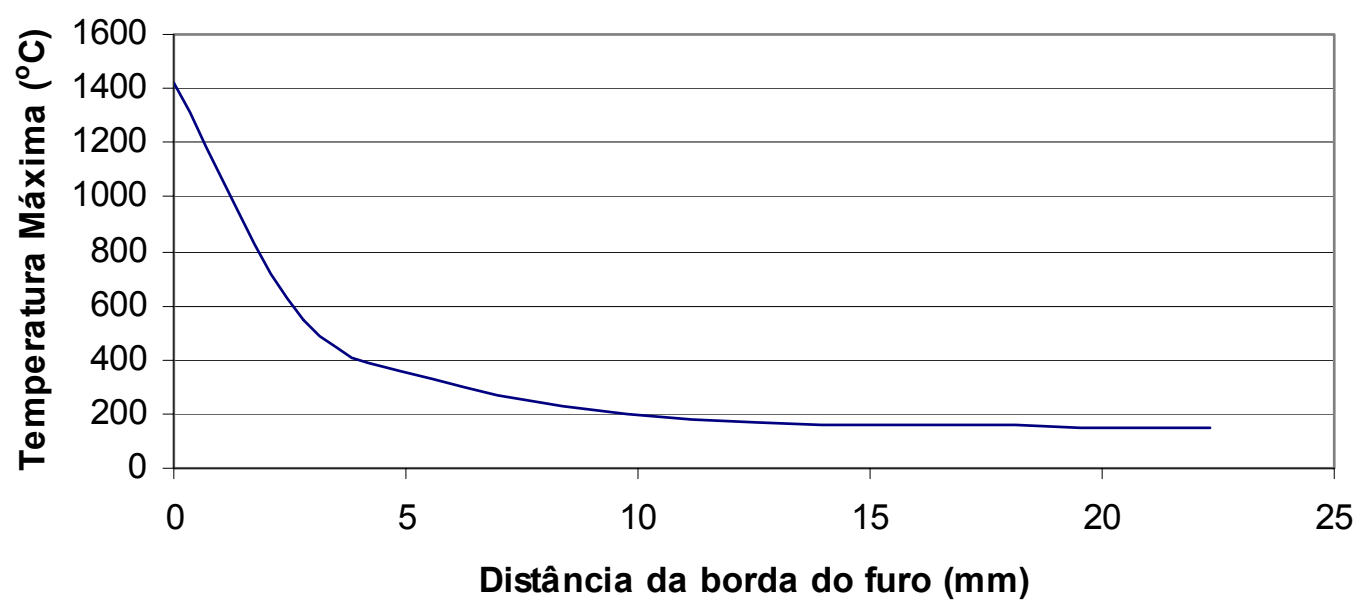

Figura 2.29 - Temperaturas Máximas no Segundo Quadrante

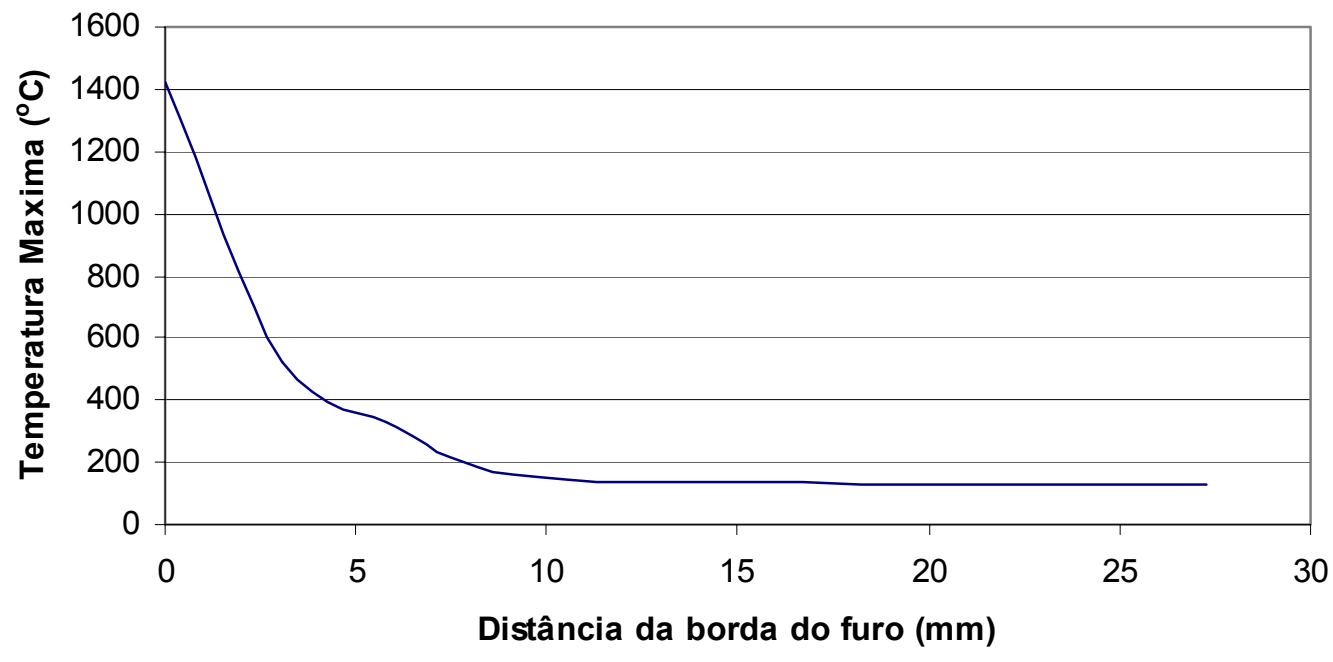

Figura 2.30 - Temperaturas Máximas no Terceiro Quadrante

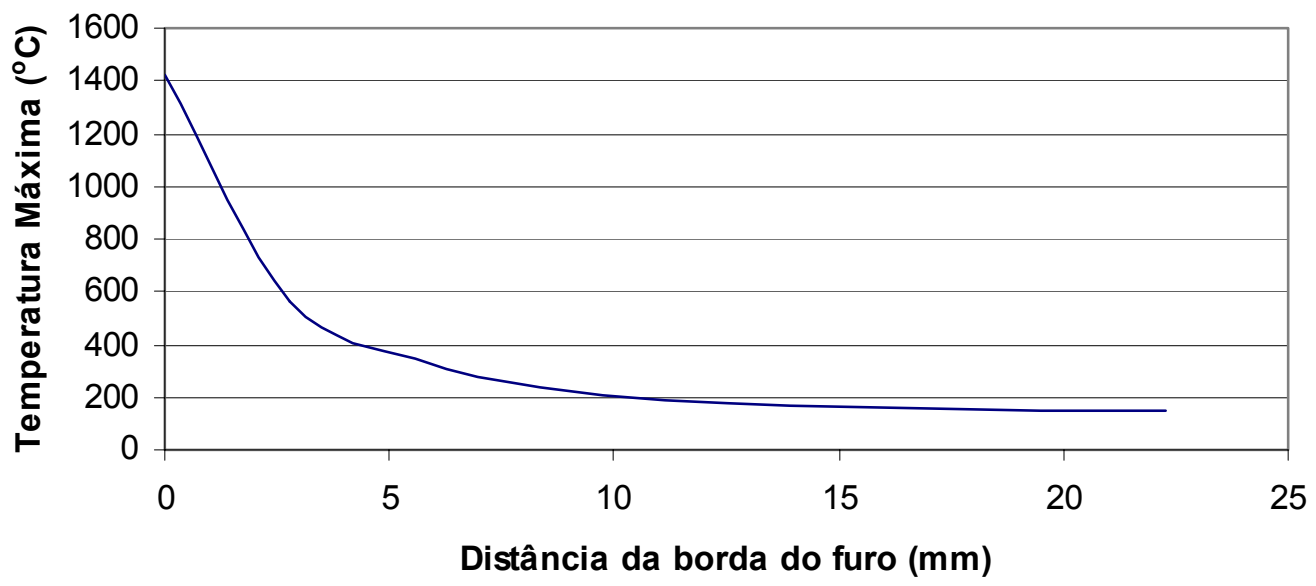

Figura 2.31 - Temperaturas Máximas no Quarto Quadrante 
Pode-se perceber que o formato das curvas dos três quadrantes é bem semelhante, portanto conclui-se que para a chapa superior a distribuição das temperaturas máximas, depende apenas do raio e não da posição angular.

Nos gráficos que seguem serão apresentados os históricos de temperatura dos quadrantes 2 e 4 . Os pontos estão identificados segundo a figura 2.32 .

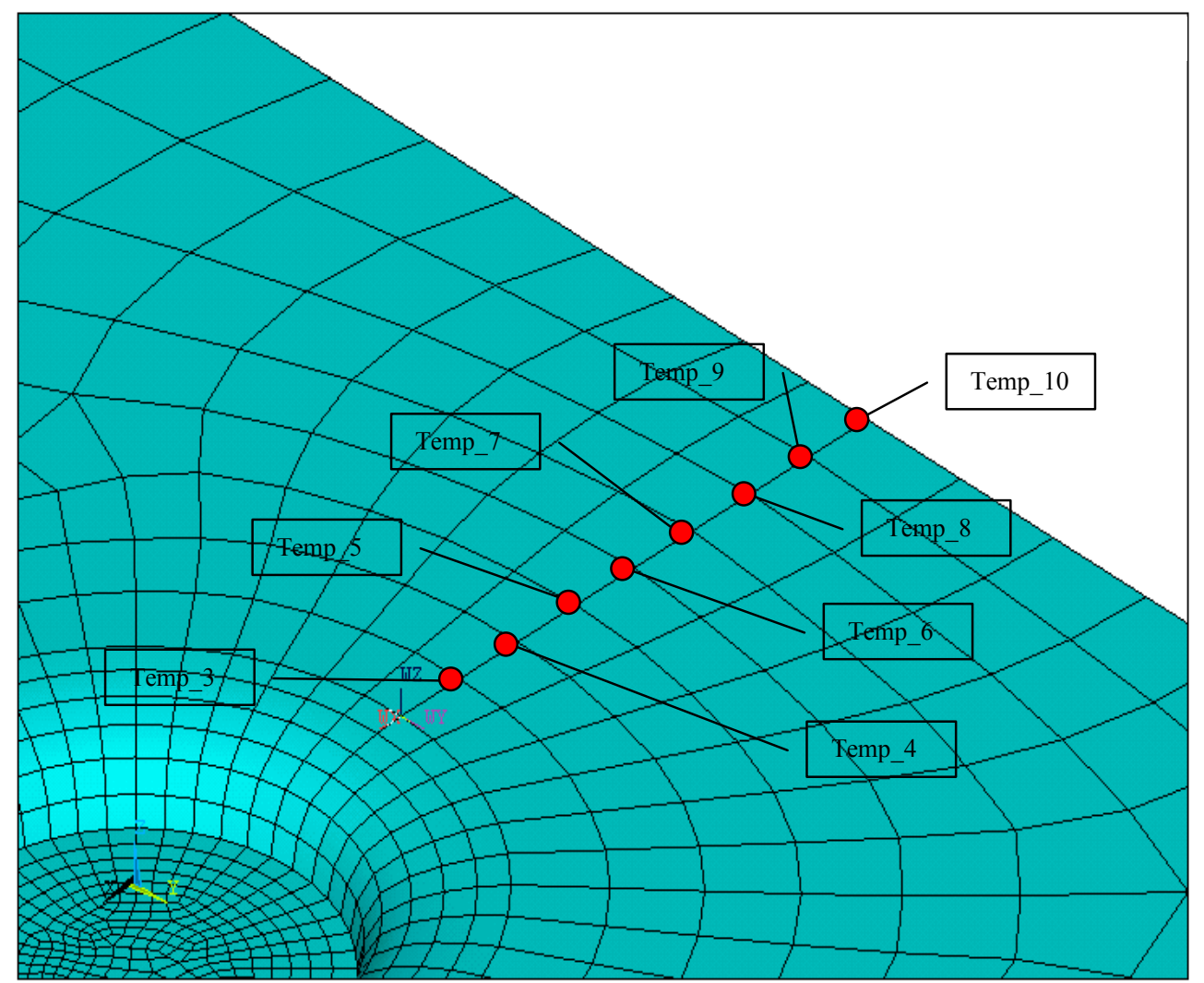

Figura 2.32 - Identificação para o Histórico de Temperaturas 


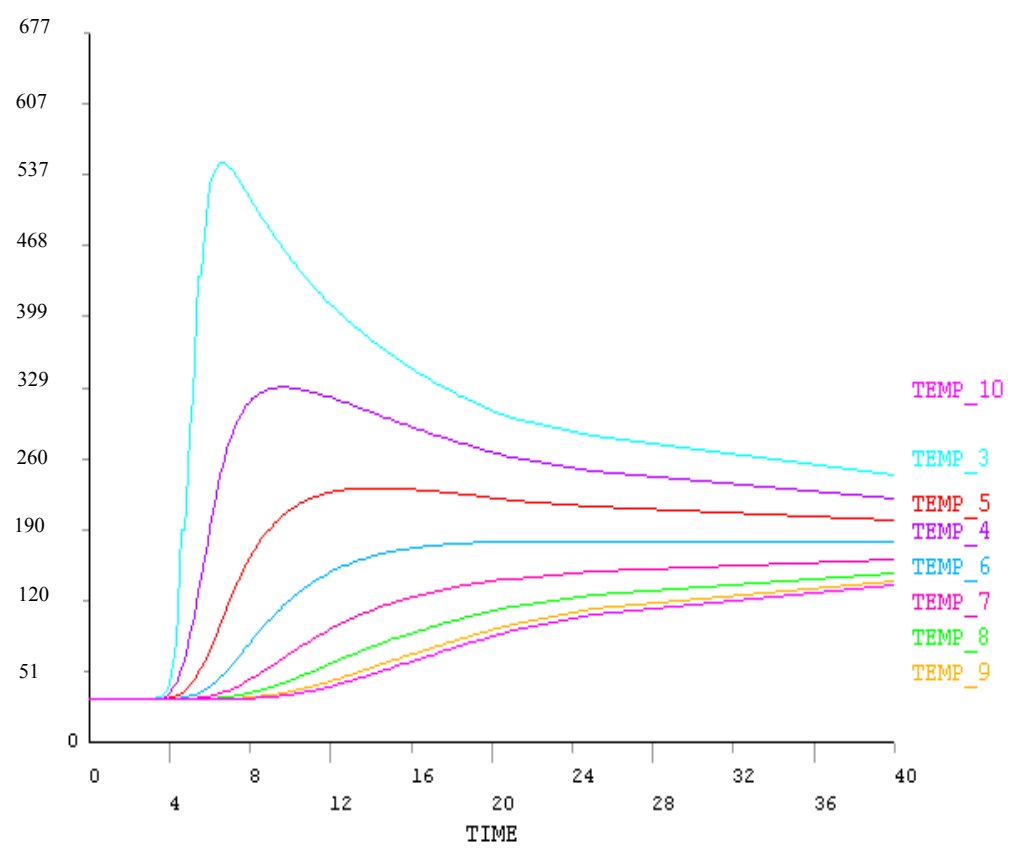

Figura 2.33 - Histórico de Temperaturas $\left({ }^{\circ} \mathrm{C}\right)$ no Segundo Quadrante

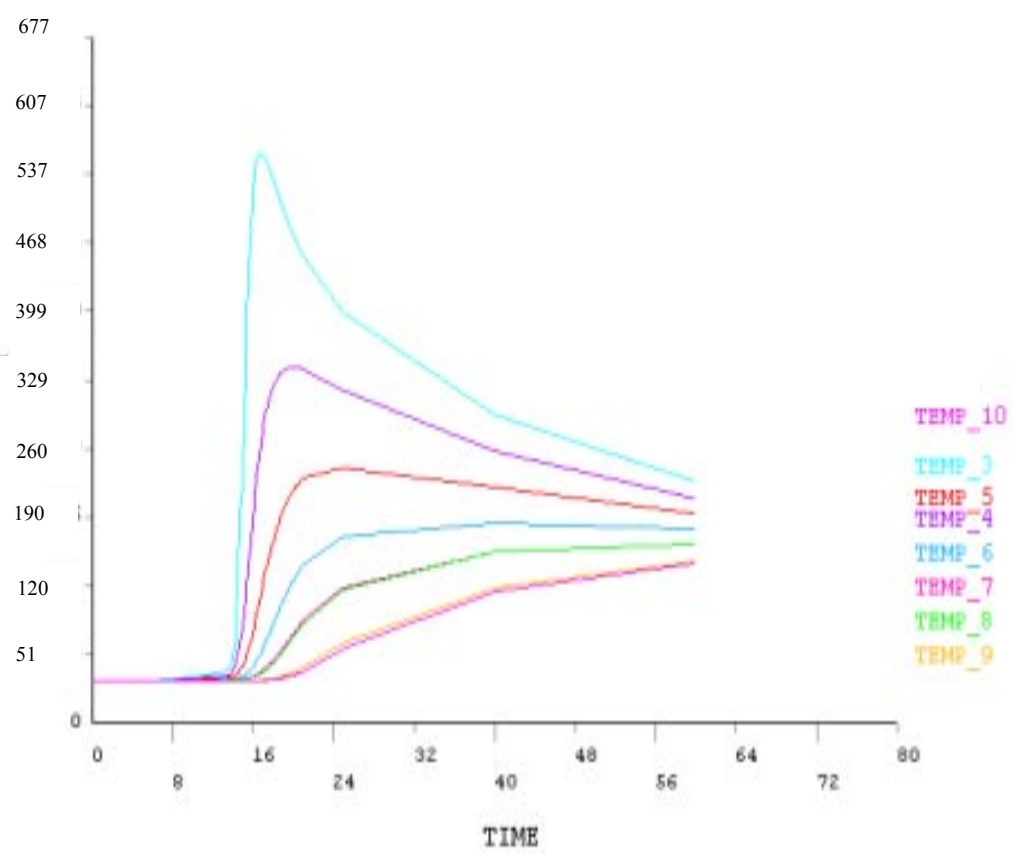

Figura 2.34 - Histórico de Temperaturas $\left({ }^{\circ} \mathrm{C}\right)$ no Quarto Quadrante

Com o campo de temperaturas determinado através do modelo de elementos finitos é possível realizar um ensaio com termopares para comparação e verificação das temperaturas calculadas. 


\subsection{Ensaio das Temperaturas}

O ensaio realizado para validação do modelo numérico consistiu-se de um corpo de prova de AISI 301L para o material base e AISI 308L para o metal de adição e o processo MIG como processo de soldagem. Foram utilizados os seguintes parâmetros para durante a execução da solda:

- Intensidade de corrente contínua: $100 \mathrm{~A}$

- Tensão: $17 \mathrm{~V}$

- Velocidade de soldagem: $4 \mathrm{~mm} / \mathrm{s}$

A instrumentação utilizada para o ensaio se compõe basicamente de dois termopares do tipo $\mathrm{K}$ em virtude da faixa de temperaturas esperadas durante a soldagem do corpo de prova. Os termopares foram posicionados em dois pontos na chapa superior. Além dos dois termopares foi utilizada uma chave de contato cujo sinal foi utilizado para a detecção do início da soldagem bem como a velocidade de deposição.

$\mathrm{Na}$ figura que segue estão representadas as posições de instalação dos termopares.

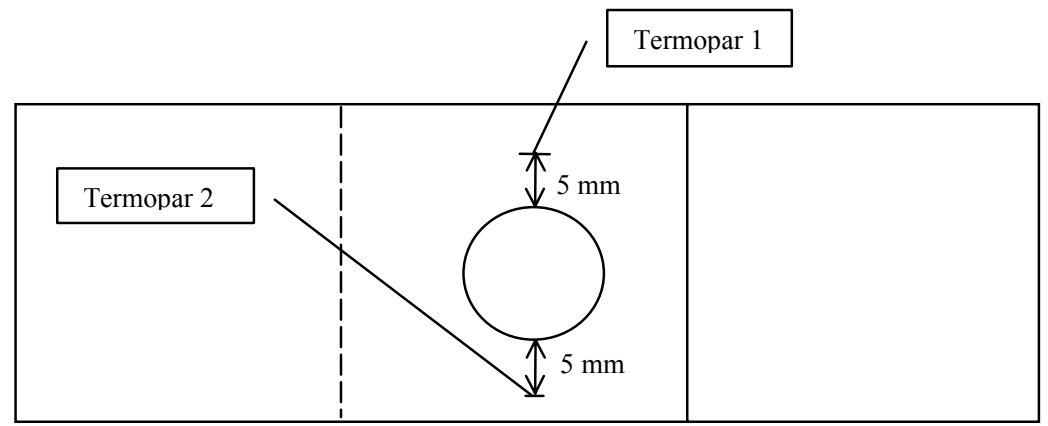

Figura 2.35 - Posição dos Termopares para o Ensaio das Temperaturas

Os dois termopares foram posicionados a $5 \mathrm{~mm}$ da borda de cada quadrante correspondente.

A taxa de amostragem utilizada para a aquisição dos dados foi de $30 \mathrm{~Hz}$. Esta taxa de amostragem é capaz de registrar os eventos sem comprometimento da medição, como por exemplo, a perda de valor máximo.

Com o corpo de prova instrumentado e preparado foi feito o ajuste dos parâmetros de soldagem e, iniciou-se a aquisição contínua dos dados. Após o início da aquisição dos dados o soldador abriu o arco e nesse instante um observador abriu a 
chave de contato registrando assim o início da soldagem. A chave de contato cada vez que é acionada fecha e abre um circuito elétrico, cujo sinal está sendo registrado assim a cada acionamento da chave é registrado um pulso no sinal do circuito elétrico.

Para cada passagem do arco elétrico nos quatro quadrantes o observador acionou a chave, registrando assim a velocidade de deposição de cada trecho e obtendo um controle preciso da sequência de eventos.

Nas figuras 2.36 e 2.37 apresentam-se os sinais dos termopares e da chave.

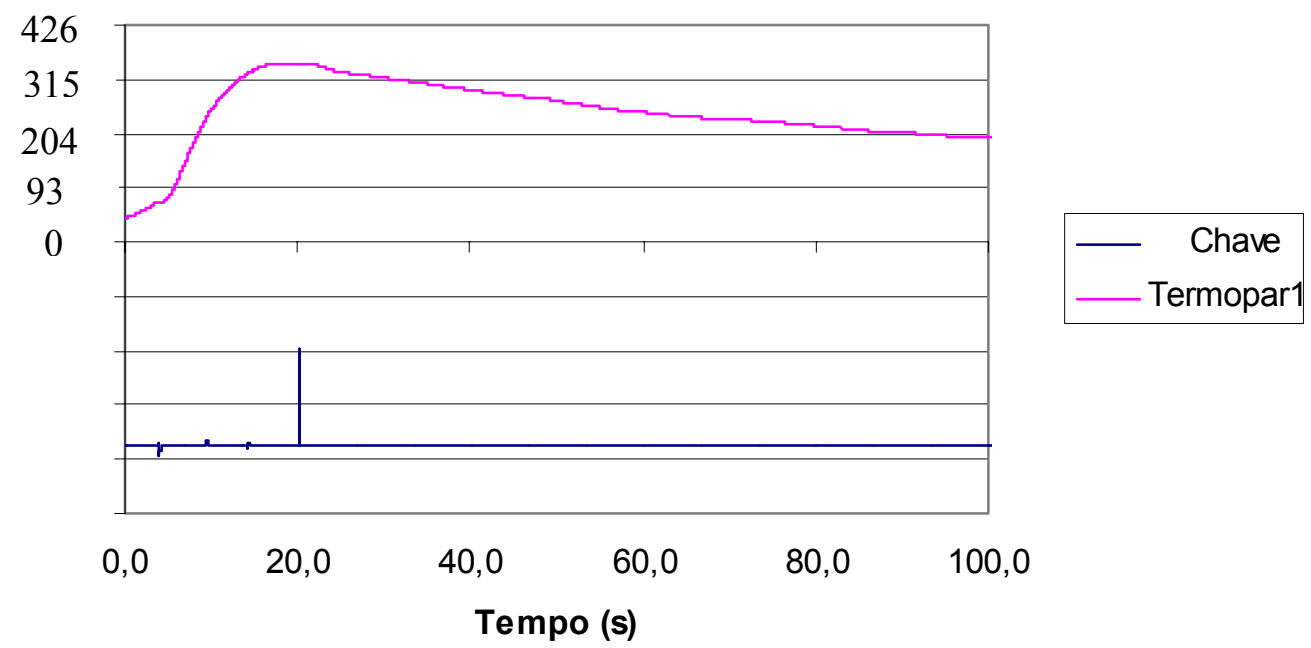

Figura 2.36 - Evolução dos Sinais do Termopar $1\left(^{\circ} \mathrm{C}\right)$ e da Chave Durante Ensaio

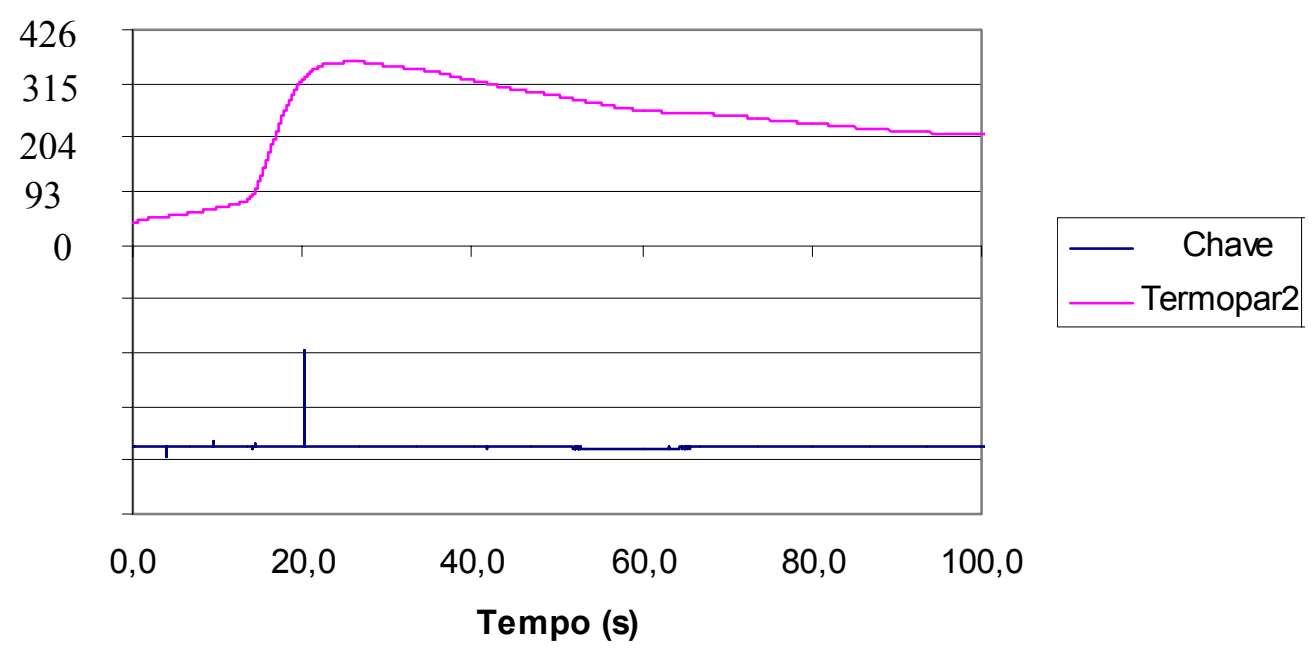

Figura 2.37 - Evolução dos Sinais do Termopar $2\left({ }^{\circ} \mathrm{C}\right)$ e da Chave Durante Ensaio

Observando-se o sinal da chave é possível verificar que a velocidade de deposição pode ser considerada uniforme, uma vez que os intervalos entre os picos se apresentaram uniformes. 


\subsection{Correlação Modelo Numérico x Ensaio}

As comparações e análises aqui apresentadas serão efetuadas com base nos dois pontos ensaiados. Ensaios com um número maior de termopares traria um maior grau de representatividade, porém representaria uma dificuldade de execução muito grande.

O posicionamento dos termopares foi escolhido de forma que as respostas obtidas permitam extrapolar os resultados para todo o corpo soldado.

Os gráficos que seguem apresentam os resultados obtidos no ensaio e os resultados obtidos da análise de elementos finitos do problema. Estes gráficos são parâmetros fundamentais para a comparação entre os resultados e a partir deles serão tiradas conclusões em relação ao modelo proposto para a solução do campo de temperaturas durante a soldagem.

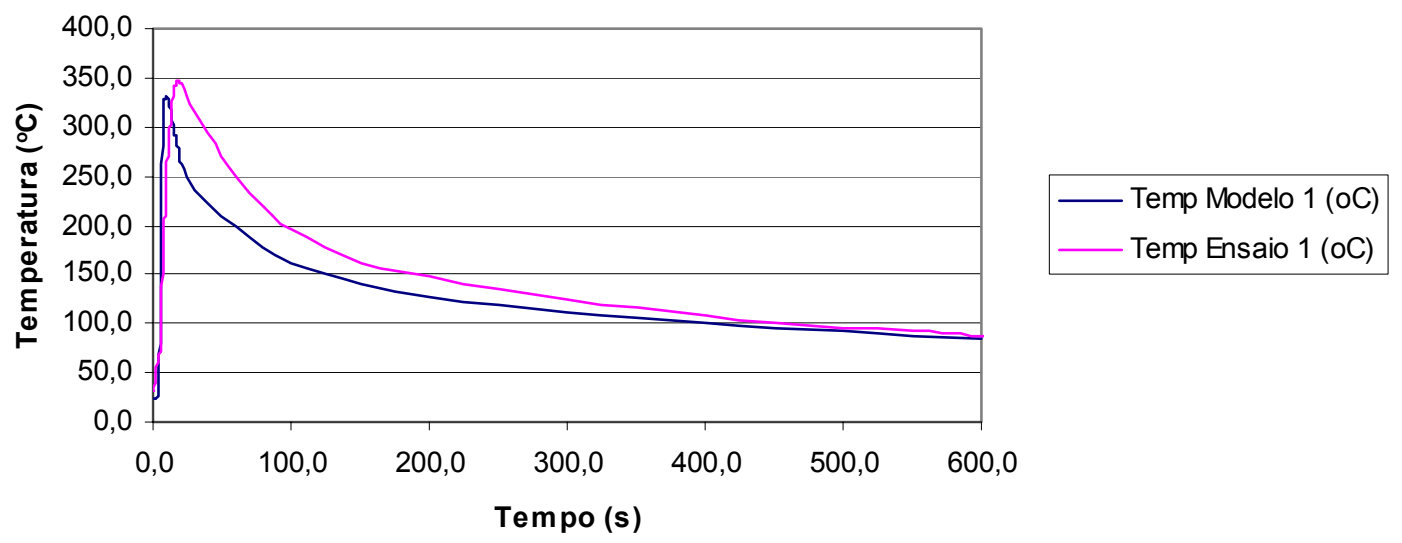

Figura 2.38 - Comparação Entre o Resultado do Modelo de Elementos Finitos e o Ensaio

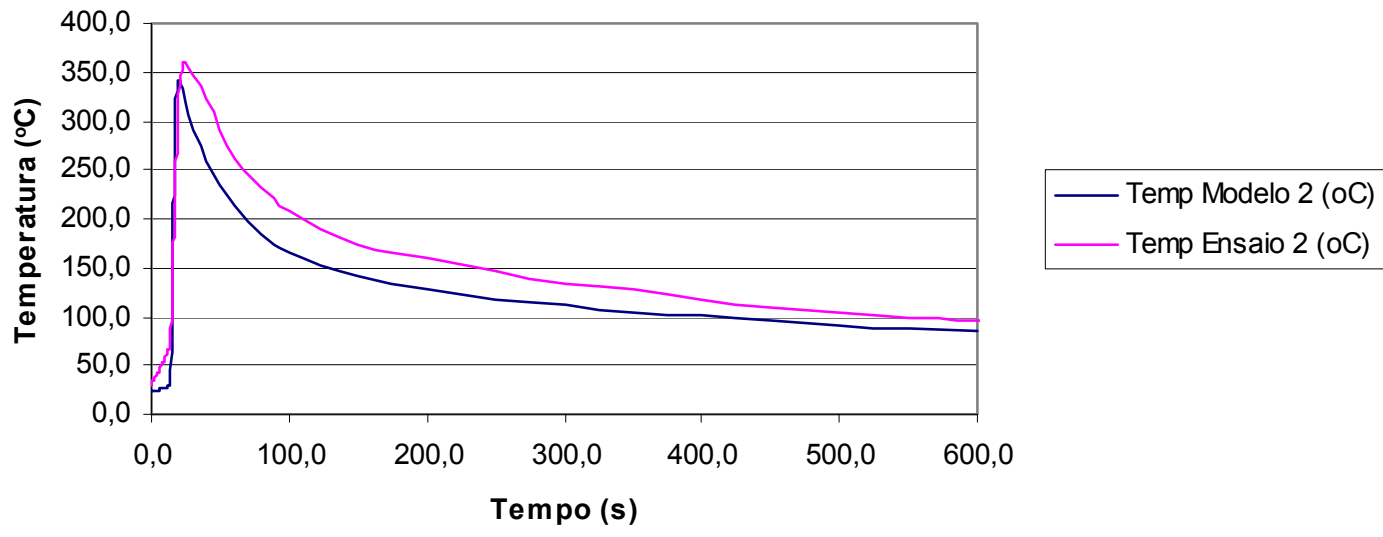

Figura 2.39 - Comparação Entre o Resultado do Modelo de Elementos Finitos e o Ensaio 
Os resultados obtidos durante o ensaio das temperaturas foram bastante satisfatórios. Os valores de pico apresentaram uma correlação excelente conforme se pode observar na tabela que segue.

Tabela 2.6 - Comparação Entre os Valores de Pico do Ensaio e do Modelo

\begin{tabular}{|c|c|c|}
\hline- & Temperatura $1\left({ }^{\circ} \mathrm{C}\right)$ & Temperatura $2\left({ }^{\circ} \mathrm{C}\right)$ \\
\hline Ensaio & 345 & 359 \\
\hline Modelo & 336 & 349 \\
\hline Diferença (\%) & 2,3 & 2,8 \\
\hline
\end{tabular}

As diferenças apresentadas acima foram calculadas com base no valor obtido no ensaio. O pico de temperatura está bem representado pelo modelo numérico apresentando desvios da ordem de $3 \%$ o que pode ser considerado bom para uma análise deste tipo onde uma abordagem simplificada do aporte de calor foi proposta.

Pode-se também verificar que ambos os gráficos de resposta possuem um formato bem similar o que revela taxas de resfriamento bem próximas entre o modelo numérico e o ensaio com termopares.

Os gráficos de resposta diferiram ligeiramente após o pico de temperatura. Este efeito de retardamento do resfriamento no sinal do ensaio pode ser explicado pelo fato de que o termopar possui massa e calor específico então a priori ele não teria uma resposta instantânea após o aquecimento visto que ele tem que vencer uma "inércia" térmica que é representada pela sua massa e seu calor específico.

O valor máximo atingido e a taxa de resfriamento são parâmetros fundamentais para uma análise térmica de um processo de soldagem, desse modo é possível concluir que o modelo de elementos finitos proposto possui uma boa correlação com os valores de ensaio, permitindo assim a sua utilização não só para análises térmicas e metalúrgicas mas também para o cálculo das tensões residuais da solda. 


\section{ANÁLISE MECÂNICA}

A análise mecânica, por elementos finitos, permitirá determinar as tensões residuais presentes após a soldagem de um ring-weld. Para tanto serão utilizadas as temperaturas determinadas na análise térmica do problema juntamente com a hipótese de que a tensão não acarreta mudança na temperatura, mas sim o inverso.

\subsection{Conceitos Fundamentais}

Durante todo o processo de soldagem um complexo campo de temperaturas se desenvolve em função da posição e do tempo. Este campo de temperaturas é certamente transitório e provoca tensões térmicas transitórias que por sua vez geram deformações. O campo de deformações gerado pelas tensões térmicas pode conter deformações inelásticas. Após se atingir o equilíbrio térmico, as deformações inelásticas são as responsáveis pelas tensões residuais no corpo soldado, e, ao contrário, se as deformações desenvolvidas durante a soldagem forem elásticas não haverá tensão residual no corpo soldado.

As possíveis deformações causadas pela solidificação e pela mudança de fase sólida não serão consideradas neste modelo.

Em geral, as tensões residuais existem sem a aplicação de esforços externos, portanto o equilíbrio sempre deve ser satisfeito como se expressa nas equações 3.1 e 3.2 .

$$
\begin{aligned}
& \int \sigma \cdot d A=0 \\
& \int d M=0
\end{aligned}
$$

Estas equações representam a condição de equilíbrio de forças e de momentos.

A seguir será apresentado o equacionamento fundamental de um problema de tensões residuais em estado plano de tensões. Com este caso é possível compreender o mecanismo de formação das tensões residuais e uma abordagem matemática para sua solução. 


\subsubsection{Tensões Residuais no Estado Plano de Tensões}

Segundo Masubuchi (1980), a existência de deformações plásticas é condição necessária para a existência das tensões residuais.

De acordo com Masubuchi (1980) as deformações mecânicas podem ser escritas como uma soma de deformações elásticas e plásticas:

$$
\begin{aligned}
& \varepsilon_{\mathrm{x}}=\varepsilon_{\mathrm{x}}^{\prime}+\varepsilon_{\mathrm{x}^{\prime}}^{\prime \prime} \\
& \varepsilon_{\mathrm{y}}=\varepsilon_{\mathrm{y}}^{\prime}+\varepsilon_{\mathrm{y}^{\prime}}^{\prime \prime} \\
& \gamma_{\mathrm{xy}}=\gamma_{\mathrm{xy}}^{\prime}+\gamma_{\mathrm{xy}}^{\prime \prime}
\end{aligned}
$$

Onde,

$\varepsilon_{\mathrm{x}}, \varepsilon_{\mathrm{y}}, \gamma_{\mathrm{xy}}$ : são componentes da deformação total,

$\varepsilon_{\mathrm{x}}^{\prime}, \varepsilon_{\mathrm{y}}^{\prime}, \gamma_{\mathrm{xy}}^{\prime}:$ são componentes da deformação elástica,

$\varepsilon_{\mathrm{x}^{\prime}}^{\prime \prime}, \varepsilon_{\mathrm{y}^{\prime}}^{\prime \prime}, \gamma_{\mathrm{xy}}^{\prime \prime}$ : são componentes da deformação não-elástica.As deformações não elásticas podem ser, deformações plásticas, deformações térmicas etc..

Utilizando a Lei de Hooke para as deformações elásticas vem:

$$
\begin{aligned}
& \varepsilon_{x}^{\prime}=\frac{1}{E}\left(\sigma_{x}-v \sigma_{y}\right) \\
& \varepsilon_{y}^{\prime}=\frac{1}{E}\left(\sigma_{y}-v \sigma_{x}\right) \\
& \gamma_{x y}^{\prime}=\frac{1}{G} \tau_{x y}
\end{aligned}
$$

Impondo as condições de equilíbrio em um elemento infinitesimal do domínio plano:

$$
\begin{aligned}
& \frac{\partial \sigma_{x}}{\partial x}+\frac{\partial \tau_{x y}}{\partial y}=0 \\
& \frac{\partial \tau_{x y}}{\partial x}+\frac{\partial \sigma_{y}}{\partial y}=0
\end{aligned}
$$

As deformações mecânicas devem atender também a equação de compatibilidade (eq.(3.11)):

$$
\left(\frac{\partial^{2} \varepsilon_{x}^{\prime}}{\partial y^{2}}+\frac{\partial^{2} \varepsilon_{y}^{\prime}}{\partial x^{2}}-\frac{\partial^{2} \gamma_{x y}^{\prime}}{\partial x \cdot \partial y}\right)+\left(\frac{\partial^{2} \varepsilon_{x}^{\prime \prime}}{\partial y^{2}}+\frac{\partial \varepsilon^{2 \prime} y}{\partial x^{2}}-\frac{\partial^{2} \gamma_{x y}^{\prime \prime}}{\partial x \cdot \partial y}\right)=0
$$


As equações acima indicam que as tensões residuais existem quando o valor de $\mathrm{R}$, que é determinado através das deformações não-elásticas, é não nulo.

$$
\mathrm{R}=-\left(\frac{\partial^{2} \varepsilon_{\mathrm{x}}^{\prime \prime}}{\partial \mathrm{y}^{2}}+\frac{\partial^{2} \varepsilon_{\mathrm{y}}^{\prime \prime}}{\partial \mathrm{x}^{2}}-\frac{\partial^{2} \gamma_{\mathrm{xy}}^{\prime \prime}}{\partial \mathrm{x} \cdot \partial \mathrm{y}}\right) \neq 0
$$

Moriguchi (1948) apud Masubuchi (1980) deu o nome da parcela esquerda da eq. (3.12) de incompatibilidade. Sendo que a existência de tensões residuais está totalmente atrelada a existência de incompatibilidade.

\subsection{Propriedades Mecânicas}

As propriedades mecânicas têm um papel fundamental em uma análise de tensões residuais. O problema da determinação das tensões residuais envolve um campo de temperaturas não uniforme e com valores muito elevados chegando até a temperatura de fusão.

Infelizmente, as propriedades mecânicas variam com a temperatura e essa variação é importante para a determinação do campo de tensões residuais.

A obtenção das propriedades mecânicas em elevadas temperaturas é difícil de ser realizada e este fato torna a obtenção dos dados para a análise de tensões residuais uma tarefa complicada.

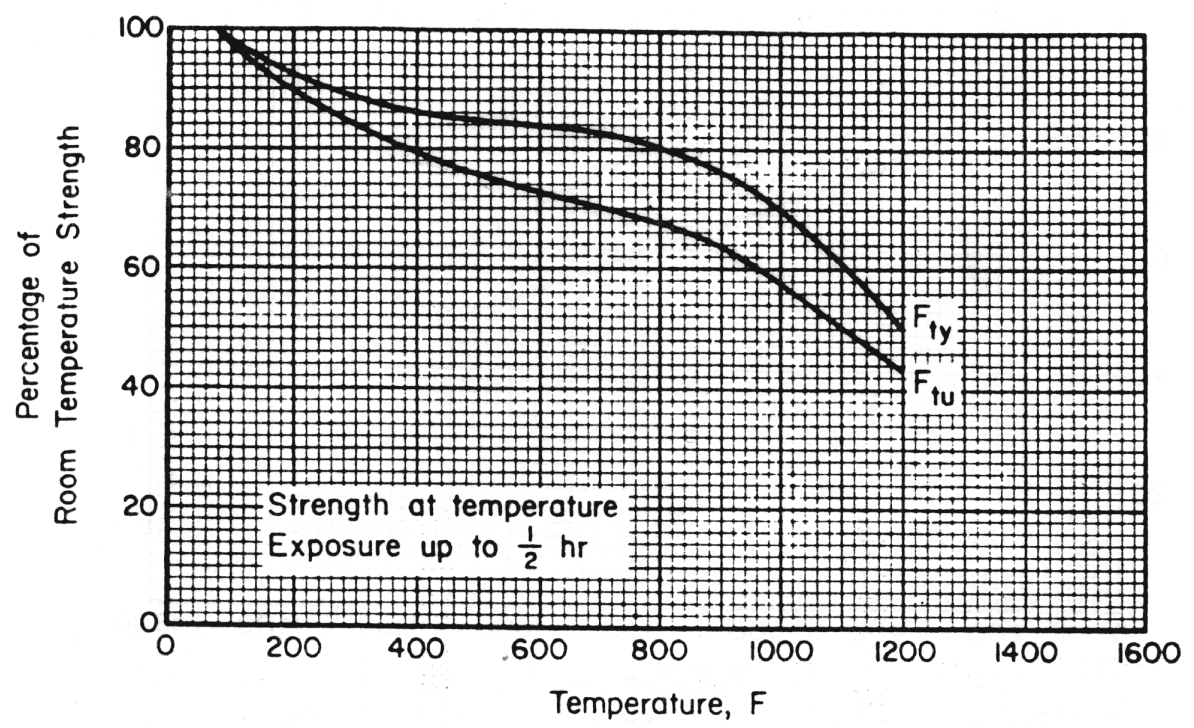

Figura 3.1 - Tensão de Escoamento e Limite de Resistência em Função da Temperatura para o AISI 301L, Department of Defense - E.U.A. MIL-HDBK-5E vol 1 (1987) 
Os aços inoxidáveis AISI 301L e AISI 308L têm um alto grau de encruamento e possuem comportamentos distintos em compressão e tração. Neste estudo será considerado o comportamento em tração tanto para estados de tensão de tração quanto para estados de tensão de compressão.

A abordagem para a caracterização do material adotada neste estudo pretende utilizar uma caracterização bilinear da curva tensão x deformação tanto do AISI 301L como do AISI 308L. Esta abordagem também foi utilizada por Papazoglou (1981) para a caracterização do HY-130 em um estudo de tensões residuais causadas por soldagem.

A curva bilinear do material é composta por dois segmentos de reta. O primeiro segmento de reta representa a porção elástica da curva e sua inclinação é caracterizada pelo Módulo de Young do material.O segundo segmento de reta representa a porção elasto-plástica e é representada pelo Módulo Tangente do material. O ponto de encontro dos dois segmentos define o valor da tensão de escoamento do material.

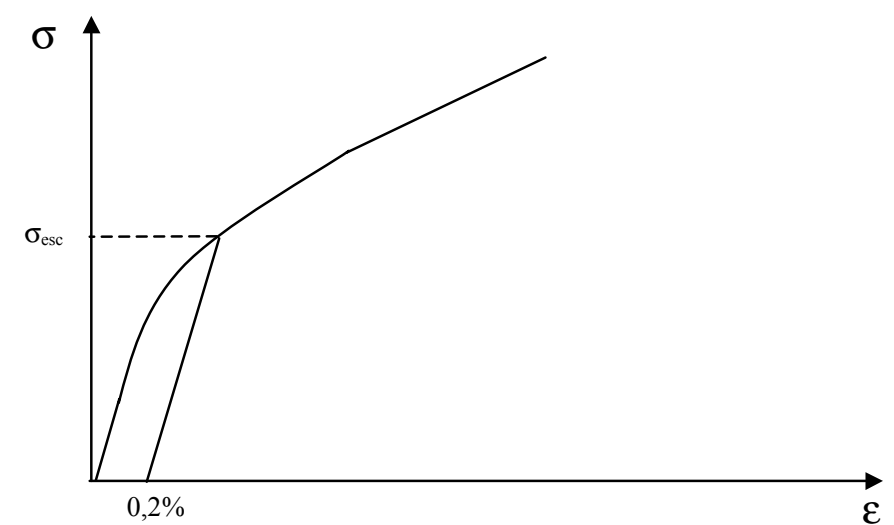

Figura 3.2 - Curva Tensão x Deformação Característica do AISI 301L/AISI 308L

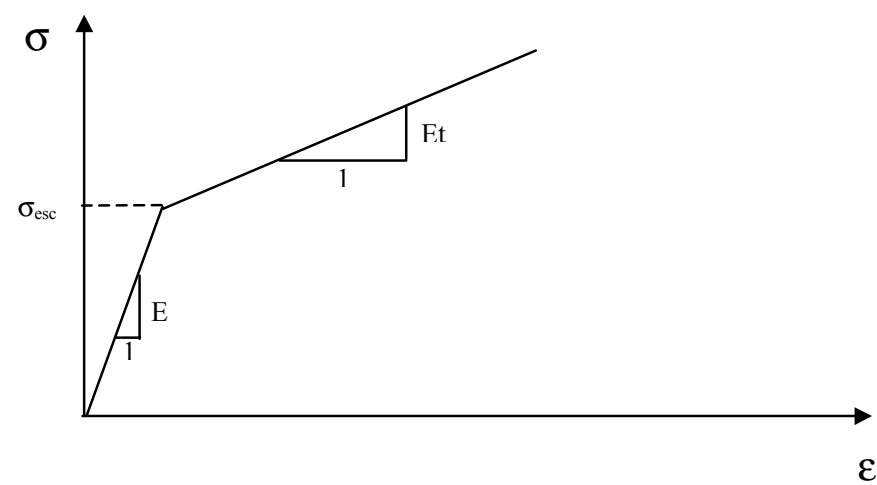

Figura 3.3 - Caracterização Bilinear do Material

$\varepsilon$ 
O gráfico mostrado na figura 3.1 apresenta a redução percentual do limite de escoamento e limite de ruptura para o AISI 301L em relação às respectivas propriedades mecânicas em temperatura ambiente. Assim é possível estabelecer a variação do limite de escoamento do AISI 301L em função da temperatura.

Não foi possível obter a curva acima para o AISI 308L. Considerou-se, no entanto, que o limite de escoamento do AISI 308L tem o mesmo comportamento que o AISI 301L no que se refere à variação da tensão de escoamento em função da temperatura, portanto as variações percentuais do limite de escoamento com a temperatura foram consideradas as mesmas.

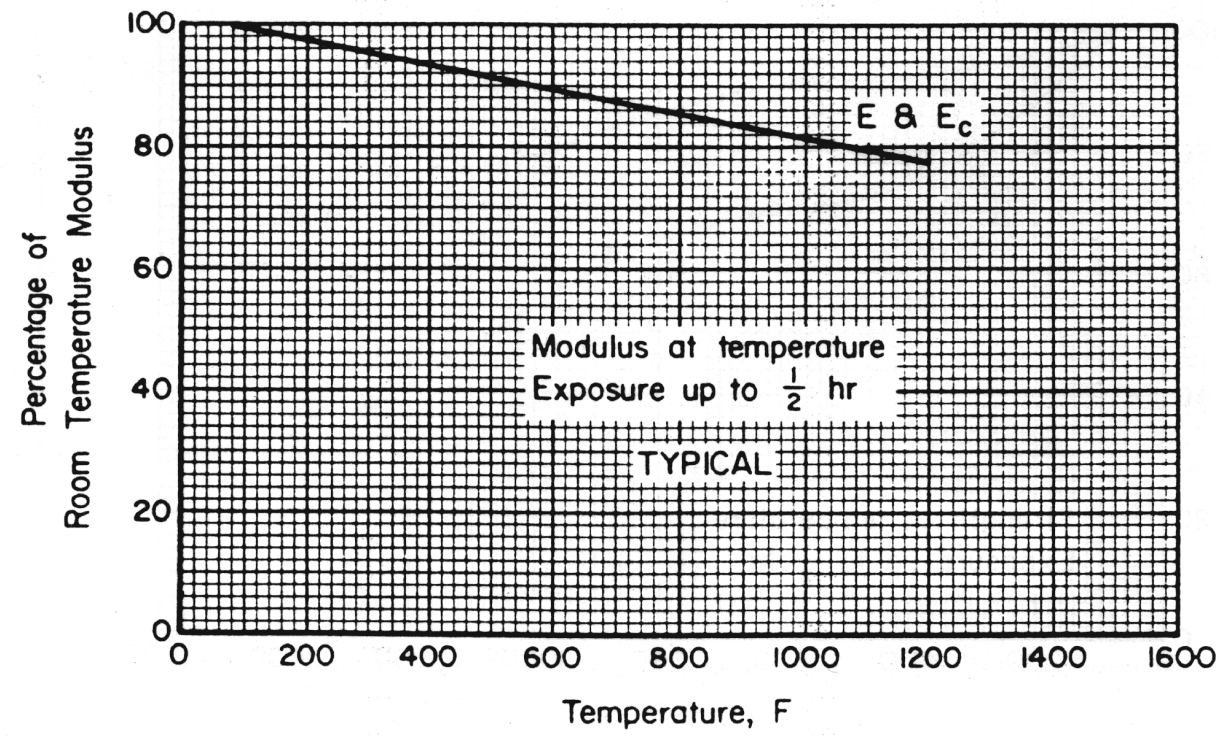

Figura 3.4 - Módulo de Young em Função da Temperatura para o AISI 301L, Department of Defense - E.U.A. MIL-HDBK-5E vol 1 (1987)

O gráfico mostrado na figura 3.4 apresenta a variação do Módulo de Young em função da temperatura para o AISI 301L. Estes valores serão utilizados para o AISI 308L visto que não foi possível a obtenção destes dados.

A variação do Módulo tangente com relação à temperatura foi assumida proporcional à variação do Módulo de Young. Papazoglou (1980) propôs a seguinte equação:

$$
\operatorname{Et}(\mathrm{T})=\frac{\mathrm{Et}(\mathrm{T} 0)}{\mathrm{E}(\mathrm{T} 0)} \cdot \mathrm{E}(\mathrm{T})
$$

Onde,

Et(T): Módulo tangente para uma temperatura T, 
Et(T0): Módulo tangente para temperatura ambiente,

E(T0): Módulo de Young para temperatura ambiente,

$\mathrm{E}(\mathrm{T})$ : Módulo de Young para uma temperatura $\mathrm{T}$.

Esta relação foi utilizada para determinação dos valores do Módulo tangente para cada temperatura.

Os módulos tangentes do AISI 301L e do AISI 308L a temperatura ambiente foram determinados com a ajuda da relação de Ramberg-Osgood.

$$
\sigma=\mathrm{k} \cdot\left(\varepsilon-\frac{\sigma}{\mathrm{E}}\right)^{\mathrm{n}}
$$

Onde,

$\mathrm{k}$ : Coeficiente de resistência

$\mathrm{n}$ : Expoente de encruamento

Considerando a tensão de escoamento $(0,2 \%)$ e a tensão de ruptura e o alongamento de ruptura a temperatura ambiente é possível determinar os valores de $\mathrm{k}$ e $\mathrm{n}$ e assim estimar o valor do módulo tangente a temperatura ambiente.

Segundo Department of Defense - E.U.A. MIL-HDBK-5E vol 1 (1987) o valor da tensão de escoamento, tensão de ruptura e alongamento para o $301 \mathrm{~L} 1 / 2$ hard a temperatura ambiente são respectivamente: $758 \mathrm{MPa}, 1041 \mathrm{MPa}$ e 0,18 . Os valores da tensão de escoamento, tensão de ruptura e alongamento a temperatura ambiente para o 308L estão apresentados na figura 3.7 e são respectivamente: $390 \mathrm{MPa}, 600 \mathrm{MPa}$ e 0,34 .

Segue abaixo as curvas de tensão $\mathrm{x}$ deformação a temperatura ambiente determinadas através da relação de Ramberg-Osgood para o 301L 1/2 hard e para o 308L. 


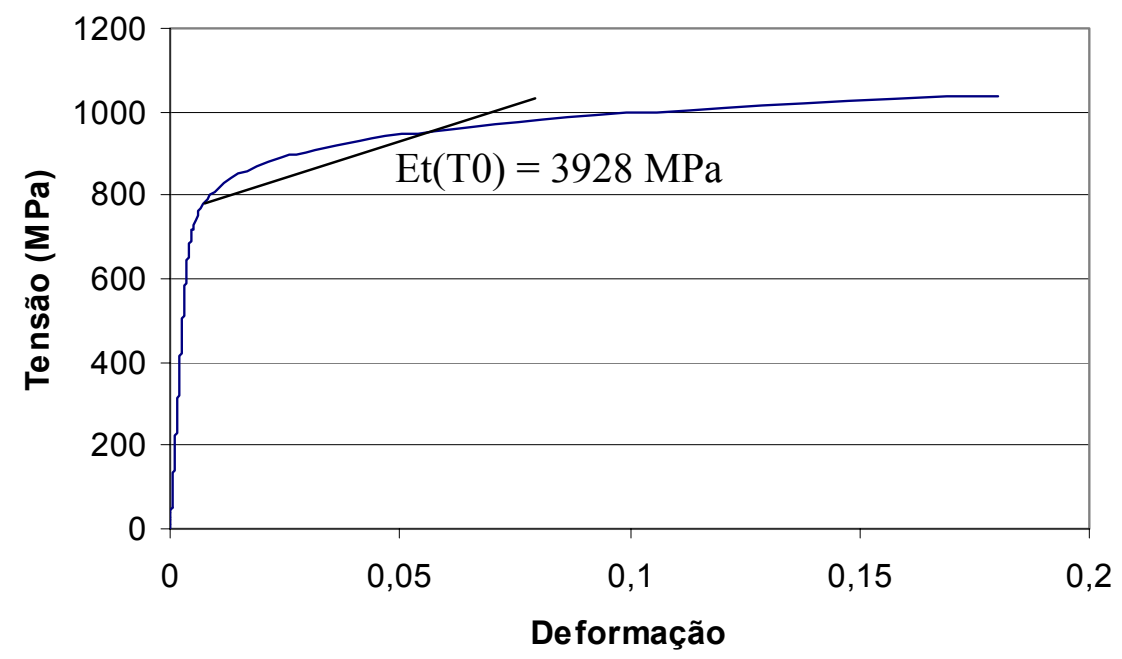

Figura 3.5 - Curva Tensão x Deformação em Temperatura Ambiente do AISI 301L 1⁄2 Hard

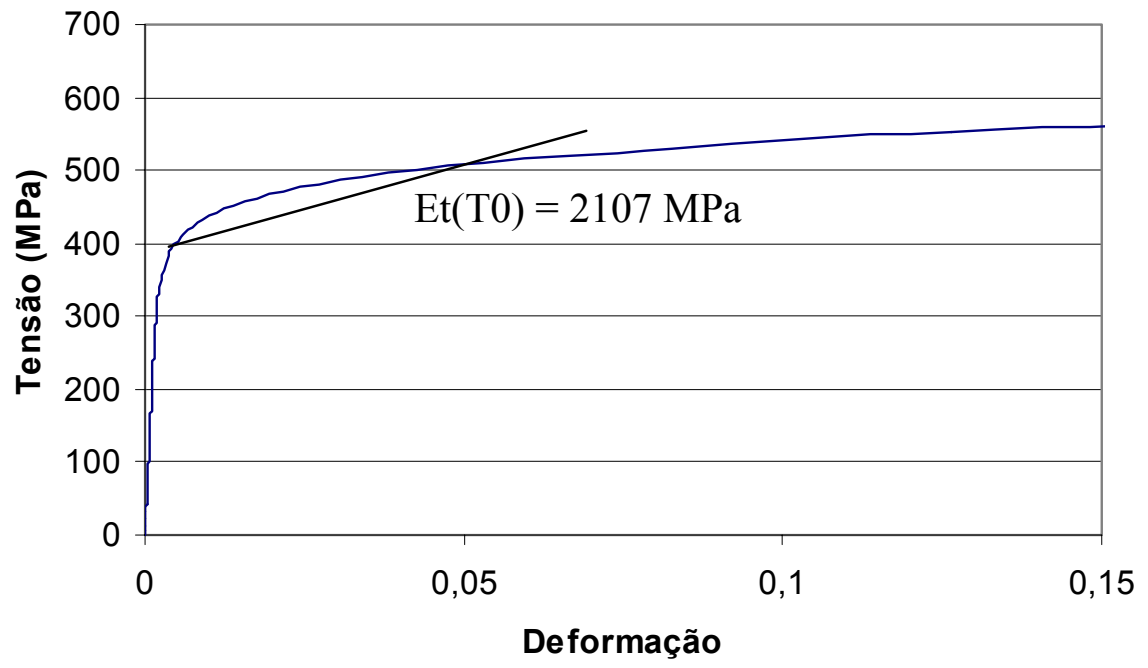

Figura 3.6 - Curva Tensão x Deformação em Temperatura Ambiente do AISI 308 L

Para a variação do Módulo de Poisson foi utilizada a hipótese proposta por Friedman apud Papazoglou (1981), que estabelece a existência da constante B que é uma relação entre o Módulo de Young e o Módulo de Poisson para uma dada temperatura.

$$
\mathrm{B}=\frac{\mathrm{E}}{3(1-2 \cdot v)}
$$

A seguir estão apresentadas as propriedades do AISI 301L e do AISI 308L para a faixa de temperatura do problema. Estas propriedades mecânicas serão utilizadas como dados de entrada do modelo de elementos finitos da análise mecânica. 
Propriedades mecânicas

\begin{tabular}{|c|c|c|c|c|}
\hline Temperatura & ${ }^{\circ} \mathrm{C}$ & 20 & 400 & -196 \\
\hline $\begin{array}{l}\text { Resistência ensaio, } R_{00}{ }^{1} \\
\text { Resistência à tração, } R_{m} \\
\text { Alongamento, } A^{\prime \prime} \\
\text { Redução de área } \\
\text { Energia de impacto, Charpy V } \\
\text { Dureza, Vickers }\end{array}$ & $\begin{array}{l}\text { Mpa } \\
\text { Mpa } \\
\% \\
\% \\
\mathrm{~J}\end{array}$ & $\begin{array}{r}390 \\
600 \\
34 \\
56 \\
135 \\
160\end{array}$ & $\begin{array}{r}290 \\
440 \\
25 \\
- \\
-\end{array}$ & $\begin{array}{l}\bar{Z} \\
\overline{60}\end{array}$ \\
\hline
\end{tabular}

Figura 3.7 - Propriedades Mecânicas do AISI 308L, Arames e Varetas de Aço Inoxidável para Soldagem Sandvik (2000).

Tabela 3.1 -Propriedades Mecânicas do AISI 301L (1/2 hard)

\begin{tabular}{|c|c|c|c|c|c|c|}
\hline \multicolumn{7}{|c|}{ Propriedades Mecânicas do AISI 301L (1/2 hard $)$} \\
\hline Temp. $\left({ }^{\circ} \mathrm{C}\right)$ & 21 & 315 & 538 & 815 & 1260 & 1426 \\
\hline $\mathrm{E}_{\mathrm{x}}(\mathrm{MPa})$ & 179386 & 138069 & 106469 & 66969 & 3769 & 10 \\
\hline$\alpha\left(1 /{ }^{\circ} \mathrm{C}\right)$ & $14,81 \cdot 10^{-6}$ & $17,19 \cdot 10^{-6}$ & $1,85 \cdot 10^{-5}$ & $1,97 \cdot 10^{-5}$ & $2,01 \cdot 10^{-5}$ & $1,99 \cdot 10^{-5}$ \\
\hline$v$ & 0,3000 & 0,2691 & 0,3219 & 0,3880 & 0,4600 & 0,4700 \\
\hline$\sigma_{\mathrm{esc}}(\mathrm{MPa})$ & 758 & 600 & 510 & 175 & 100 & 80 \\
\hline $\mathrm{E}_{\mathrm{t}}(\mathrm{MPa})$ & 3928 & 3067 & 2365 & 1487 & 83 & 1 \\
\hline
\end{tabular}

Tabela 3.2 - Propriedades Mecânicas do AISI $308 L$

\begin{tabular}{|c|c|c|c|c|c|c|}
\hline \multicolumn{7}{|c|}{ Propriedades Mecânicas do AISI 308L } \\
\hline Temp. $\left({ }^{\circ} \mathrm{C}\right)$ & 21 & 315 & 538 & 815 & 1260 & 1426 \\
\hline $\mathrm{E}_{\mathrm{x}}(\mathrm{MPa})$ & 179386 & 138069 & 106469 & 66969 & 3769 & 10 \\
\hline$\alpha\left(1 /{ }^{\circ} \mathrm{C}\right)$ & $14,81 \cdot 10^{-6}$ & $17,19 \cdot 10^{-6}$ & $1,85 \cdot 10^{-5}$ & $1,97 \cdot 10^{-5}$ & $2,01 \cdot 10^{-5}$ & $1,99 \cdot 10^{-5}$ \\
\hline$v$ & 0,3000 & 0,2691 & 0,3219 & 0,3880 & 0,4600 & 0,4700 \\
\hline$\sigma_{\mathrm{esc}}(\mathrm{MPa})$ & 390 & 300 & 255 & 88 & 50 & 40 \\
\hline $\mathrm{E}_{\mathrm{t}}(\mathrm{MPa})$ & 2107 & 1590 & 1182 & 772 & 45 & 1 \\
\hline
\end{tabular}

\subsection{Modelo de Elementos Finitos}

O modelo de elementos finitos empregado para a solução das tensões residuais é um modelo axi-simétrico simplificado. A abordagem é simplificada, pois o carregamento térmico não tem uma característica totalmente axi-simétrica. Os efeitos da deposição de metal, bem como as condições de início e término do cordão não serão contempladas neste modelo, mas devido às propriedades térmicas do aço 
inoxidável e a grande velocidade de soldagem acredita-se que o modelo axi-simétrico possa representar com um certo grau de precisão as tensões residuais.

O modelo tridimensional seria capaz de contemplar os efeitos de início e fim da soldagem bem como a simulação da deposição de metal fundido, porém após algumas tentativas verificou-se que o emprego deste modelo acarretara análises altamente não-lineares e com um número de graus de liberdade três vezes maior do que o modelo térmico tridimensional, caracterizando assim um impedimento de cunho computacional.

A seguir serão apresentados alguns conceitos fundamentais do modelo de elementos finitos para a determinação das tensões residuais, o modelo axi-simétrico e suas condições de contorno, os resultados obtidos e a conclusão a respeito.

\subsubsection{Conceitos Fundamentais}

A solução do modelo mecânico para obtenção das tensões residuais é essencialmente não-linear. O carregamento aplicado nada mais é do que as temperaturas obtidas na análise térmica para uma seção, visto que a abordagem adotada para a solução das tensões foi utilizar um modelo axi-simétrico. Assim para cada etapa de carregamento as temperaturas correspondentes são aplicadas e a solução daquele passo de carregamento é obtida. Este processo se repete até que os 48 passos de carregamento gerados anteriormente na análise térmica sejam aplicados e resolvidos.

De acordo com Hedblom (2002), o procedimento para a solução de um problema deste tipo se inicia no princípio dos trabalhos virtuais aplicado em um instante $\mathrm{t}^{\mathrm{n}+1}$ e integrado na configuração geométrica corrente dos elementos finitos. Este fato implica a solução de um sistema de equações não lineares. O resíduo $\left\{\mathrm{R}_{\mathrm{m}}\right\}^{\mathrm{n}+1}$ deverá tender a um valor estipulado pelo critério de convergência.

$$
\left\{\mathrm{R}_{\mathrm{m}}\right\}^{\mathrm{n}+1}=\{\mathrm{F}\}_{\mathrm{int}}^{\mathrm{n}+1}-\{\mathrm{F}\}_{\mathrm{ext}}^{\mathrm{n}+1}
$$

Onde,

$\{\mathrm{F}\}_{\mathrm{ext}}^{\mathrm{n}+1}:$ são as forças externas.

$\{\mathrm{F}\}_{\text {int }}^{\mathrm{n}+1}:$ são as forças internas. 
$\mathrm{O}$ valor de $\left\{\mathrm{R}_{\mathrm{m}}\right\}^{\mathrm{n}+1}$ (resíduo) deve tender, ao longo do processo de solução, a um valor de tolerância estabelecido na solução próximo de zero, uma vez que o cálculo das forças internas é aproximado e iterativo.

As forças internas calculadas nos elementos podem ser escritas como segue.

$$
\{\mathrm{F}\}_{\mathrm{int}}^{\mathrm{n}+1}=\int_{\Omega}[\mathrm{B}]^{\mathrm{T}}\{\sigma\}^{\mathrm{n}+1} \mathrm{~d} \Omega
$$

Onde,

$\{\sigma\}$ : são as tensões de Cauchy,

[B]: matriz que relaciona as velocidades de deformações, $\{d\}$ e as velocidades nodais, $\{\dot{\mathrm{u}}\}$, escrita como $\{\mathrm{d}\}=[\mathrm{B}]\{\dot{\mathrm{u}}\}$.

O processo de solução se inicia para $n=0$ computando-se assim os vetores deslocamento e as tensões e deformações correspondentes $\{\mathrm{U}\}^{0}=\{\mathrm{U}\}^{\text {inicial }}$.

Para o próximo incremento o contador de iterações assume o valor $i=1$ e os deslocamentos são estimados como ${ }_{i}\{U\}^{n+1}=\{U\}^{n}$ e as tensões e deformação são calculadas a partir dessa situação. A partir deste ponto, inicia-se um processo iterativo em i, no instante $t_{n+1}$, utilizando as equações 3.18 a 3.22 .

$$
\begin{aligned}
& { }_{i}\left[K_{m}\right]_{i}\{\Delta U\}^{n+1}=-{ }_{i}\left\{R_{m}\right\} \\
& { }_{i}\left[K_{m}\right]=\frac{\partial}{\partial\{U\}^{i}}\left\{R_{m}\right\} \approx \int_{V_{e}}[B]_{i}^{T}[\bar{E}]_{i}[B] d V \\
& { }_{i}\left\{R_{m}\right\}={ }_{i}\{F\}_{\text {int }}^{n+1}-{ }_{i}\{F\}_{e x t}^{n+1}=\left(\int_{i}[B]_{e}^{T}\{\sigma\}^{n+1} d V\right)-{ }_{i}\{F\}_{e x t}^{n+1} \\
& {[\bar{E}]=\left[\frac{d \sigma}{d \varepsilon}\right]}
\end{aligned}
$$

Ao final do processo, os deslocamentos são atualizados:

$$
{ }_{i}\{U\}^{n+1}={ }_{i-1}\{U\}^{n+1}+{ }_{i-1}\{\Delta U\}^{n+1}
$$

Este processo é realizado até que o critério de convergência seja satisfeito, ou seja, a diferença entre as forças internas e externas, no instante $t_{n+1}$ fique menor que um valor pré-estabelecido.

\subsubsection{Condições de Contorno e Malha}


O modelo axi-simétrico foi feito utilizando-se o modelo tridimensional da análise térmica. Os nós do segundo quadrante foram exportados para posteriormente serem incorporados no modelo axi-simétrico.

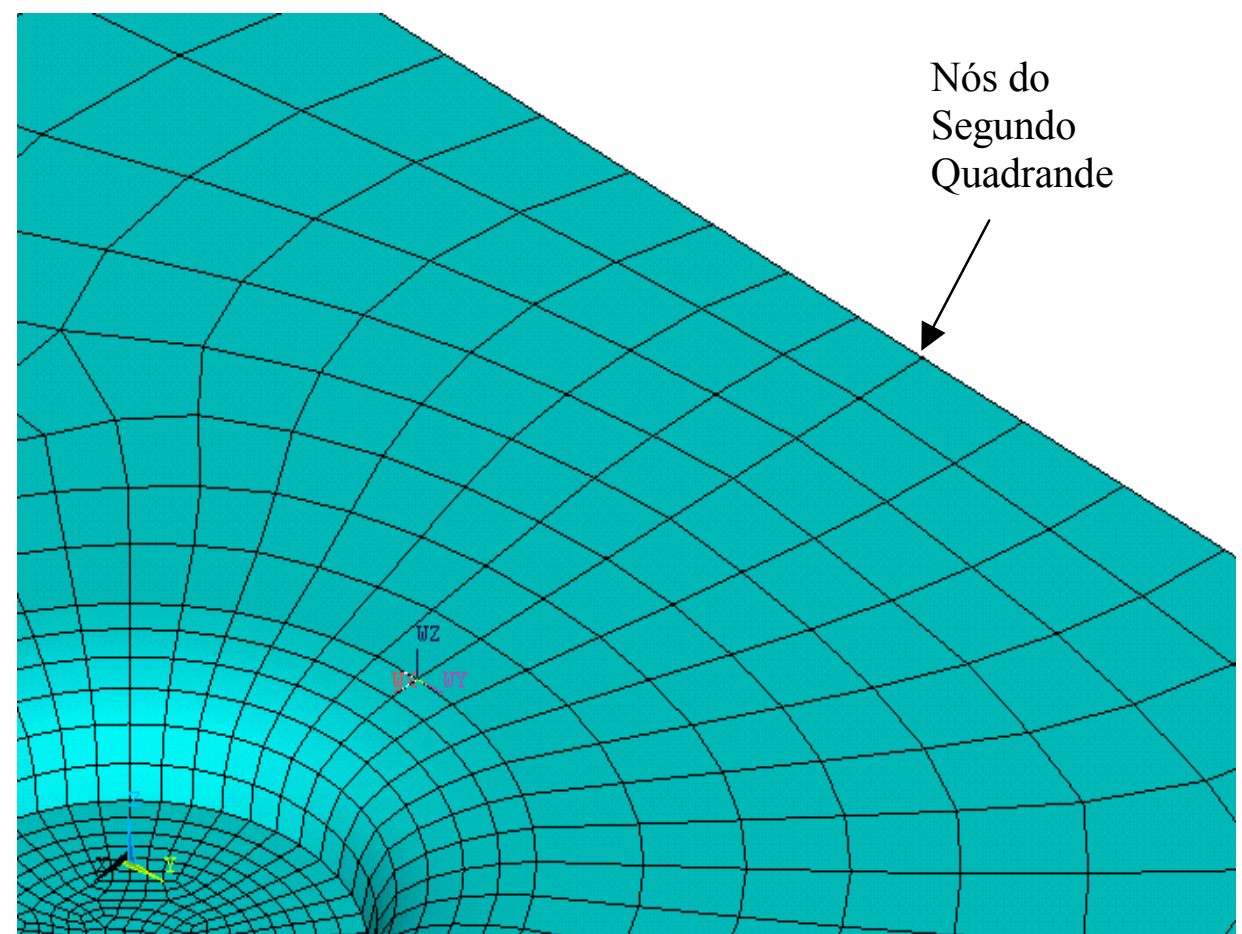

Figura 3.8 - Nós do Segundo Quadrante do Modelo de Elementos Finitos Tridimensional

Com os nós do segundo quadrante o modelo axi-simétrico foi feito de elementos planos, PLANE43 da biblioteca de elementos do ANSYS, com plasticidade e endurecimento cinemático incorporados.

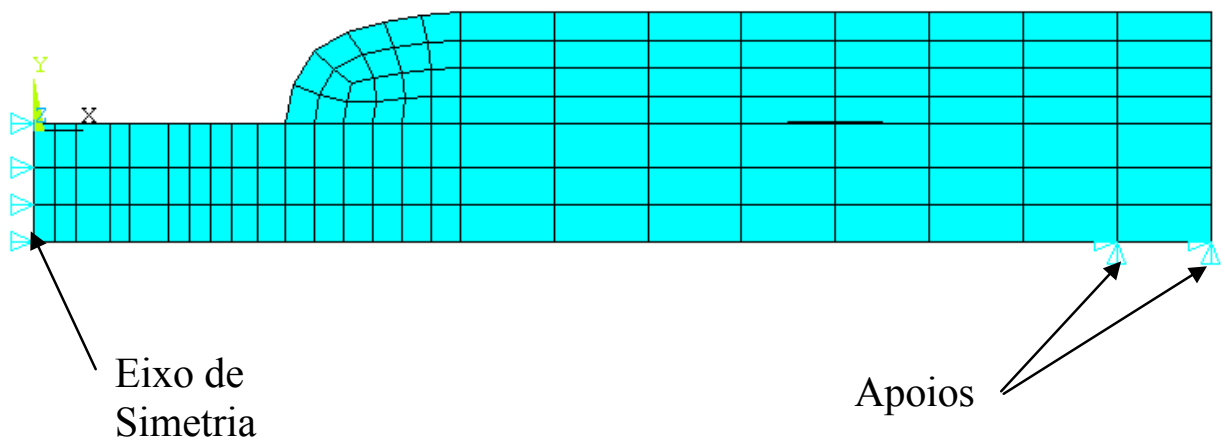

Figura 3.9 - Modelo Mecânico Axi-simétrico e Condições de Contorno 
Ao modelo apresentado foram aplicadas as condições de contorno de simetria e apoio de dois nós (Ux e Uy) para dar estabilidade ao modelo.

\subsubsection{Resultados}

Com o modelo e condições de contorno mostrados anteriormente as temperaturas determinadas pelo modelo térmico são aplicadas a cada passo de carregamento até que se atinja o equilíbrio térmico e a convergência do modelo mecânico.

A seguir serão apresentadas as tensões residuais para $\mathrm{t}=3000$ s. Para este instante de tempo o equilíbrio térmico já foi atingido.
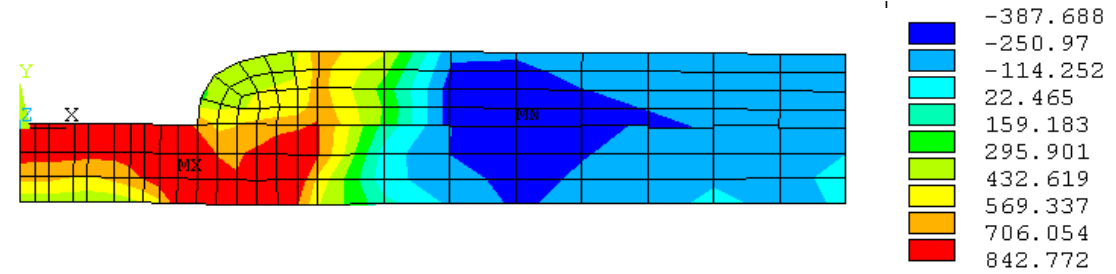

Figura 3.10 - Tensões Residuais Tangenciais (MPa)

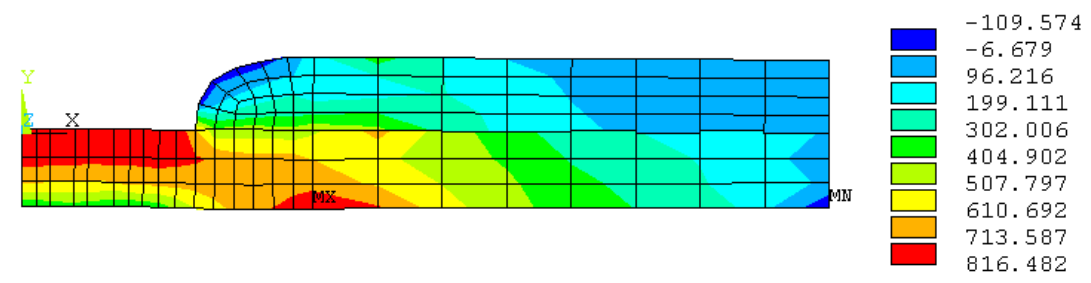

Figura 3.11 - Tensões Residuais Radiais (MPa)

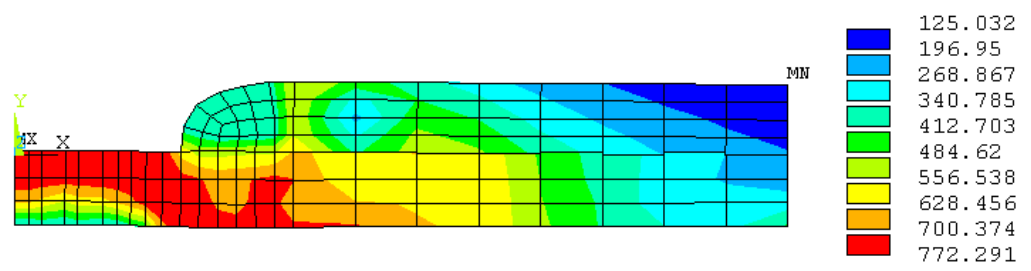

Figura 3.12 - Tensões Residuais Equivalentes von Mises (MPa) 


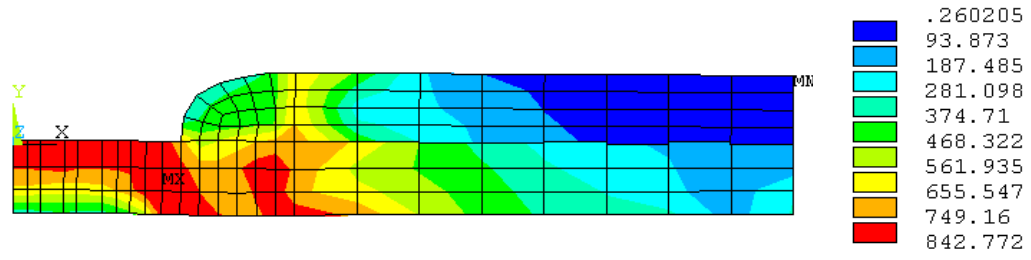

Figura 3.13 - Tensões Residuais Principais Máximas (MPa)
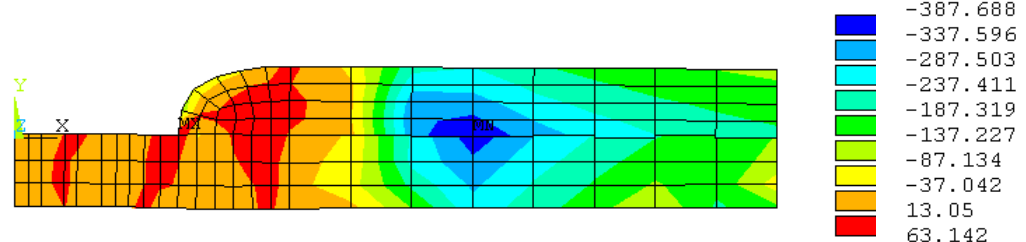

Figura 3.14 - Tensões Residuais Principais Mínimas (MPa)

Para melhor entendimento do campo de tensão residual obtido alguns gráficos foram levantados. Estes gráficos apresentam o valor das tensões residuais tangenciais e radiais em função da posição central do furo e da chapa envolvida.

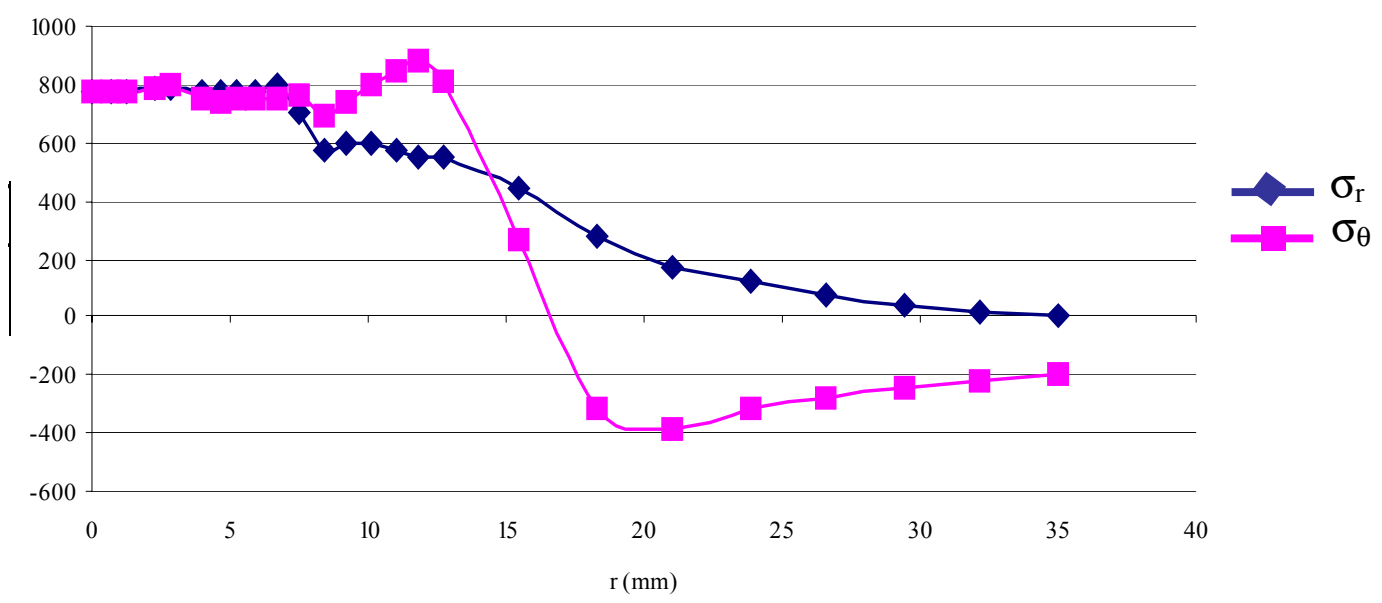

Figura 3.15 - Tensões Residuais Tangencial e Radial em Função da Posição r na Chapa Inferior 


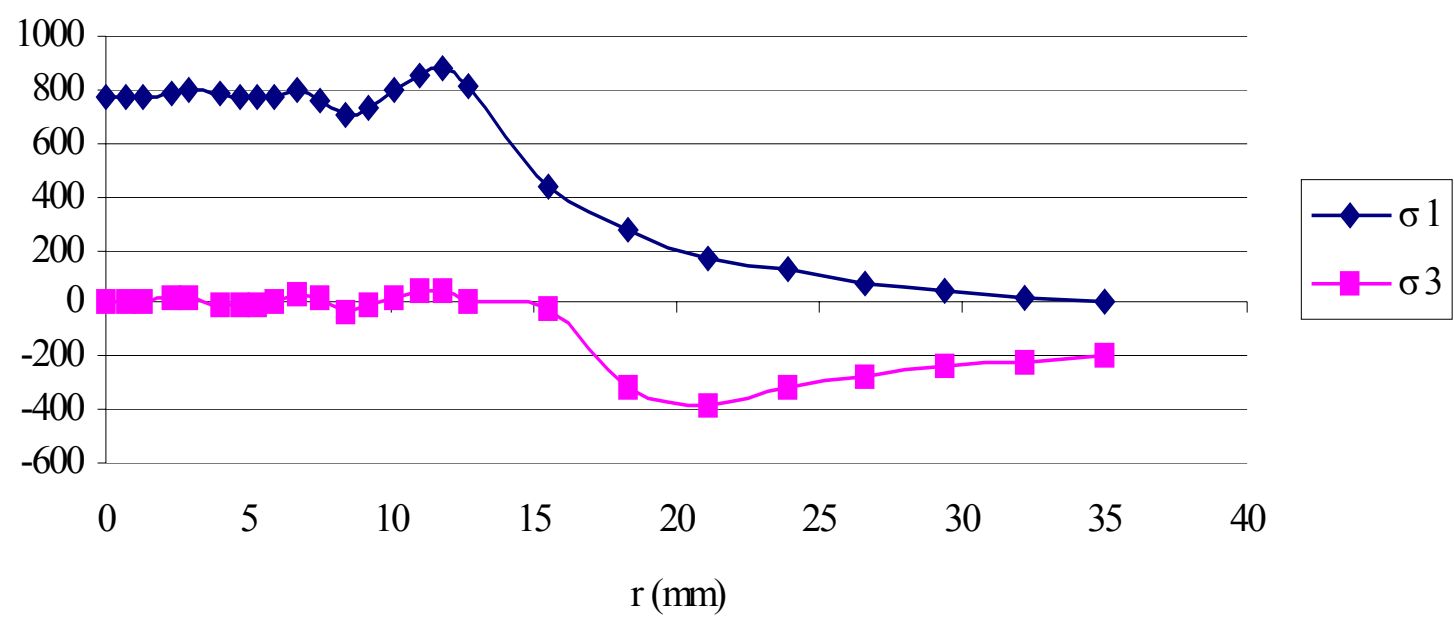

Figura 3.16 - Tensões Principais em Função da Posição r na Chapa Inferior

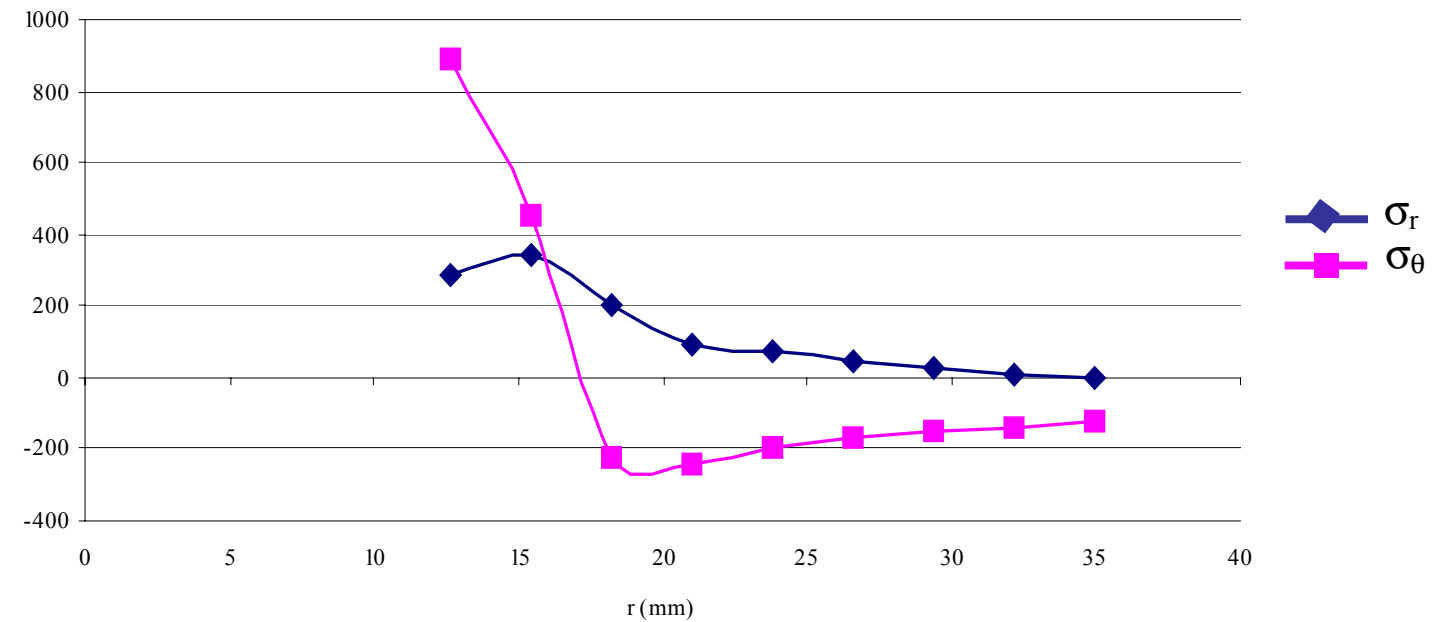

Figura 3.17 - Tensões Residuais Tangencial e Radial em Função da Posição r na Chapa Superior

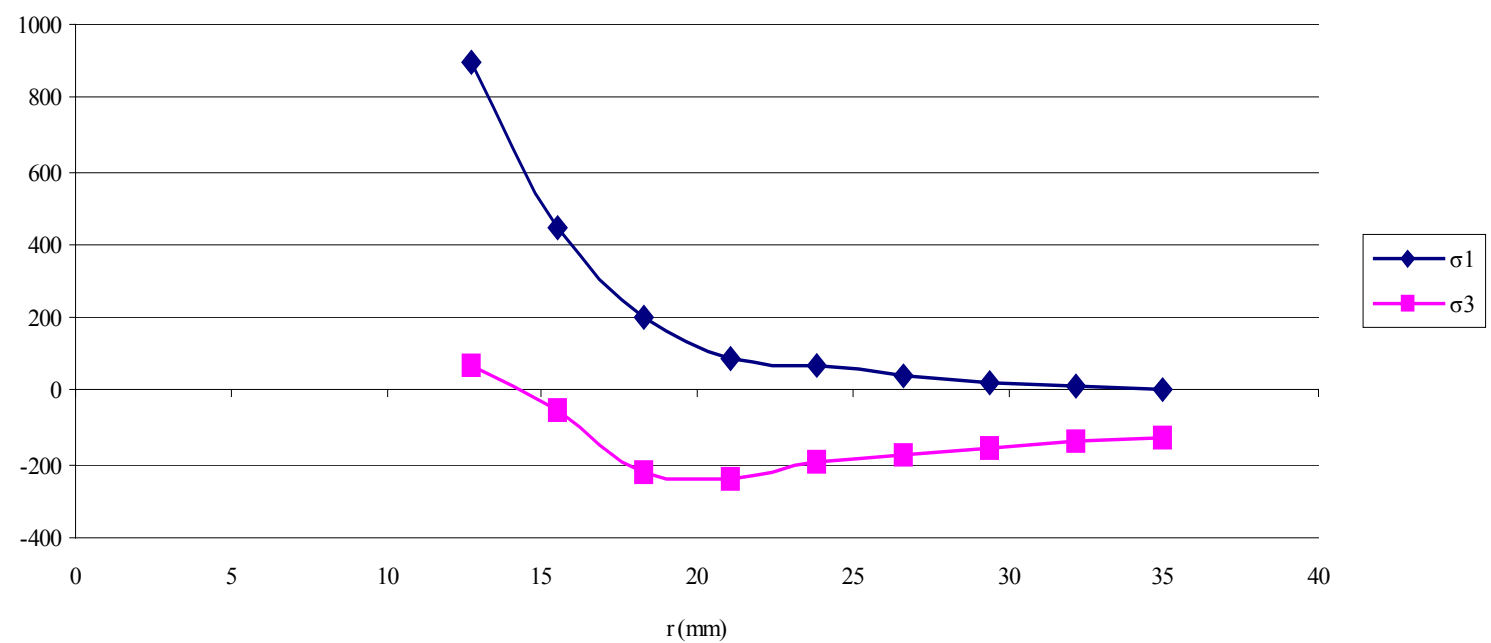

Figura 3.18 - Tensões Principais em Função da Posição r na Chapa Superior 
Observando os resultados é notório o fato de que nas regiões próximas ao cordão de solda as tensões residuais apresentaram valores próximos ao valor do limite de escoamento. O sinal da tensão também ficou bem claro nos resultados do modelo de elementos finitos. Grandes tensões residuais tangenciais de tração se desenvolveram desde o centro do furo do ring-weld até $\mathrm{r}=15 \mathrm{~mm}$, invertendo seu sinal a partir desta posição.

Toda a porção interior ao furo desenvolveu tensões equivalentes da ordem da tensão de escoamento do material.

Masubuchi (1980), apresentou resultados de tensões residuais em soldas circulares. Estas soldas são muito utilizadas para reparação de chapas com furos circulares e consiste em soldar um pedaço de chapa circular em uma chapa com um furo circular que se deseja ser consertado. Um esquema da solda circular apresentada por Masubuchi (1980) segue na figura 3.19.

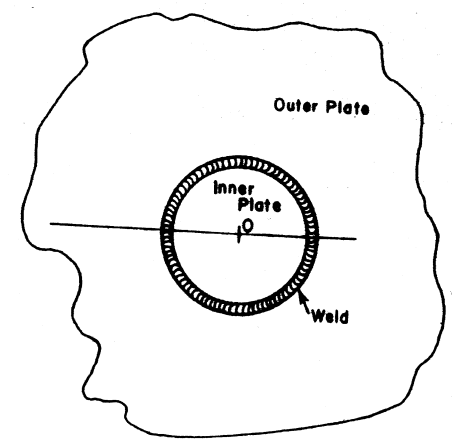

Figura 3.19 - Esquema de Solda Circular, Masubuchi (1980)

Este tipo de solda se assemelha muito ao ring-weld, principalmente a chapa inferior do mesmo. Desse modo os resultados apresentados por Masubuchi (1980) poderão ser comparados, a título de uma verificação qualitativa entre os resultados, com os obtidos pelo modelo mecânico aqui proposto. Os resultados apresentados por Masubuchi (1980) seguem na figura 3.20. 


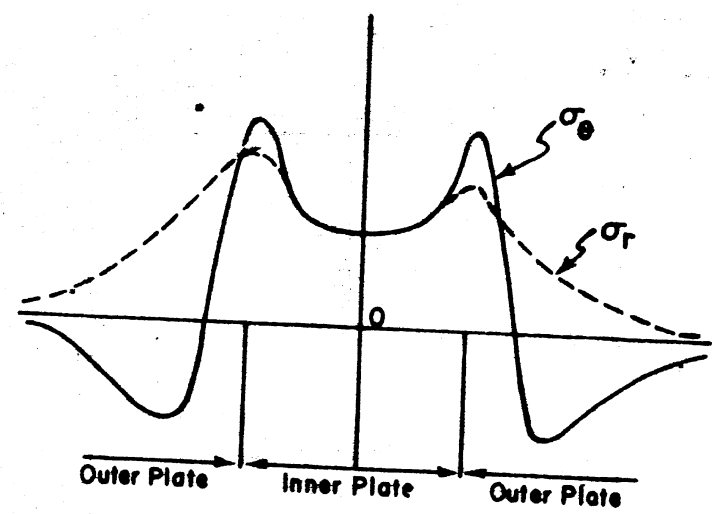

Figura 3.20 - Resultados de Tensão Residual para Solda Circular, Masubuchi (1980)

Pode-se notar através da figura 3.20 que os campos de tensão residual tangencial e radial apresentaram uma distribuição muito semelhante aos campos de tensão residual tangencial e radial na chapa inferior do ring-weld apresentados na figura 3.12, indicando uma coerência do modelo numérico proposto neste trabalho. 


\section{CONCLUSÕES E RECOMENDAÇÕES PARA FUTUROS TRABALHOS}

A abordagem para a solução do problema térmico se mostrou exeqüível em aplicações de problemas cotidianos de engenharia, visto que conhecendo a geometria do cordão depositado é possível determinar o campo de temperaturas com uma boa correlação com os resultados dos ensaios de temperaturas. A determinação apurada do campo das temperaturas permite obter um grau maior de certeza nos resultados do modelo mecânico utilizado para a determinação das tensões residuais.

A determinação das tensões residuais é um problema complexo visto que muitos fenômenos estão envolvidos. No modelo aqui apresentado adotou-se uma série de simplificações de ordem computacional e de caracterização mecânica e metalúrgica dos materiais envolvidos durante a soldagem, apesar disto os resultados tiveram uma boa correlação com o modelo analítico para soldas circulares apresentado por Masubuchi (1980).

As curvas de propriedades de material propostas para o aço inox 301L e 308L são simplificadas, pois, considerou-se que o comportamento mecânico de ambos os aços é mesmo tanto em compressão como em tração e este fato não ocorre na realidade, complicando ainda mais o tratamento matemático dado ao material em uma análise de tensões residuais.

A adoção do modelo axi-simétrico é obviamente uma simplificação do modelo do processo de soldagem, visto que o carregamento de temperaturas não pode ser considerado totalmente axi-simétrico, além do fato que a deposição de material do cordão não pode ser considerada nessa análise.

A utilização do campo de temperaturas e tensões residuais é muito importante para estudos de otimização do número de soldas empregado na estrutura, pois conhecendo melhor o estado de tensão residual presente em uma solda é possível otimizar o seu emprego sem prejudicar a vida em serviço da estrutura. O campo de temperaturas aqui determinado também fornece dados importantes para a otimização do processo de soldagem em si. 
Um estudo interessante seria a preparação de um modelo detalhado tridimensional que contemplaria os efeitos de deposição de material bem como uma modelagem mais requintada das propriedades mecânicas dos materiais empregados nesta soldagem, assim poderá se verificar se o modelo simplificado é capaz de representar bem o fenômeno sem um gasto computacional e de pesquisa muito elevado para a solução de um problema cotidiano que surge no ambiente industrial, pois em geral não se dispõe de muito tempo nem recursos para a solução. Assim os modelos simplificados se justificam face às restrições severas impostas ao engenheiro nos dias atuais.

A determinação experimental das tensões residuais da solda aqui estudada seria de grande valia, pois validaria as abordagens de modelagem aqui propostas, tornando o modelo numérico mais confiável. 


\section{REFERÊNCIAS BIBLIOGRÁFICAS}

ALMENDRA, A. C. et alii Soldagem. 1 ${ }^{\mathrm{a} E d i c ̧ a ̃ o, ~ S a ̃ o ~ P a u l o, ~ D i v i s a ̃ o ~ d e ~ R e c u r s o s ~}$ Didáticos SENAI - Departamento Regional de São Paulo, Brasil. 1997.(Coleção Tecnologia SENAI).

ANSYS User's Manual . Theory Manual. ANSYS revision 5.2 . 1995.

ARAMES E VARETAS DE AÇO INOXIDÁVEL PARA SOLDAGEM SANDVIK (Manual Técnico do Fornecedor, 2000)

BACHORSKI, A.; PAINTER, M.J.; SMAILES, A. J.; WAHAB, M. A. Finiteelement prediction of distortion during gas metal arc welding using the shrinkage volume approach. Journal of Processing Technology, 92-93, p.405409, 1999.

BATHE, K.J.,Finite Element Procedures • 1ªEdição, New Jersey - PrenticeHall, 1996.

ISBN 0-13-301458-4

DEPARTMENT OF DEFENSE - E.U.A. MIL-HDBK-5E. Metallic Materials and Elements for Aeospace Vehicles Structures. Vol. 1 of 2. 1987.

ISBN 0-08-022714-7.

GOLDAK, J.; GU, M.; Mathematical Modelling of Weld Phenomena 2. Computational Weld Mechanics of the Steady State. $2^{\mathrm{a}}$ Edição, E.U.A. Maney. 1995.

ISBN: 0901716634.

HEDBLOM, E.; Multipass welding of nuclear components - computations. Research Report - Lulea University of Technology, Suécia.2002.

INCROPERA, F. P.; WITT, D. P. Fundamentos de Transferência de Calor e de Massa $3^{\mathrm{a}}$ Edição, Rio de Janeiro, Brasil. LTC - Livros Técnicos e Científicos Editora S.A..1992.

JANG, G. B.; KIM, H. K.; KANG, S. S. The Effects of Root Opening on Mechanical Properties, Deformation and Residual Stress of Weldments. Welding Journal, E.U.A., p.80s-89s, March-2001.

MASUBUCHI, K. Analysis of Welded Structures. Residual Stresses, Distorcion, and their Consequnces. First Edition, New York, E.U.A.. Pergamon Press Ltd.. 1980.

ISBN 0-08-022714-7. 
OHKITA, S.; MORIMOTO H.; INOUE, H. Mathematical Modelling of Weld Phenomena 2. Computer Simulation of Solidication and Transformation in Austenitic Stainless Steel Weld Metals. 2ªdição, E.U.A. Maney. 1995.

ISBN: 0901716634.

PAPAZOGLOU, V. J. Analytical Techniques for Determining Temperatures, Thermal Strains, and Residual Stresses during Welding. 1981. Thesis (Ph.D.) Massachussets Institute of Technology, Massachussets, E.U.A.

ROELENS, J. B. Mathematical Modelling of Weld Phenomena 2. Determination of Residual Stresses in Submerged Arc Multi-pass Welds by Means of Numerical Simulation and Comparison with Experimental Measurements2 ${ }^{\mathrm{a} E d i c ̧ a ̃ o, ~}$ E.U.A. Maney. 1995.

ISBN: 0901716634.

SARKANI, S.; TRITCHKOV, V.; MICHAELOV, G. An efficient approach for computing residual stresses in welded joints. Finite Elements Analysis and Design, E.U.A., 35, p.247-268, 2000.

SOUZA, G. F. M. Análise de Tensões Residuais em Estruturas Soldadas. 1989. Tese (Mestrado) - Universidade de São Paulo, São Paulo, Brasil.

TALJAT, B.; RADHAKRISHNAN, B.; ZACHARIA, T. Numerical Analysis of GTA welding process with emphasis on post-solidification phase transformation effects on residual stresses. Materials Science Engineering, E.U.A., A246, p.45-54, 1998.

TANG, S. S.; HERRERA, M. L.; GORDON B. M.; GORDON, G. M. Weld Residual Stress Analyses of Closure Lid Welds for the Waste Packages at the Potential Yucca Mountain Repository. Lawrence Livermore National Laboratory, Livermore, CA. 2000.

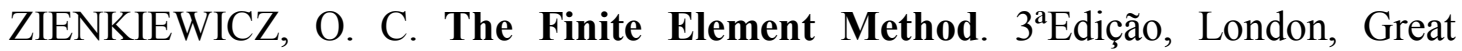
Britain. McGRAW-HILL. 1977. ISBN 0-07-084072-5. 